\title{
DIE BEDEUTUNG DER BUCHGLIEDERUNG FÜR DIE KOMPOSITIONELLE GESTALTUNG DER METAMORPHOSEN OVIDS
}

\author{
Thomas Gärtner
}

\section{Zusammenfassung}

Die Makrostruktur der ovidischen Metamorphosen bildet ein bislang ungelöstes Problem der Forschung. Ältere Gliederungsansätze abstrahieren völlig von der vom Autor vorgegebenen Buchstruktur und nehmen nach genealogischen Kriterien eine der überlieferten Buchgliederung gänzlich fremde Einteilung vor. Dagegen orientieren sich neuere Forscher wieder mehr an der vorgegebenen 15-Bücher-Form und suchen vor allem die Buchpentade mit weitreichenden Folgerungen als strukturelles Prinzip zu erweisen. Entgegen diesen Ansätzen wird in der vorliegenden Arbeit versucht, auf die Annahme einer makrostrukturellen Epochengliederung zu verzichten und stattdessen die einzelnen Bücher als autonome Dispositionseinheiten zu verstehen, die ihren Reiz zumeist aus einer Dichotomie von zwei konträren Großteilen erhaben-epischen bzw. erotisch-elegischen Inhalts beziehen. Die Spannung zwischen solchen konträren Gestaltungsweisen einzelner Großteile bestimmt das Innere der einzelnen Bücher als Lektüreeinheiten wie auch die Grenzen zwischen den einzelnen Büchern.

\begin{abstract}
The macrostructure of Ovid's Metamorphoses is a hitherto unsolved problem. Earlier studies entirely ignore the structure of books given by the author and impose a disposition totally alien to the transmitted grouping of books. On the other hand, more recent approaches emphasize the division of the poem into 15 books and try especially to demonstrate that five-book groups are the main structural principle in order to draw from this far-reaching conclusions. Deviating from these approaches, the present article intends to dismiss the thesis of a macrostructural order of epochs and rather to understand the single books as autonomous structural units which owe their attractiveness to the tension arising between two main parts of either epic or elegiac content. This tension characterizes the whole of the single books as reading units and also the transitions between single books.
\end{abstract}

\section{Inhaltsübersicht}

1. Das Problem

2. Zusammenfassung der Einzelergebnisse

3. Einzelbesprechungen

3.1. met. I: Weltschöpfung - göttliche Liebesaffairen

3.2. met. II: Phaethon und der Sturz des Sonnenwagens - göttliche Liebesaffairen et alia

3.3. met. III: „Thebais“ I — Tiresiasgeschichten erotischer und bacchischer Art

3.4. met. IV: Minyaden — „Thebais“ II — odysseischer Teil der „Perseis“

3.5. met. V: iliadischer Teil der „Perseis“ — göttliche Abstrafung menschlicher Frevler I (mit erotischer Proserpina-Erzählung)

3.6. met. VI: göttliche Abstrafung menschlicher Frevler II — thrakischathenische Liebesverhältnisse

3.7. met. VII: Medea - athenisch/kretischer Krieg I mit Anhängseln (athenische Perspektive: Binnengespräche des Cephalus auf Salamis) 
3.8. met. VIII: athenisch/kretischer Krieg II mit Anhängseln (kretische Perspektive: Scylla, Daedalus; athenische Perspektive: Calydonische Jagd) - AchelousSymposion

3.9. met. IX: „Herculeis“ — diverse, zunehmend erotische Geschichten

3.10. met. X: unglückliche Liebe zwischen Orpheus und Eurydike und durch diese veranlaßter „homoerotischer" Binnengesang des Orpheus

3.11. met. XI: erster Trojanischer Krieg mit Anhängseln — elegische Erzählungen mit Vogelverwandlungen

3.12. met. XII: zweiter Trojanischer Krieg - (eingeschachtelt) Binnenerzählung Nestors über Caenis/Caeneus (erotisch) und die Lapithen-und-CentaurenSchlacht

3.13. met. XIII: Armorum iudicium - Retrospektiven von Opfern auf den Trojanischen Krieg (Hecuba, Aurora, Anius) - Erotisches um Galatea und Scylla (bis zu Circes Auftritt)

3.14. met. XIV: Circe I - odysseischer Aeneisteil - Binnengespräch zwischen Achaemenides und Macareus, hierin: Circe II (Picus-Geschichte) — iliadischer Aeneisteil - Nachfolger des Aeneas in Latium bis Romulus

3.15. met. XV: Numa und Pythagoras' Philosophie - neue Gottheiten im republikanischen Rom (Aesculap und Caesar)

4. Das Problem der Buchgrenzen

5. Literaturverzeichnis

\section{Das Problem}

Die Frage nach der Bedeutung der Buchgliederung für die kompositionelle Gestaltung der Metamorphosen ist seit jeher umstritten ${ }^{1}$. Während frühere Strukturanalysen, z.B. die von Walter Ludwig, bewußt von der Bucheinteilung abstrahierten ${ }^{2}$ und - z.T. unter Verwendung dem Text relativ fernstehender genealogischer Kriterien - Großteile abgliederten, die mit den Buchgrenzen nichts gemein hatten ${ }^{3}$, wird in jüngerer Vergangenheit die von Ovid selbst als äußeres Organisationsprinzip verwendete 15-Bücher-Form wieder stärker in den Mittelpunkt gerückt. Rudolf Rieks entwickelt eine Gliederungsweise, welche die großen Binnengesänge bzw. -reden am Ende sämtlicher Buchpentaden in den Vordergrund stellt, und sucht die einzelnen Pentaden jeweils durch den Sprecher bzw. Sänger des sie beschließenden intradiegetischen Einschubs zu charakterisieren: So werden die Bücher I-V als „musisch“, VI-X als „,orphisch“ und XI-XV als ,,pythagoreisch“ gekennzeichnet ${ }^{4}$. Niklas Holzberg knüpft an diesen Dispositionsversuch an, betont aber weniger als Rieks den epochenab-

\footnotetext{
${ }^{1}$ Forschungsüberblick bei Nagle 1989, 29-31.

${ }^{2}$ Vgl. Crabbe 1981, 2274 f.: „Book divisions are rarely brought into the discussion“.

${ }^{3}$ Gegen Ludwig vgl. Crabbe 1981, 2275 und vor allem Schmidt 1991, 80 ff., besonders gegen die Dreiteilung „Urzeit - Mythos — Geschichte“ (81 mit Anm. 3). Verwandt mit Ludwigs Strukturgliederung sind die von Adamik 1999, 258 f. im Anschluß an von Albrecht herausgearbeiteten zwölf Themenkreise.

${ }^{4}$ Gegen Rieks (zu dessen forschungsgeschichtlichen Vorläufern: Dippel 1990, 12 f. Anm. 11) vgl. Schmidt 1991, 86; 2001, 175 f. mit dem wichtigen Hinweis, daß die Junktur ter quinque volumina (trist. I 1, 117 und III 14, 19) rein metrisch bedingt ist. Bartenbach versucht in ihrer Arbeit über die Bücher met. V, X und XV im Gegensatz zu Rieks nicht, die Buchpentaden als ganze im Sinne einer Epochengliederung zu charakterisieren.
} 
grenzenden Charakter der intradiegetischen Einschübe am Ende der einzelnen Penta$\mathrm{den}^{5}$; stattdessen sieht er in diesen Einschüben ,implicit poetological epilogues“ $\mathrm{zu}$ den einzelnen Pentaden, die jeweils ,all present in their own way a carmen perpetuum in a nutshell“", also jeweils mikrokosmische Spiegelungen des Werkganzen bilden ${ }^{6}$.

Als Problem dieser jüngeren arithmetisch-symmetrischen Gliederungsansätze bleibt ihre Verifizierbarkeit am Text hervorzuheben: Einserseits müßte es, wenn Rieks' Auffassung zuträfe, gelingen, im Text der einzelnen Buchpentaden über die abschließenden Einschübe hinaus objektive Kriterien für eine „musische“, „orphische“ bzw. ,pythagoreische“ Prägung nachzuweisen. Andererseits müßte sich, wenn Holzberg zurecht den metapoetischen Charakter der Binnengesänge bzw. -reden am Ende der Pentaden betonte, nachweisen lassen, daß (1.) die Darstellung der Entführung von Proserpina durch Dis und der damit zusammenhängenden Geschichten wesentlich abweicht von ähnlichen — nicht metapoetischen — Erzählungen, welche Ovid auktorial (also extradiegetisch) wiedergibt, ${ }^{7}$ und (2.) daß die erotischen Episoden

${ }^{5}$ Gleichwohl geht auch Rieks' Argumentation (1980, 90 ff.) von der Voraussetzung aus, daß die „Rahmenpartien“ der übrigen ovidischen Dichtungen programmatisch-poetologische Überlegungen enthalten und daß sich auch in den Metamorphosen solche Rahmenpartien finden müssen.

${ }^{6}$ Zweifel an dieser Auffassung (hinsichtlich Musen- und Orpheus-Gesang in met. V bzw. X) äußert Rosati 2002, 286.

${ }^{7}$ Holzberg 1997, 135 sucht den Calliope-Gesang mit schwierigen strukturalistischen Überlegungen als „,einen Spiegel des Werkabschnitts I 5 - IV 249“ zu erweisen. Nagles Versuche, den metapoetischen Charakter des Calliope-Gesangs zu erweisen, laufen darauf hinaus, die Entsprechungen zwischen Calliopes intradiegetischem und Ovids extradiegetischem „Gesang“ herauszuarbeiten (z.B. 1988, 104: „Her narrative procedure thus reflects Ovid's own in recasting the material of Classical mythology in the poem as a whole“; 1988, 108: „In the story of Arethusa, she [Calliope] follows another Ovidian procedure, attributing a story to a fictional narrator"). Damit wird aber letztlich nur gezeigt, daß in diesem Fall die intradiegetische Erzählung durch vergleichbare Prinzipien bestimmt wird wie die extradiegetische; ein Beweis für den besonderen, „metapoetischen“ Charakter des Binnengesangs wird damit nicht erbracht. - Mit dieser Argumentation soll nicht etwa einer Position das Wort geredet werden, wie sie der von Rosati 2002, 282 ff. kritisierte Solodow vertritt, daß die Identität der „,narrating voice“ im wesentlichen gleichgültig sei. Natürlich bedingt in vielen Fällen die subjektive Haltung eines intradiegetischen Sprechers zum Geschehen die Weise seines Erzählens (z.B. wenn ein Mythos als Exempel-Erzählung herangezogen wird, um auf eine andere Person protreptisch einzuwenden), und im Falle des Calliope-Gesangs in met. V hat Zissos in seiner Interpretation versucht zu zeigen, daß die starke Betonung von Nebenfiguren wie der Nymphen Cyane und Arethusa sich aus dem Bestreben erklärt, die als Schiedsrichterinnen fungierenden Nymphen zu Calliopes Gunsten zu beeinflussen (eine ähnliche auf die Beeinflussung der Erzählweise durch ihren intradiegetischen Charakter hinauslaufende Interpretation der Arethusa-Episode bietet Barchiesi 2002, 188 ff., besonders 192). Doch im allgemeinen wird in solchen Fällen, wo ein längerer künstlerischer Gesang entweder anläßlich eines Wettbewerbs (Calliope in met. V) oder ohne konkreten Anlaß (Orpheus in met. X) stattfindet, zumindest für eine subjektiv-rhetorisch bedingte Überformung des mythischen Inhalts weniger Anlaß bestehen als etwa bei der exempelhaften Heranziehung von mythischem Material, und der Beweis, daß die Gestaltung von Erzählungen innerhalb eines solchen umfangreichen Binnengesangs substantiell abweicht von der Gestaltung extradiegetischer Erzählungen und insbesondere durch metapoetische Aspekte bestimmt ist, bleibt noch zu erbringen. - Überzeugender ist die Argumentation von Hofmann 1986, 227-230, der den metapoetischen Charakter der Musenepisode weniger am Gesang der Musen als solchem als vielmehr am weiteren Kontext (Besiegung der Pieriden durch die Musen) befestigt: Wenn Ovid einen solchen verschachtelten Binnengesang wie den der Calliope in einem dichterischen Wettstreit den Sieg davontragen läßt, so liegt darin sehr wahrscheinlich ein positives Urteil über solche Verschachtelungstechnik, die in der Tat auch in den übrigen Metamorphosen ähnlich verwandt wird. Ovid würde schwerlich einen Gesang siegreich sein lassen, der seinem eigenen (sich in der Gestaltung der Metamorphosen bekundenden) künstlerischen Geschmack widerspräche; insofern ist die Parallelität zwischen Calliope-Gesang und Gesamtwerk eigentlich naheliegend. Weniger klar ist, ob hinter dem unterliegenden Gesang der Pieriden eine von Ovid abgelehnte Dichtungsgattung zu suchen ist, vgl. unten Anm. 72. 
innerhalb des Orpheus-Gesangs sich substantiell unterscheiden von denjenigen außerhalb; so müßte z.B. die Liebe Apollos zu Hyacinthus wesentlich anders dargestellt werden als diejenige zu Cyparissus, oder die Liebe Myrrhas zu ihrem Vater müßte wesentlich verschieden geschildert werden im Vergleich etwa zur Liebe der Byblis zu ihrem Bruder am Ende von met. IX ${ }^{8}$ (beide Liebesverhältnisse werden von den jeweiligen Sprechern übereinstimmend als nicht wünschenswerte Beispiele weiblichen Verhaltens hervorgehoben $\left.{ }^{9}\right)$. Gerade in solchen Unterschieden der narrativen Vorgehensweise innerhalb der Binnengesänge gegenüber der außerhalb müßte sich der „metapoetische“ Charakter der Einschübe verifizieren lassen, wenn man den Begriff „metapoetisch“ nicht in dem trivialen Sinne einer Wiedergabe beispielhafter Dichtungen innerhalb einer Dichtung versteht (in diesem beschränkten Sinne sind der Calliope- wie der Orpheus-Gesang natürlich unbestreitbar „,metapoetisch““10), sondern im Sinne Holzbergs hinter „metapoetischen“ Stücken eine epiloghafte Reflexion auf das Gesamtwerk und insbesondere auf die jeweils vorausgehende Pentade sucht.

Die Pythagorasrede im fünfzehnten Buch ist sicher auch „metapoetisch“ in dem höheren Sinne, daß sie die Gesamtthematik der Metamorphosen mikrokosmisch aufgreift; ob sie aber als eine für das Gesamtwerk gültige und somit deutungs-

\footnotetext{
${ }^{8}$ Holzberg 1997, 143 verweist nur auf das Zurücktreten wörtlicher Rede hinter den narrativen Passagen in der Myrrha-Erzählung im Gegensatz zur Byblis-Episode. Einen ausführlichen Vergleich zwischen Byblis- und Myrrha-Episode bietet Nagle 1982, die die Byblis-Geschichte charakterisiert als „a study in self-delusion“, dagegen bei Myrrha „excruciating self-knowledge and moral awareness“ findet $(1982,315)$; der extradiegetische Erzähler stehe Byblis von Anfang an mit Sympathie gegenüber, wohingegen Orpheus (als intradiegetischer Erzähler) Myrrha zumindest anfangs scharf verurteile. Aus diesen graduellen Unterschieden ergibt sich jedoch kaum eine Rechtfertigung, die MyrrhaErzählung als ,metapoetisch“ und damit wesentlich verschieden von der Byblis-Episode anzusehen. Ausführlich wird der „metapoetische“ Charakter des gesamten Orpheus-Gesangs thematisiert bei Nagle 1988, 111 ff. (vgl. auch oben Anm. 6). Die Aussage „Orpheus, like Ovid, explicitly sets out to sing a series of tales, the content of which is amatory“ $(1988,112)$ bleibt sehr allgemein und besagt zudem nicht mehr, als daß die intradiegetische Erzählung unter diesem Gesichtspunkt mit der extradiegetischen vergleichbar ist. Auch Nagles weitere Vergleiche zwischen dem Binnengesang des Orpheus und dem Gesamtwerk „Metamorphosen“ (1988, 112 f.) fördern nichts anderes als diese Feststellung zutage. Gleiches gilt für die Aussage „Like Ovid, and like Calliope, Orpheus too attributes a tale to a fictional narrator, when he has Venus tell Adonis the story of Atalanta and Hippomenes“" (1988, 114). Eine Liste ähnlicher Argumente für den „metapoetischen“ Charakter des OrpheusGesangs findet sich auch bei Nagle 1982, 304 f. Hofmann 1986, 227 argumentiert speziell hinsichtlich des Prooemiums des Orpheus-Gesangs: „The proem of Orpheus' song (10,148-54) must be read in the light of Metamorphoses 1,1-4 ... By putting this carmen deductum into the mouth of the poet and singer Orpheus, Ovid makes him opt for the same poetic content and manner as he himself does"; ähnlich Galinsky 1999, 312 zu demselben Orpheus-Prooemium: „Orpheus announces boundaries [in seiner Themenangabe] only to transgress them, a procedure that is central to the poetics of the Metamorphoses [obwohl Ovid in seinem Prooemium über den allgemeinen Begriff der Verwandlung hinaus keine konkreten Themenangaben macht]“. In solchen Übereinstimmungen liegt vielleicht eine bemerkenswerte Parallelität (die man freilich auch sehr trivial damit erklären könnte, daß hinter dem Orpheus-Gesang eben doch als Autor der Metamorphosendichter steht), aber noch kein Beweis für den „metapoetischen“ Charakter des Orpheus-Gesangs. Im übrigen hat die sich im Prooemium des Orpheus-Gesangs bekundende programmatische Beschränkung des Folgenden auf homosexuelle Liebesaffairen von Göttern und unerlaubte Liebessehnsüchte von Mädchen gemäß der unten gegebenen Deutung eher die Funktion, den Inhalt des Orpheus-Lieds vom Rest der Metamorphosen (der eben nicht ausschließlich erotischer Art ist, sondern auch ernste „epische“ Themen behandelt) zu distanzieren und somit insbesondere den extraordinären Charakter weiter Teile des zehnten Buchs zu exponieren.

${ }^{9}$ met. IX 454; X 300 ff.

${ }^{10}$ In diesem Sinne spricht etwa Bartenbach 1990, 308 von einer ,poetologischen Thematik“ der Metamorphosenbücher $\mathrm{V}, \mathrm{X}$ und $\mathrm{XV}$.
} 
relevante rückwärtige Reflexion betrachtet werden kann, wird in der modernen Ovidforschung wohl zurecht bezweifelt ${ }^{11}$.

Einen metapoetischen Charakter im Sinne einer reflektiven Aufnahme und mikrokosmischen Spiegelung der Gesamtthematik wird man eher als den intradiegetischen Einschüben am Ende der Pentaden wohl der symposiastischen Behandlung des Metamorphosenthemas beim Gelage des Achelous im zentralen achten Buch der Metamorphosen zusprechen dürfen, wie im Laufe der folgenden Ausführungen gezeigt werden soll.

Vor allem aber soll im folgenden versucht werden, die Buchgliederung der Metamorphosen aus einem neuen Blickwinkel zu verstehen. Denn die Versuche, in der Makrostruktur der Metamorphosen eine ovidische Epochengliederung zu finden - vergleichbar etwa der Epochengliederung, welche Ennius in seinen Annalen der römischen Geschichte durch die triadische Buchgliederung aufprägt ${ }^{12}$ — sind bislang fehlgeschlagen, und die Wahrscheinlichkeit, daß sich eine solche Epochengliederung noch unerkannt hinter der 15 -Bücher-Form ${ }^{13}$ verbirgt, darf man wohl als gering veranschlagen, zumal sich eine solche Epochengliederung — wie wiederum der Vergleich mit den ennianischen Annalen zeigt - durch ihre einleuchtende Evidenz, nicht aber durch ihre verschleierte Obskurität auszeichnen sollte ${ }^{14}$. Es empfiehlt sich also, den Wert der ovidischen Buchgliederung weniger makrostrukturell, d.h. in der schematisierenden Strukturierung des Gesamtgeschehens der Metamorphosen, zu sehen als vielmehr mikrostrukturell, d.h. in der modellierenden Abteilung kleinerer Erzähleinheiten, nämlich der Einzelbücher ${ }^{15}$.

Im folgenden wird also der Blick weitaus mehr auf die Struktur der einzelnen Bücher in sich als auf den Gesamtaufbau des Werks aus 15 Einzelbüchern gerichtet

\footnotetext{
11 Zum Problem vgl. Döpp 1992, 121 mit Anm. 8; Hardie 1995, 204. Gegen eine Auffassung der Pythagoras-Rede als „Schlüssel zur Interpretation der Metamorphosen“ wendet sich Holzberg selbst (1997, 151 ff.); ferner vgl. Fränkel 1945, 109 f.; Ludwig 1965, 71 f.; Coleman 1971, 462 f.; Rieks 1980, 100 mit Anm. 74; Schmidt 1991, 38 ff.; 46 ff.; 2001, 183 (in Übereinstimmung mit dem dort rezensierten Harzer); Wheeler 2000, 117; Barchiesi 2002, 184 f. (eher harmonisierend jetzt wieder Erbse 2003, 349). Im einzelnen vgl. den auf diese Frage bezüglichen Forschungsbericht bei Little 1970, 341 ff. (ferner Dippel 1990, 8 f. Anm. 40). Little selbst kommt zu sehr skeptischen Ergebnissen (a.a.O. 360): „Ovid included it [the Pythagoras digression] because of its superficial correspondence with his subjectmatter, but the correspondence was not meant to be examined too closely" (in einer späteren Publikation [1974, 20] sieht Little in der Pythagorasrede immerhin ,,a natural supplement to a poem which was truly universal“). Vgl. auch Galinsky 1998, 330: „Ovid's treatment of the discourse of Pythagoras is viewed best not as a unifying philosophical pivot of the Metamorphoses, but as a contribution to an ungoing discussion about the roles of myth and philosophy in the grand poetic tradition“. Unorthodox ist der Ansatz von Bartenbach 1990, 221 f., „daß diese Rede Kriterien und Maßstäbe für das Bewerten der Persönlichkeiten im 15. Buch abgibt“".

${ }^{12}$ Vgl. Classen 1992, $133 \mathrm{f}$.

${ }^{13}$ Hofmann 1986, 225 findet allein in der Buchzahl ,,a witty Ennian superstructure“. Hiergegen kritisch Merli 2004, 305 (mit Doxographie), die eine Anspielung auf die — später um drei Bücher erweiterte - 15-Bücher-Fassung der Annalen (gewissermaßen eine „,erste Auflage“) zurecht obskur findet. Merli selbst sieht in der Buchzahl 15 eine programmatische Abwendung Ovids von typisch epischen Buchzahlen, die in der Regel ein Vielfaches von Sechs bilden, und eine paradoxerweise gerade im Großgedicht „Metamorphosen“ erfolgende Hinwendung zur typisch augusteischen Kleindichtung, innerhalb deren Gedichtbüchern die Gedichtzahl oft Vielfache von Fünf betrage (a.a.O. 306); insbesondere verweist Merli auf die ovidischen Amores (a.a.O. 306 f.).

${ }^{14}$ Aus dem offensichtlichen Fehlen einer solchen evidenten makrostrukturellen Organisationsform schließt Glei 1998, 90, daß es sich bei den Metamorphosen um ein „Erzählchaos“ handele.

${ }^{15}$ Die Wichtigkeit der kompositionellen Gestaltung des Einzelbuchs als „Leseeinheit“ sucht von Albrecht 2000, 209; 264 ff. anhand des hermeneutischen Mittels der Buchillustrationen wieder in den Mittelpunkt zu rücken. Kritisch gegenüber diesem Ansatz Schmidt 2001, 179 f.
} 
werden. Dabei wird sich zeigen, daß die kompositorische Zusammenfügung der Einzelbücher in den meisten Fällen auf einer Spannung zwischen verschiedenen Gestaltungselementen bzw. Gestaltungsweisen beruht, einerseits zwischen erhabenepischen (entweder kosmologischen oder militärisch-politischen) und erotischelegischen Elementen und andererseits zwischen zusammenhängender (epischer) und episodischer (katalogsgedichtartiger) Erzählweise. In den meisten Büchern lassen sich zwei quantitativ ungefähr aequivalente Großteile nachweisen, die nicht nur unter thematischem Gesichtspunkt, sondern auch unter Heranziehung der aufgezählten Kriterien in einem deutlichen Kontrast zueinander stehen ${ }^{16}$. In diesem Fall ist eine solche spannungsreiche Dichotomie offenkundig konstitutiv für die Gesamttektonik des jeweiligen Buchs.

In den ersten Büchern besteht diese spannungsreiche Dichotomie jeweils darin, daß einem episch-zusammenhängenden Großteil erhabenen Inhalts ein zweiter episodisch angelegter Großteil vorwiegend erotischen Inhalts folgt. In den folgenden Büchern wechselt gelegentlich die Reihenfolge der so bestimmten Großteile; mitunter verschieben sich diese Kriterien auch gegeneinander, so daß z.B. der episodische Großteil an ein militärisch-episches Thema anknüpft oder der zusammenhängende eher erotischen Inhalts ist. Solche Dichotomie zweier Großteile ist, wie gesagt, das bestimmende Merkmal der meisten Einzelbücher. Allerdings findet sich auch (in den Büchern IV und XIII) eine Dreiteilung mit einem dritten ins nächste Buch hineinragenden Großteil. In met. X fehlt jegliche Dichotomie, was mit dem weite Teile des Buchs abdeckenden, erotische Episoden kumulierenden Binnengesang des Orpheus zu tun hat. Hier scheint das Fehlen einer solchen dichotomischen Struktur von Ovid bewußt erstrebt zu sein, insofern Orpheus im poetologischen Prooemium seines Gesangs sich ausdrücklich von epischer Darstellung distanziert. Dagegen scheint sich das Fehlen einer entsprechenden Struktur in met. XIV eher aus der „Quellenlage“ in diesem Abschnitt zu erklären: Ovid ist relativ eng an die vergilische Aeneis bzw. an die ihm vorschwebende Liste italischer Könige gebunden und kann sich von dieser Vorgabe nur durch die Verkürzung bzw. erweiternde Ausgestaltung vorgegebener Episoden befreien. Insofern besitzt er hier nicht die kompositorische Freiheit, die ihn sonst frei die verfügbaren Mythen kombinieren und fast immer die erläuterte Dichotomie zweier Großteile herstellen läßt.

\footnotetext{
${ }^{16} \mathrm{Vgl}$. die horizontale, vertikale oder diagonale Zweiteilung bestimmter Buchillustrationen (von Albrecht 2000, 265 f.), besonders in den ersten beiden Metamorphosenbüchern.
} 


\section{Zusammenfassung der Einzelergebnisse}

Die Dichotomie zwischen einem episch-geschlossenen Großteil von inhaltlicher Erhabenheit und einem zweiten eher episodisch-elegischen, zumindest teilweise erotisch geprägten „leichterer“ Art ist in ihrer Reinform in den ersten beiden Büchern der Metamorphosen erhalten, wo die Schöpfungsgeschichte bzw. die Phaethonerzählung (zwei Ereignisse von wahrhaft kosmischer Dimension) jeweils den ersten Großteil bestimmt. Auch im dritten Buch trägt die erste Buchhälfte mit der thebanischen Gründungsgeschichte noch durchaus epische Züge; in die zweite drängt sich neben das erotische Motiv (Narcissus/ Echo) das aus der Semele-Episode des ersten Großteils herauswachsende bacchische Element. Im vierten Buch wird die Reihenfolge der Großteile verkehrt: Ein bacchisch-erotischer Abschnitt (Minyaden) macht den Anfang, und die Fortsetzung der thebanischen Gründungsgeschichte folgt als zweiter Großteil; als weitere Besonderheit enthält das vierte Buch einen dritten Großteil erneut epischer Prägung, den „odysseischen“ Abschnitt der Perseus-Erzählung. Das fünfte Buch fügt sich mit der Dichotomie „Perseus (,,iliadischer“ Abschnitt) Musen" wieder gut in das primäre Schema, zumal der Musenteil quantitativ dominiert wird durch die erotische Erzählung vom Raub der Proserpina. Hinter diesem erotischen Aspekt drängt sich allerdings in der Rahmenerzählung über den Wettkampf zwischen Musen und Pieriden bereits der thematische Aspekt des hybrishaften Vergleichs Sterblicher mit Göttern hervor, der auch die erste Hälfte von met. VI mit der Geschichte von Niobe in ihrem Zentrum bestimmt. Wie beim Übergang von met. III zu met. IV korrespondiert der episodische zweite Großteil des vorausgehenden Buchs mit dem ersten des folgenden, und wieder wird das Thema charakteristisch verschoben: In met. III/IV wurden die Themenaspekte „erotisch“ und „bacchisch“ in ein anderes Verhältnis zueinander gesetzt, hier tritt der erotische Aspekt (nur noch im Arachnegewebe) zugunsten des thematischen (Vergleich Sterblicher mit Göttern) zurück. Mit diesem Zurücktreten des erotischen Aspekts im ersten, episodischen Großteil dürfte es zusammenhängen, daß im zweiten Großteil (der demnach eigentlich episch-zusammenhängender Art sein müßte) das erotische Element stark hervortritt, nämlich in der Tereus-Procne-Episode (anders als in den ,epischen“ Großteilen von met. I-V). Diese „Erotisierung des Epischen“ setzt sich in met. VII fort: Der erste, zusammenhängende Großteil von met. VII nimmt sich anfangs aus wie eine Neugestaltung des epischen Argonautenstoffes, entwickelt sich dann aber zu einer Chronik der (letztlich erotisch motivierten) Verbrechen Medeas; auch der episodische, zweite Großteil knüpft an einen epischen Stoff an (Krieg zwischen Athen und Kreta), läßt diesen militärischen Bezug aber in den Gesprächen während der AeginaGesandtschaft des Cephalus (endend mit der Schilderung von Cephalus' unglücklicher Beziehung zu Procris) völlig zurücktreten. An denselben Krieg, jedoch diesmal an die kretische Partei des Kriegsgeschehens (Minos), knüpft der erste Großteil von met. VIII an, zerfällt aber ebenfalls in Episoden (vor allem Scylla, Daedalus, Calydonische Jagd, letztere wieder bei der athenischen Seite, nämlich bei Theseus, anknüpfend); der zweite Großteil wird konstituiert durch die Gespräche beim Symposion des Achelous und ist vorwiegend thematisch bestimmt (Thema: Verwandlung als göttliche Belohnung oder Strafe); erstmals sind beide Großteile episodisch, im zweiten tritt der episodische Charakter durch die intradiegetisch-symposiastische Form (vgl. den ersten Großteil von met. IV, die Erzählungen der Minyaden) deut- 
licher hervor; wichtig sind ferner die deutlich ausgeprägten Korrespondenzen der Binnenerzählungen zur Gesamtthematik der Metamorphosen, welche dem AchelousSymposion ein geradezu metapoetisches Gepräge geben. Buch IX restituiert gewissermaßen die primäre Dichotomie: erster Großteil „Herculeis“, zweiter Großteil diverse Episoden, am Schluß erotischer Art (Byblis und Iphis). Dieser erotische Faden wird in met. X durch das Hymenaeus-Motiv aufgenommen, offenkundig führt er aber im Falle des Orpheus ins Unglück, wodurch sich eine mutierte Form der Erotik, nämlich die Homosexualität bzw. Frauenfeindlichkeit, als thematischer Rahmen des OrpheusGesangs ergibt. Dieser thematische Rahmen wird aber bei genauer Betrachtung durch die Episoden des Gesangs wieder gesprengt. Strukturell bedeutsam ist der singuläre erotisch-episodische Charakter des gesamten Buchs met. X (ohne Dichotomie), auf den im Prooemium des Orpheus-Gesangs poetologisch in Form einer Zurückweisung herkömmlicher epischer Dichtung reflektiert wird. Buch XI restituiert wieder einigermaßen das ursprüngliche dichotomische Schema, allerdings in der geradezu konträren Spielform, daß hier an einen epischen Stoff (Troja) bzw. seine Personen episodische Begebenheiten angeknüpft werden (Großteil I), während der zweite, zusammenhängende Großteil (Ceyx und Alcyone) eindeutig elegisch-erotischer Art ist. In Buch XII ergibt sich die Dichotomie im Prinzip einfach durch den Gegensatz zwischen extradiegetischer (Kampf um Troja) und eingeschachtelter intradiegetischer Handlung (Caeneus-Erzählung des Nestor, am Anfang durchaus erotisch), wobei die besondere narrative Funktion der sich an den Caeneus-Komplex anschließenden Geschichte des Kampfes zwischen Lapithen und Centauren in der Substitution der im ovidischen Trojakrieg eigentlich fehlenden Kampfhandlung liegt. Buch XIII wird (wie met. IV) durch eine ungewöhnliche Dreiteilung bestimmt, wobei der dritte Teil wieder ins folgende Buch überragt: Die Großteile 1 (Antilogie zwischen Aiax und Odysseus) und 2 (Folgen des Trojanischen Kriegs für die Hinterbliebenen der Opfer) sind wieder eher epischer Art, der dritte (Scylla, mit eingeschachtelter GalateaEpisode) ist dezidiert erotischer Natur. In Buch XIV finden sich neben der Fortführung der Scylla-Geschichte die Irrfahrten des Aeneas, sein Kampf in Latium und der Beginn der italischen Herrscherliste bis zum ersten König Romulus. In diesem Buch scheint Ovid durch mythologische Vorgaben so stark gebunden, daß kein eine vollständige Buchhälfte bestimmender erotischer Großteil zustandekommt, sondern nur einige erotische Einsprengsel in das Ovid durch seine Quellen (vor allem Vergil) vorgegebene Erzählgefüge eingearbeitet werden. Buch XV greift wieder auf die herkömmliche Dichotomie zurück, wobei aber der erste Großteil diesmal im Kontrast zum episierend-zeitgeschichtlichen zweiten (Aesculap, Caesar) philosophische Züge trägt (Lehrrede des Pythagoras über die Veränderlichkeit der Welt). 


\section{Einzelbesprechungen}

\section{1. met. I}

Das erste Buch der Metamorphosen ist durch eine deutliche Zweiteilung charakterisiert: Der erste Großabschnitt ist dem Thema der Weltschöpfung gewidmet, welches wiederum in die Unterabschnitte "primäre Weltschöpfung aus dem Chaos", "menschliche Deszendenz", "göttliche Strafhandlung/ Sintflut" und "Neuschöpfung nach Sintflut durch Deucalion und Pyrrha" zerfällt. Dabei schließen sich bestimmte Einzelepisoden noch funktional an diese Unterabschnitte an, so z.B. die Gigantenkampferzählung, welche die eigentlich auf innerer Dynamik beruhende, sich im Vierzeitaltermythos bekundende menschliche Deszendenz zusätzlich durch ein äußeres Aition (Abstammung der Menschen aus dem Blut der Giganten) erklärt, oder die LycaonErzählung, welche als Paradebeispiel für menschliche Versündigung in der Götterversammlung das Zustandekommen einer göttlichen Strafhandlung rechtfertigt.

An diesen in sich homogenen Zusammenhang der Weltschöpfung schließt sich durch eine recht gesuchte gedankliche Kette (Entstehung der Pythonschlange deren Erlegung durch Apollo — Einrichtung der Pythien - Eichenkranz für die Sieger der Wettkämpfer - Nichtvorhandensein von Lorbeer) ${ }^{17}$ der zweite Großabschnitt des ersten Buches an. Er zerfällt in zwei Liebesaffairen zwischen einem Gott und einer Sterblichen, nämlich in die Daphne-Geschichte ${ }^{18}$ und die IoErzählung. Schon oberflächliche Betrachtung zeigt, daß hier völlig andere, nämlich erotische, Gesichtspunkte im Mittelpunkt stehen und vor allem die Götter, die im ersten Großabschnitt als verantwortungsvolle Lenker der Schöpfungsgeschichte auftraten, welche sich der menschlichen Deszendenz entgegenstemmten ${ }^{19}$, nunmehr

\footnotetext{
${ }^{17}$ Zur Bewertung dieses komplizierten Übergangs in der Metamorphosenforschung vgl. Wheeler 2000, 55 f. Den motivischen Hintergrund (Euphorion) behandelt die Arbeit von Hollis 1996.

${ }^{18}$ Holzberg 1999, 324 erkennt den Neueinsatz in der „Daphne-Erzählung, die dem Leser erstmals das Wesen dieses neuen Gattungstyps [der elegisch-erotischen Erzählung] exemplarisch vor Augen führt“ (vgl. auch Doblhofer 1960, 79 im Anschluß an Fränkel; Jacobsen 1984, 52: „The comic behavior of Apollo in his pursuit of Daphne sets the tone for the romantic escapades of the other gods, as lovestruck deities behave like men and divine dignity consistently is undercut"; Myers 1993-94, 225).

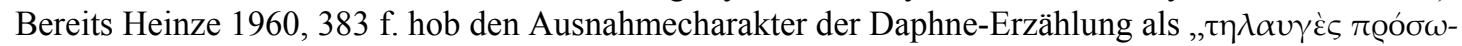
זov aller erotischen Verwandlungsgeschichten“ hervor und berief sich insbesondere auf die Exposition der Geschichte durch die beiden in konträrer Weise wirkenden Pfeilschüsse Amors gegen Apollo und Daphne. Dabei ist Heinze entsprechend seiner Grundthese (vgl. unten Anm. 20) bemüht, in der Darstellung des liebenden Apollo noch einen gewissen Rest „epischer Erhabenheit“ nachzuweisen. In diametralem Gegensatz zu dieser Anschauung versucht in jüngerer Vergangenheit etwa Therese Fuhrer in ihrer Interpretation der Daphne-Geschichte die Vermenschlichung des liebenden Gottes Apollo durch den Dichter zu zeigen; ähnlich argumentiert Doblhofer 1960, 84 ff., der die „Vermenschlichung“ Apollos in dieser Episode allerdings weniger als eine lächerlich machende Herabziehung des Gottes durch die Infragestellung seiner göttlichen Attribute denn als eine Herausarbeitung der „Zartheit“ menschlichen Fühlens begreift, und auch Barnard, die in der ovidischen Zeichnung Apollos nicht nur Vermenschlichung, sondern vor allem auch komische Deformation sieht (besonders a.a.O. 353; 362). - Das Eingreifen des Liebesgotts Cupido in met. I 453 ff. hat Nicoll (1980) in Verbindung gebracht mit der Theophanie desselben Gotts in am. I 1, der dort explizit poetologisch wirkt und das Zustandekommen einer epischen Dichtung durch „Stehlen eines Versfußes“ (am. I 1, 4) verhindert; auch diese Betrachtungsweise erhärtet die anti-epische Stoßrichtung, mit welcher der zweite Großteil von met. I beginnt.

${ }^{19}$ Anders urteilt zumindest über den Jupiter der Götterversammlung des ersten Buchs Markus Janka, welcher Jupiter ansieht ,als hartherzigen und unmäßig strafenden Willkürherrscher, der seinen ebenso
} 
ihrerseits ziemlich menschlich und teilweise sogar entweder hilflos oder willkürlich gezeichnet werden ${ }^{20}$.

Die kompositorische Zusammengehörigkeit der beiden Liebesepisoden ${ }^{21}$ im zweiten Großabschnitt steht außer Frage: Daphne und Io sind als Töchter zweier Flußgötter (Peneius bzw. Inachus) ${ }^{22}$ deutlich parallelisiert, und auch die Geschichten sind parallel konstruiert einerseits durch strukturelle Gemeinsamkeiten (Verfolgung der widerstrebenden Geliebten durch den Gott) und andererseits durch offenkundig erstrebte Antithesen: So erfüllt die von Daphne herbeigesehnte Verwandlung dieser, insofern sie ihre Jungfräulichkeit bewahren kann, einen persönlichen Wunsch ${ }^{23}$, während Ios Verwandlung in eine Kuh (welche nur auf einem Strategem Jupiters beruht) die Verwandelte quält und belastet ${ }^{24}$.

einsamen wie ziemlich aus der Luft gegriffenen Entschluß zur Vernichtung der gesamten Menschheit mit ungereimten und beliebig wirkenden „Argumenten“ stützt“ (1999, 351). Eine ähnliche Tendenz eignet der Arbeit von Anderson 1989b, der das Verhalten von Jupiter im Zusammenhang mit Lycaon und der anschließenden Strafmaßnahme als ein „deceptive paradigm“ betrachtet, welches dann im weiteren Verlauf der Metamorphosen durch das Verhalten der Götter (insbesondere Jupiters und Apollos in den erotischen Episoden im zweiten Großteil von met. I, Anderson 1989b, 99 f.) korrigiert werde. Zugrundeliegt dieser Auffassung offenkundig das Bestreben, die epischen Tendenzen (im ersten Großteil von met. I: Jupiter als Weltlenker) den elegischen Tendenzen (im zweiten Großteil: Jupiter als Liebhaber) unterzuordnen. Eine Doxographie über die verschiedenen Auffassungen zur Götterversammlung in met. I bietet Müller 1987, 276 f. — Daß die beiden erwähnten konträren Tendenzen speziell im ovidischen Jupiter-Bild gleichberechtigt nebeneinanderstehen, beweist übrigens schon der auktoriale Kommentar zum Verhalten des Götterkönigs in der Europa-Episode (II 846 f. Non bene conveniunt nec in una sede morantur/ Ma i es tas e t a $m$ or ), den Segal 2001/2002, 82 zurecht als programmatisch ansieht.

${ }^{20}$ Die episch-erhabene Tendenz im ovidischen Jupiter-Bild betont Herter 1983, 331 f.: Jupiter ,,zehrt [in den Liebesepisoden] ... von dem Respekt, den er sich im Diluvium erworben hat." Vgl. auch das Kapitel „The Two Faces of Jupiter“ bei Wheeler 2000, $63 \mathrm{ff}$. — Sehr künstlich ist die Interpretation von Spahlinger 1996, 340, der zwischen zwei Rollen des ovidischen Apollo unterscheidet: einem „machtvollen Heilbringer Apollo“ und einem „elegischen Apollo“ (in der Daphne-Episode), welche beiden Manifestationen sich auf dem Wege eines „multiple change“ ineinander verwandeln. — Daß die Götter in den ovidischen Metamorphosen laszive Züge tragen, wurde bestritten von Heinze 1960, 315 ff.; 382 ff., dessen Auffassung geprägt ist vom Systemzwang der Grundthese, daß die epische Erzählung anderen Stilgesetzen unterliege als die elegische und daß durch diese Stilgesetze im Epos ein erhabenes Götterbild bedingt sei (gegen Heinzes ,allzu starre Vorstellung eines Gattungsschemas“ vgl. Doblhofer 1960, 64 f.). Heinzes Auffassung eines grundsätzlich ernst-erhabenen Götterbilds in den Metamorphosen wird in jüngerer Zeit aufrechterhalten von Lieberg 1998-99 (ausführliche Doxographie: a.a.O. 74 ff.), der jedoch abweichend von Heinze meint, das Götterbild Ovids sei keine Folge des epischen Stils, sondern der epische Stil der Metamorphosen diene seinerseits dem Zweck, die Götter erhaben darzustellen (a.a.O. 77).

${ }^{21}$ Vgl. Schubert 1989a, 175 und jetzt Wheeler 2000, 59 ff. Herter 1983, 316 f. argumentiert gegen die denkbare Möglichkeit, Ovid habe diese Kombination bereits einer Quelle entnommen.

${ }^{22}$ Die Parallelität zwischen den Vätern wird besonders deutlich durch ein Detail: Peneius wünscht sich wie Inachus Schwiegersohn und Enkel, met. I 481 f. Saepe pater dixit ,,generum mihi, filia, debes “,/ Saepe pater dixit ,,debes mihi, nata, nepotes “ (Bretzigheimer 545 sieht hier eine Anspielung auf die augusteische Ehegesetzgebung) I 659 Spesque fuit generi mihi prima, secunda nepotum. Allerdings ist der Unterschied zu beachten, daß im Falle der Daphne dieser Wunsch schon durch die nach Jungfräulichkeit strebende Disposition der Tochter zunichte wird, im Fall der Io erst durch die Verwandlung in ein nicht-menschliches Wesen.

${ }^{23}$ Natürlich kommt dieser Wunsch nur aus „,der äussersten Bedrängnis“ zustande und ist der Ausgang der Episode somit nicht als „ein für Daphne glücklicher Ausgang“ zu betrachten, vgl. Herter 1983, 330.

${ }^{24}$ Vgl. Fränkel 1945, 79: „The next metamorphosis differs in that the change does not heal a breach, but creates one." Porod behandelt die Io-Geschichte im Rahmen seiner Typologie der ovidischen Verwandlungsgeschichten als repraesentativen Vertreter des Typus 2 (der Verwandlungsakt führt ,,zu einem auf Dauer unhaltbaren Zustand, der nach Wiederauflösung drängt“, a.a.O. 116): Die Ver- 
Eine besonders subtile Verbindung zwischen beiden Episoden wird durch eine Binnenerzählung innerhalb der Io-Geschichte gewonnen: Mercur schläfert den Bewacher der Io, den hundertäugigen Riesen Argus, durch einen Gesang über die Liebesaffaire zwischen Pan und Syrinx ein ${ }^{25}$. Der Ablauf dieser Erzählung gleicht der Episode zwischen Apollo und Daphne (Verfolgung einer nach Jungfräulichkeit strebenden Sterblichen durch den Gott; Bitte um Verwandlung; Verwandlung in ein botanisches Wesen; Aneignung des botanischen Verwandlungsprodukts durch den Gott $)^{26}$ so stark, daß eine Ausgestaltung der Erzählung Dubletten entstehen ließe ${ }^{27}$, die Ovid jedoch geschickt vermeidet, indem er die Syrinx-Episode nur andeutungsweise erzählt und von wörtlicher Wiedergabe in Oratio recta übergeht zu einer bloßen Aufzählung des noch zu berichtenden Stoffes ${ }^{28}$ (restabat ... referre) $^{29}$ in dem Moment, als Argus endlich eingeschlafen ist ${ }^{30}$. Es scheint, als ob das Einschlafen des Argus zugleich die wahrscheinliche Reaktion des Lesers andeutet für den Fall, daß die Syrinx-Episode tatsächlich narrativ ausgestaltet würde ${ }^{31}$. Somit hat Ovid in die zweite Liebesgeschichte ein subtiles mikrokosmisches Analogon ${ }^{32}$ zur ersten in intradiegetischer Form eingelegt.

wandlung in eine Kuh ist nur eine „Verlegenheitslösung“ Jupiters, das Unglück der Io besteht „,in dem Umstand, daß sie [als Kuh] in ihrem gesamten Bewußtsein, in ihrem Denken und Fühlen nach wie vor unverändert das Mädchen Io geblieben ist" (a.a.O. $116 \mathrm{f}$.).

${ }^{25} \mathrm{Vgl}$. Barchiesi 2002, 184: ,the only clear example of a narrative that achieves a practical result“. Aufgrund u.a. des verschiedenen Erfolgs intradiegetisch dargestellter sprachlicher Bemühungen sieht Fredericks (1977) durch Mercur bzw. Apollo in met. II bzw. met. I die Aspekte „divine wit“ bzw. ,divine folly“ repraesentiert.

${ }^{26}$ Murgatroyd 2001, $622 \mathrm{f}$. betont dagegen die - weniger hervorstechenden — Parallelen zwischen der Syrinx-Episode und der sie unmittelbar umgebenden Io-Erzählung.

${ }^{27}$ Vgl. Fredericks 1977, 245; Konstan 1991, 18.

${ }^{28}$ Zur narratologischen Singularität dieser Darstellungsweise vgl. Schubert 1989b, 116; Jenkins 2000, 450: „The direct speech ... is focalized through the ears of the monster; the rest of the tale, related in indirect speech, is only for the ears (and two eyes) of the reader of Ovid“; Murgatroyd 2001, $620 \mathrm{f}$.

${ }^{29}$ met. I 700.

${ }^{30}$ Dieser Moment scheint auch in der Io des C. Licinius Calvus eine besondere Rolle gespielt zu haben, vgl. fr. $11 \mathrm{Morel} /$ Blänsdorf.

${ }^{31}$ Zur Syrinx-Episode vgl. (neben Murgatroyd) den Aufsatz von Konstan, besonders a.a.O. 18: „Perhaps Ovid fears that the reader, too, might be inclined to doze at this point“ (nach einer Formulierung von Charles Henderson). Ähnlich Fränkel 1945, 85; Coleman 1971, 465 f.; Nagle 1988, 99 f.; Schmidt 1991, 104 f.; Heath 57 f.; Rosati 274 f. Vgl. auch Wheeler 1999, 2: „, a self-referential joke about the repetition of a narrative pattern“; Segal 1999, 410: „Argus' weariness wittily recognizes the reader's possible weariness with the repetition“. Unter strukturalistischem Gesichtspunkt sieht Ludwig 1965, 21 in der Syrinx-Erzählung zurecht eine „Verzahnung“ zwischen Daphne- und Io-Episode. Stilistisch in einen engen Zusammenhang gebracht werden Syrinx und Daphne auch bei Nonn. Dion. 42, 383-390:

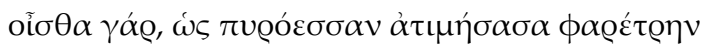

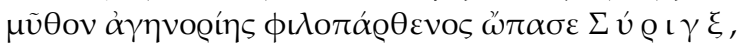

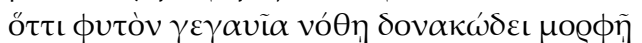

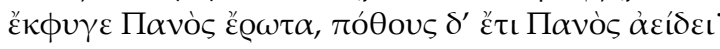

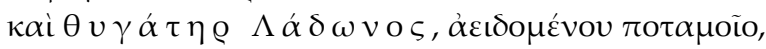

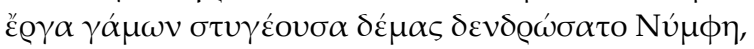

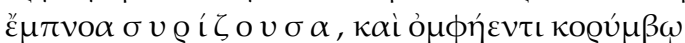

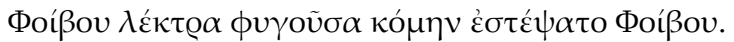

$\mathrm{Ob}$ sich hieraus eine hellenistische Vorlage für die ovidische Assoziation zwischen Daphne und Syrinx erschließen läßt, ist zweifelhaft, vgl. Herter 1983, $318 \mathrm{f}$.

${ }^{32} \mathrm{Zu}$ solchen mikrokosmischen „Spiegelungen“ als Kompositionsprinzip vgl. Rosati 2002, 271 ff., besonders $286 \mathrm{ff}$. 
Das Problem der Vermeidung narrativer Dubletten spielt auch im Verhältnis der beiden großen Episoden des zweiten Großteils von met. I (Daphne und Io) eine gewichtige Rolle: So wird etwa die Verfolgung der Geliebten durch den Gott im Falle der Daphne-Episode breit ausgestaltet durch eine Rede Apollos ${ }^{33}$, die Daphne von der Flucht abzuhalten sucht und aus Furcht um die Unversehrtheit der Geliebten paradoxerweise sogar eine beiderseitige Verlangsamung der Geschwindigkeit anbietet, und ein Gleichnis ${ }^{34}$, welches die Verfolgungsjagd mit einem Jagdhund und einem Hasen in Verbindung bringt; dasselbe Motiv findet sich auch in der Io-Episode, wird aber dort am Ende von Jupiters Werberede nur kurz in geradezu mimetischer Weise als eine Gegebenheit der äußeren Szenerie erwähnt und vom Erzähler ebenso lapidar bestätigt: ,.../ Ne fuge me! “ - fugiebat enim ${ }^{35}$... Das Motiv, welches in der DaphneGeschichte ca. 40 Hexameter einnimmt, wird hier in weniger als einem Vers abgehandelt.

\section{2. met. II}

Im zweiten Buch ist eine dem ersten entsprechende Zweiteilung ${ }^{36}$ nicht minder deutlich: Die erste Hälfte des Buchs wird bestimmt durch die Phaethon-Erzählung, die das Metamorphosenmotiv erst an ihrem Ende nach dem Tod des Helden durch die Verwandlung seiner Schwestern, der Heliaden, und seines Verwandten Cygnus zur Geltung bringt ${ }^{37}$. Die ganze Erzählung weist ähnlichen Ernst $^{38}$ und ähnlichen kosmischen Zuschnitt auf wie die Geschichte der Weltschöpfung im ersten Buch; hier wie dort sind die beteiligten Gottheiten (in der Phaethon-Episode vor allem: Apollo als besorgter Vater, Tellus als von dem Beinahe-Weltbrand betroffene Instanz, Jupiter als sorgenvoller Beschützer "seiner" Welt) ernsthaft und göttlich gezeichnet.

Ganz anders steht es wiederum im zweiten Großabschnitt des zweiten Buchs $^{39}$ : Eine Inspektionsreise Jupiters auf die Erde ${ }^{40}$ (die man zunächst als eine Fortsetzung seiner Besorgnis um den Kosmos verstehen wird $^{41}$ ) führt dazu, daß Jupiter

\footnotetext{
${ }^{33}$ met. I $504 \mathrm{ff}$.

${ }^{34}$ met. I $533 \mathrm{ff}$.

35 met. I 597.

${ }^{36}$ Zur Parallelität zwischen met. I und met. II vgl. Holzberg 1998, 89.

${ }^{37} \mathrm{Zu}$ der Frage, warum Ovid die ihm mythengeschichtlich sicher zu Gebot stehende Version eines
} Katasterismos des Phaethon und die damit gegebene Metamorphose nicht adaptierte, vgl. Döpp 1992, $151 \mathrm{ff}$.

${ }^{38}$ Ludwig 1965, 20 ff. ordnet die - erotischen Elementen völlig fernstehende — Phaethon-Episode in einen vorwiegend erotisch geprägten Großteil (I 452 - II 835) ein (ähnlich von Albrecht 2000, 300). Diese unglückliche Einordnung wird mit dem Argument gestützt, daß die „Liebe des Gottes [Phoebus] zu der Sterblichen [Clymene]“ hier nur die „Voraussetzung“ (a.a.O. 22; 25) der Erzählung bilde. Gegen diese (auch von Otis empfohlene) Gliederungsweise vgl. jetzt Wheeler 2000, $48 \mathrm{f}$.

${ }^{39}$ Zur Parallelität zwischen Jupiter in met. II und Apollo in met. I vgl. Wheeler 2000, 46.

${ }^{40} \mathrm{Zu}$ ähnlicher Anbahnung einer göttlichen Liebesaffaire vgl. unten Anm. 73.

${ }^{41}$ Vgl. Segal 1999, 407: „Immediately after the Phaethon episode, Jupiter seems once more to be the responsible pater omnipotens (2.401) as he inspects the „vast walls of the heavens“ for possible damage (2.401f.)“. Doblhofer 1975, 498 ff. zeigt, daß Ovid durch die Wiederholung der Vokabel ignis (met. II 402. 410) den Widerspruch zwischen den beiden Rollen Jupiters ins Licht setzt: „Der Jupiter, der löschen sollte, entbrennt selber; er, der Ordnung herstellen und halten soll im Kosmos, verstößt durch seine zügellose Leidenschaft selbst gegen diese Ordnung, wie Callistos Schicksal lehrt“ (a.a.O. 501). Wenig überzeugend hält Lieberg 1998-99, 83 Anm. 29 der Argumentation Doblhofers entgegen, die Liebe Jupiters zu Callisto symbolisiere gerade das Wiedereintreten eines normalen Weltablaufs (,Obiciendum ... est Iovis amorem erga virginem tantum abesse, ut leges rerum violet, ut is amor ipse 
sich erneut in eine Sterbliche verliebt, nämlich Callisto, der er (im Vergleich zur Io-Episode im ersten Buch) mit größerer Raffinesse begegnet, indem er sich nämlich in deren Schutzgottheit verwandelt, die Jagd- (und Keuschheits-)Göttin Diana ${ }^{42}$. Im Anschluß an eine Eifersuchtsszene der Juno wird von deren Tier, dem Pfau, übergegangen zum Tier des Apollo, dem Raben, der die Geschichte der Liebe seines Herrn zu der Sterblichen Coronis berichtet: Wenn man so will, bieten die zweiten Buchhälften der ersten beiden Metamorphosenbücher bis jetzt in chiastischer Anordnung $^{43}$ jeweils zwei Liebesgeschichten über Apollo ${ }^{44}$ und Jupiter ${ }^{45}$. Der Rabe wird vorgeführt im Gespräch mit der Krähe, die ihrerseits von ihrer Verwandlung berichtet (welche ihr durch Minerva ermöglicht wurde, nachdem sie als eine regia virgo vom Meeresgott sexuell bedrängt wurde), und ihr eigenes Streben nach Keuschheit in dieser Situation kontrastiert mit der (gleichfalls von der Krähe erzählten) Vorgeschichte der Eule (Nyctimene) vor ihrer Verwandlung; diese hatte ein inzestuöses Liebesverhältnis mit ihrem Vater und wird trotzdem jetzt von Minerva bevorzugt. Die bei Apollos Sohn von Coronis, dem zukünftigen Heilgott Aesculap, einsetzende Ocyroe-Prophezeiung ermöglicht einen Übergang zu zwei das Buch beschließenden Mercur-Episoden, in welchen der Götterbotte zwei Menschen (Battus und Aglaurus), die sich trotz reichlicher Entlohnung dem Gott gegenüber illoyal verhalten, als Strafe hierfür in einen Stein verwandelt ${ }^{46}$; die zweite Episode (Aglauros) trägt mit der Liebe des Mercur zu Herse wieder deutlich erotische Züge.

Wie im ersten Buch tritt einem ersten Großteil von kosmischer Dimension und epischer Erhabenheit wieder ein zweiter wesentlich heterogener gestalteter gegenüber, der in mehrere meist erotische Episoden zerfällt (die sich durch diese Aufspaltung ergebende Heterogenität ist im zweiten Buch, wo der zweite Großteil wesentlich komplexer strukturiert ist, noch erheblich deutlicher ausgeprägt als im ersten). Das zweite Buch schließt mit einer weiteren Liebesgeschichte, der Annäherung Jupiters an die Phoenizierin Europa. Damit wird bezeichnenderweise das erotisch-laszive Vorspiel eines durchaus ernsten politischen Vorgangs (der Gründung von Theben), der den ersten Großteil des dritten Buchs bestimmen wird, mit planvoller Disposition noch in den heterogen-erotischen Schlußteil des zweiten gesetzt ${ }^{47}$.

\section{3. met. III}

Die Thematik der Stadtgründung und der Frühgeschichte Thebens steht also im Mittelpunkt des ersten Großteils von Buch III. Dabei muß der Dichter ähnlich wie in

documento sit vires omnibus animantibus post incendium mundi rediisse ... Ignes ... amoris, quibus Iuppiter calescere ... dicitur, novam vitam post incendium in mundum reversam significant“ — doch war Jupiter gerade derjenige, der vom Weltenbrand offenbar persönlich nicht leidend betroffen war, und überhaupt tritt die von Lieberg behauptete kosmisch-symbolische Dimension dieser Liebesaffaire in der ovidischen Erzählung nirgends hervor).

${ }^{42} \mathrm{Vgl}$. Amphis fr. $46 \mathrm{Kassel} /$ Austin.

${ }^{43}$ Vgl. Ludwig 1965, 25.

${ }^{44} \mathrm{Zu}$ den Liebschaften Apollos in den Metamorphosen vgl. Schmidt 1991, 101-103.

${ }^{45}$ Zur besonderen Bedeutung der Gottheiten Apollo und Jupiter im Eingang der Metamorphosen vgl. (unter deutlicher Betonung des zeitgeschichtlich-augusteischen Gesichtspunkts) Buchheit 1966, 106.

${ }^{46}$ Zur Parallelität der beiden Episoden vgl. Fredericks 1977, 246 f.

${ }^{47}$ Holzberg 1998, 92 sieht im Übergang von met. II zu met. III eine Täuschung der Erwartung des Lesers, der eine narrative Ausgestaltung des erotischen Abenteuers von Jupiter mit Europa erwarte. Vergleichbar argumentiert auch Wheeler 1999, 89 ff. An anderer Stelle $(2000,84)$ äußert sich Wheeler dagegen kritisch gegen die ähnliche Deutung des dort zitierten Fowler. 
der Phaethon-Erzählung im zweiten Buch lange auf eine Metamorphose verzichten. Er hilft sich, indem er nach dem Drachenkampf des Cadmus eine göttliche Stimme einführt, die eine Verbindung schafft zwischen dem von Cadmus erlegten Drachen und derjenigen Schlange, in die Cadmus später verwandelt werden soll, worin zugleich ein im zweiten Großteil des vierten Buchs aufgegriffener Link angelegt ist. Der motivische Leitfaden, dem entsprechend die Frühgeschichte Thebens abgehandelt wird, ist das Unglück der Nachfahren des Cadmus, welches dem scheinbaren Glück des Stadtgründers nach seiner Heirat mit Harmonia entgegengesetzt wird gemäß dem solonisch-herodoteischen Topos, daß kein Sterblicher vor seinem Tode glücklichzupreisen ist ${ }^{48}$. In der Katastrophe des Actaeon, der Diana versehentlich nackt beim Bade erblickt hat, kann man noch einen zufälligen, sich für den Betroffenen verhängnisvoll auswirkenden Zornüberschuß einer ungnädigen Gottheit sehen ${ }^{49}$. Doch in der nächsten Episode, dem Tod der Semele, wird Juno als Gegenspielerin der neugegegründeten Stadt Theben (ganz wie sie in der Aeneis der Gründung Roms entgegenarbeitet) deutlich profiliert; hier liegt kein zufälliger Zornüberschuß, sondern eine prinzipielle Aversion seitens der zürnenden Gottheit vor, womit eine geradezu epische Situation konstituiert wird (eine bedeutende politische Handlung, nämlich das Heranreifen einer neugegründeten Stadt, wird durch eine feindliche Gottheit behindert).

Doch diese sich andeutende epische Konfliktsituation wird von Ovid zu Beginn des zweiten Großteils des dritten Buchs gleich wieder bewußt entschärft. Nachdem Bacchus gerettet ist, befindet sich Jupiter in entspannter Stimmung und beginnt einen spielerischen Streit mit Juno, ob Mann oder Frau die größere Lust beim Coitus empfinde. Mit diesem Übergang wird ein deutlich "leichterer" Stoff angekündigt im Vergleich zur vorausgegangenen Semele-Episode, in der sich Jupiter und Juno in einer wesentlich ernsteren Konfliktsituation gegenüberstanden ${ }^{50}$. Wie in den ersten beiden Büchern ist vor dem Auftakt des zweiten Großteils vonseiten der jeweiligen Gottheit eine „ernste“, dem Wohl der Welt dienende Aufgabe erledigt worden: hier die Sicherung der Aufzucht des Weingotts Bacchus durch Jupiter ${ }^{51}$, in met. I die Erlegung der Pythonschlange durch Apollo ${ }^{52}$, in met. II die Inspektion der vom Phaethon-Sturz geschädigten Welt durch Jupiter ${ }^{53}$.

In dem „spielerischen” Streit zwischen Jupiter und Juno wird Tiresias als Schiedsrichter herangezogen, dem von Juno als unverhältnismäßige Strafe für die nicht genehme Auskunft das Augenlicht genommen, von Jupiter aber als ausgleichende Belohnung die Sehergabe verliehen wird. Derselbe Tiresias steht in seiner neuen Funktion als Seher über den beiden Blöcken des "spielerisch-leichten" zweiten Großteils des dritten Buchs. Hierbei handelt es sich zunächst um die NarcissusErzählung, in die das Geschick der Echo eingeflochten ist, und dann um die PentheusErzählung, in welche die Geschichte von den Tyrrhenischen Seeleuten eingeschoben

\footnotetext{
${ }^{48}$ met. III $135 \mathrm{ff}$.

${ }^{49}$ Vgl. hierzu die Abhandlung von Schmitzer 2001, der zeigt, daß sich Ovid grundsätzlich an die kallimacheische Version einer unverschuldeten und ungewollten Verfehlung Aktaions (hymn. 5, 107

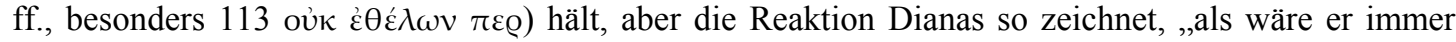
noch der Frevler, der er bis zur Korrektur der Sage durch Kallimachos war“ (a.a.O. 314). Ähnlich schon Bretzigheimer 1994, $526 \mathrm{ff}$.

${ }^{50}$ Dies gilt ungeachtet (oder, besser gesagt, gerade vor dem Hintergrund) der juristischen Terminologie, die K. M. Coleman in der Tiresias-Episode nachweist (1990, 577): „Legal jargon contributes an atmosphere of incongruous pomposity to the divine comedy".

${ }^{51}$ met. III $316 \mathrm{f}$.

52 met. I $441 \mathrm{ff}$.

${ }^{53}$ met. II $401 \mathrm{ff}$.
} 
wird. Diese beiden Erzählblöcke des zweiten Großteils von met. III zeigen zwei in verschiedener Weise bedenklich verstockte Personen: einerseits Narcissus, der gegen die Liebe anderer Personen verstockt ist, und andererseits Pentheus, der sich gegen den neuen Bacchus-Kult sperrt. Beiden Personen wird ihr schließliches übles Geschick durch den wissenden Seher Tiresias vorausgesagt. Beide Personen erhalten durch die Konfrontation mit einer anderen, nicht verstockten Person die Chance, ihre eigene Verstockung zu erkennen und aufzugeben: So könnte Narcissus die Liebe Echos erwidern und wäre dann nicht mehr in Gefahr, sich in sich selbst zu verlieben; Pentheus könnte aus der Geschichte des Acoetes die Lehre ziehen, daß Bacchus sehr mächtig ist, und seinem Unglück entgehen. Doch Narcissus bleibt gegenüber Echo verhärtet wie Pentheus gegenüber Acoetes; bei Pentheus ist diese Schuldhaftigkeit des eigenen Verhaltens (die profiliert wird durch eine ausgeschlagene Möglichkeit zur Umkehr) deutlicher gezeichnet als bei Narcissus ${ }^{54}$. Strukturell entsprechen sich die beiden Erzählblöcke durch die Gemeinsamkeit, daß jeweils eine weitere Geschichte in sie eingeschachelt wird (Echo bzw. die Tyrrhenischen Seeleute). Die beiden Komplexe werden äußerlich durch das seherische Wirken des Tiresias zusammengehalten, also formal nicht mit dem thebanischen Gründungsgeschehen verknüpft, welches im Mittelpunkt des ersten Hauptteils des dritten Buchs steht. Der NarcissusKomplex hat de facto nichts mit der thebanischen Gründungsgeschichte $\mathrm{zu}$ tun $^{55}$, wohl aber der Pentheus-Komplex, denn den Untergang des Pentheus könnte man durchaus auch den Unglücksfällen der Nachkommen des Cadmus zurechnen, die das vereinigende Moment der eigentlichen Gründungsgeschichte Thebens bilden: Aber diese mögliche Verbindungslinie zieht Ovid eben nicht. Allerdings scheint dieser

\footnotetext{
${ }^{54}$ Manuwald zeigt, daß Ovid im Vergleich zu seiner Vorlage (die wohl greifbar wird durch die von Konon überlieferte Parallelversion, FGrHist 26 F 1 XXIV) das Schuld-Strafe-Motiv relativ abschwächt. Wenn Ovids Vorlage tatsächlich der Konon-Fassung entsprach, so dürfte das Motiv, welches Ovid zu einer Parallelisierung der Narcissus- mit der Pentheus-Episode bestimmte, das beiden Geschichten gemeinsame Element der hybrishaften Mißachtung einer Gottheit gewesen sein: In Ovids Quelle verachtete Narcissus den Eros wie in der anderen Geschichte Pentheus den Bacchus, und die Thespier zogen aus Narcissus' Schicksal die Konsequenz, Eros intensiver zu verehren (FGrHist 26 F 1 XXIV 3), ähnlich wie Pentheus' Untergang die Thebanerinnen zu einem intensiveren Bacchus-Kult antreibt (met. III 732 f.). In Ovids erzählerischer Ausgestaltung der Narcissus-Episode trat dann dieser moralisierende Zug zugunsten anderer Aspekte, vor allem einer konsequenten Zeichnung von Narcissus’ Psychologie, zurück. Allgemein zum „Vergeltungsgedanken“ in der Narcissus-Erzählung vgl. jetzt Erbse 2003, 327.

${ }^{55}$ Gildenhard und Zissos (2000) versuchen, die Narcissus-Erzählung als ein intertextuelles Substitut für die in den Metamorphosen fehlende Oedipus-Erzählung zu verstehen; sie verweisen besonders auf das Vorkommen des Tiresias in beiden Erzählungen und die Parallele, daß das Sich-Selbst-Erkennen sowohl Narcissus (met. III 348) als auch Oedipus ins Verderben stürzt. Fraglich erscheint vor allem die der Argumentation von Gildenhard und Zissos zugrundeliegende Voraussetzung, der Metamorphosenleser müsse 1. die Narcissus-Echo-Episode als einen Fremdkörper innerhalb des Thebenkomplexes auffassen und 2. die Oedipussage vermissen. $\mathrm{Zu} \mathrm{1:} \mathrm{Die} \mathrm{Metamorphosen} \mathrm{enthalten} \mathrm{unzählige} \mathrm{dem}$ Haupthandlungsfaden fremde Digressionen, und man könnte sich nicht weniger etwa an der Einschachtelung der Minyaden-Erzählungen in den Thebenkomplex stören (Schade 2001, 527 vergleicht unter diesem Gesichtspunkt den Cadmus-Zyklus mit dem Aeneas-Zyklus). Zu 2: Ovids Metamorphosen sind kein auf Vollständigkeit abzielendes mythologisches Compendium, und beispielsweise der in der griechischen Tragödie sehr bedeutende Mythos des Kampfs der Sieben gegen Theben, mit dem sich auf thebanischer Seite die Episode des Brudermords von Eteocles und Polynices verbindet, bleibt in den Metamorphosen ebenfalls weitgehend ausgeblendet (angedeutet in der Themis-Prophezeiung met. IX 403 ff., ähnlich wie der Oedipus-Mythos in der Cephalus-Erzählung kurz anklingt, met. VII 759-761). Nach der hier vorgelegten Aufbau-Analyse ist das von Gildenhard und Zissos als störend empfundene spannungsreiche Nebeneinander „großer“ tragisch-epischer und „kleiner“ elegisch-erotischer Stoffe gerade konstitutiv für die Tektonik der Einzelbücher.
} 
zweite Komplex (Pentheus) des zweiten Großteils von met. III de facto eine Zurücklenkung auf Theben (im vierten Buch) vorzubereiten. Dieser Eindruck bestätigt sich dadurch, daß in der Pentheus-Erzählung ausführlich das Wirken der neuen, jungen Gottheit Bacchus zur Sprache kommt und somit gewissermaßen ein Anschluß an die Semele-Erzählung (im ersten Großteil) hergestellt wird. Zugleich bildet das Motiv der sich ausbreitenden neuen bacchischen Religion auch die Schnittstelle zum vierten Buch: denn es heißt am Buchende, daß die Thebanerinnen durch solche Exempel (wie Pentheus) gemahnt den neuen Kult eifrig betreiben. Solcher Bacchus-Beflissenheit der übrigen Frauen werden am Beginn des vierten Buchs mit nachdrücklichem At die Minyaden entgegengesetzt ${ }^{56}$, die sich hartnäckig dem neuen Kult widersetzen. Also wird durch den zweiten Komplex (Pentheus) des zweiten Hauptteils von met. III einerseits eine deutliche Zurücklenkung auf die Theben-Thematik und andererseits durch die Bacchus-Thematik eine Verknüpfung mit dem Folgenden bewirkt. Es ändert sich jedoch nichts daran, daß der zweite Großteil des dritten Buchs mit seinem im Vergleich zum ersten Großteil inhomogen-episodischen Aufbau "leichtere" Themenkreise, nämlich einerseits wieder den erotischen (Narcissus und Echo) und andererseits den bacchischen (Pentheus und Acoetes), anklingen läßt.

\section{4. met. IV}

Die Verbindung von erotischen und bacchischen Elementen kennzeichnet auch den ersten Großteil des vierten Buchs. Hier werden beide Elemente jedoch ganz anders miteinander kombiniert: Das bacchische Element beherrscht die Rahmenhandlung, den verstockten Widerstand der völlig Minerva ergebenen Töchter des Minyas gegen den neuen Bacchuskult (eine deutliche Entsprechung zu der met. III beschließenden Pentheus-Handlung). Die schließliche Verwandlung der Mädchen in Fledermäuse ${ }^{57}$ hat enge motivische Parallelen zu der ebenfalls "bacchischen" Verwandlung der Tyrrhenischen Seeleute im dritten Buch (u.a. Efeuranken ${ }^{58}$ ). Innerhalb der drei Erzählungen, mit welchen sich die Minyaden die Zeit des Spinnens verkürzen, herrschen dagegen erotische Themen vor: der Pyramus-und-Thisbe-Stoff, die Liebesaffairen des Sonnengotts und die aitiologische Geschichte von Hermaphroditus und Salmacis $^{59}$, welche die unmännlich machende Wirkung der gleichnamigen Quelle erklärt. Offenkundig hat man hier das erste Metamorphosenbuch vor sich, welches in seinem ersten Großteil keine geschlossene Handlung epischer Größe praesentiert; es

\footnotetext{
${ }^{56}$ Die Minyaden sind der Gegensatz, der Ovid bei den Schlußworten des dritten Buchs gedanklich vorschwebt (anders Holzberg 1998, 87, der eine Anspielung auf den Schluß der euripideischen Bakchen vermutet).

${ }^{57}$ Ovid hat die eigentliche Geschichte der Minyaden im Vergleich zu Nikander (sofern sich dieser aus Anton. Lib. 10 zurückgewinnen läßt, fr. 55 Schneider) sehr stereotyp und detailarm dargestellt. Offenbar diente ihm die Geschichte vor allem als Gefäß der drei Binnenerzählungen. Bei der Schilderung der schließlichen Verwandlung in Fledermäuse scheint er ein vorgegebenes Motiv (Anton. Lib. 10, 4

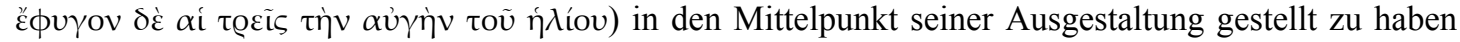
(met. IV $405 \mathrm{ff}$.).

${ }^{58}$ met. III 664 f.; IV $394 \mathrm{f}$.

59 Nach der Interpretation von Robinson liegt der Schwerpunkt der Salmacis-HermaphroditusGeschichte bei einer (schon vor der eigentlichen Metamorphose festzustellenden) Beeinträchtigung der üblichen Geschlechtsrollen: ,,a complex play with gender roles“ (1999, 218). Diese Eigenart verbindet die Episode weniger mit der Narcissus-Echo-Erzählung (Robinson a.a.O. 218 Anm. 47) als mit der programmatisch den zweiten (erotisch-elegischen) Großteil von met. III einleitenden Geschichte von der zweimaligen Geschlechtsumwandlung des Tiresias.
} 
handelt sich vielmehr um das gerade Gegenteil, eine episodische Aneinanderreihung erotischer Einzelgeschichten, deren Zusammenhang im Gespräch der Minyaden beliebiger nicht sein könnte, wie vor dem Beginn der ersten und der letzten Erzählung offenbar wird durch die Andeutung von möglichen Alternativerzählungen, die genausogut an die Stelle der tatsächlich gebotenen treten könnten ${ }^{60}$. Das aus den ersten drei Büchern bekannte Dispositionsschema wird im vierten Buch umgekehrt: An eine betont unorganische Anreihung erotischer Episoden schließt sich eine betont epische Fortführung der thebanischen Gründungsgeschichte aus dem ersten Großteil des dritten Buchs an.

Dieser betont epische Charakter des zweiten Großteils von met. IV ergibt sich durch das Wiederauftauchen der göttlichen Gegenspielerin Juno, welche nach dem heiteren Intermezzo im zweiten Großteil von met. III wieder die ernste Auseinandersetzung aufnimmt. Sie überträgt den $\mathrm{Ha} ß$ auf ihren Stiefsohn Bacchus auf dessen Tante und Amme Ino mitsamt ihrem Ehemann Athamas. Sie bekundet ihren Haß in einem erneuten Zornmonolog, womit sich ein typisches episches Formelement aus der Semele-Episode in met. III wiederholt. Diese motivische Wiederholung ist nicht nur als Verbindungsglied zwischen dem ersten Großteil von met. III und dem zweiten von met. IV signifikant, sondern verweist auch ihrerseits auf ein episches Vorbild Ovids ${ }^{61}$ : $\mathrm{Zu}$ Beginn der ersten und zweiten Aeneis-Hälfte, in den Büchern I und VII, bekundet Juno ihren Haß auf die Aeneaden in zwei vom Dichter ebenfalls bewußt parallel gestalteten Zornmonologen ${ }^{62}$. Unübersehbar wird diese strukturelle Entsprechung aber erst dadurch, daß sich Juno bei Ovid nach ihrem zweiten Zornmonolog unmittelbar in die Unterwelt begibt, wie die vergilische Juno im siebenten Buch. Damit wird die Aufhetzung des Athamas in deutliche Analogie zu der Aufhetzung der Amata gesetzt $^{63}$, und die Zerteilung des Thebenstoffs in zwei Abschnitte (erster Großteil von met. III und zweiter Großteil von met. IV) tritt in eine enge Entsprechung zu der makrostrukturellen Gliederung der Aeneis in zwei Werkhälften ${ }^{64}$. Das Geschick von Ino wird wiederum umittelbar parallelisiert mit den in met. III geschilderten Episoden um Actaeon und Semele: All diese Begebenheiten vergrößern das Unglück des zunächst scheinbar glücklichen Stadtgründers Cadmus. Insofern aber Ino und ihr kleiner Sohn Melicertes bei ihrem Sprung ins Wasser eigentlich nicht zu Schaden kommen, sondern in Meeresgötter verwandelt werden, muß sich Ovid auf das Unwissen des Cadmus über das genaue Geschick seiner Tochter und seines Enkels berufen. Bevor die eine abschließende Klammer um den Thebenkomplex ${ }^{65}$ legende Geschichte der Verwandlung von Cadmus und Harmonia in Schlangen erzählt wird, greift eine wörtliche Bezugnahme des Cadmus auf den von ihm vor der Stadtgründung erlegten Drachen noch einen bereits im dritten Buch angelegten Link zwischen den beiden Schlangenepisoden auf.

Mit dem Schluß der Thebenepisode ist das vierte Metamorphosenbuch aber noch nicht beendet. Dieses Buch unterscheidet sich von den ersten drei nicht nur durch eine Umkehr der üblichen Abfolge der Großabschnitte, sondern auch durch die zusätzliche Einführung eines dritten Großteils. Die Verstocktheit des argivischen

\footnotetext{
${ }^{60}$ met. IV 43 ff.; 276 ff.

${ }^{61}$ Vgl. Hardie 1990, $225 \mathrm{ff}$.

${ }^{62} \mathrm{Zu}$ intertextuellen Parallelitäten zwischen Metamorphosen und Aeneis in der Aitiologie von Junos Haß (vor allem in der Mehrgliedrigkeit der Begründung) vgl. Hardie 1990, 231 f.; Wheeler 2000, 86 f.

${ }^{63}$ Vgl. Hardie 1990, 228.

${ }^{64}$ Vgl. Hardies drittes Kapitel: „The interventions of Juno“ (1990, $231 \mathrm{ff}$.).

${ }^{65} \mathrm{Zu}$ dieser Funktion des Schlangenmotivs vgl. Ludwig 1965, 27; Wheeler 2000, 51. Norwood 1963, 172 dehnt das Motiv in fragwürdiger Weise auf die Schlangen in der Tiresias-Episode aus.
} 
Königs Acrisius sowohl gegenüber der neuen thebanischen Gottheit Bacchus als auch gegenüber seinem eigenen Enkel Perseus bietet den Übergang zur Perseus-Episode, die nicht nur den Schluß des vierten, sondern auch den Anfang des fünften Buchs einnimmt.

Man darf die Frage stellen, warum Ovid sich hier zum ersten Mal entschloß, einen offensichtlich zusammengehörigen, nicht durch Exkurse zertrennten Erzählblock episch-erhabener Ausprägung auf zwei Bücher zu verteilen. Die Schilderung beginnt bei der Rückkehr des Perseus nach der Tötung der Medusa, erstreckt sich dann über die Versteinerung des Atlas und die Befreiung der Andromeda bis hin zum Gelage der Hochzeit zwischen Perseus und Andromeda, wo Perseus Gelegenheit findet, die von Ovid ausgelassene Vorgeschichte, die eigentliche Tötung der Medusa und die Provenienz dieses Ungeheuers, in einer Binnenrede darzustellen. Diese friedliche Gelagesituation wird unterbrochen durch den Beginn des fünften Buchs und durch den Kampflärm, der erregt wird von dem eifersüchtigen Phineus und seinen Gefolgsleuten, die Perseus in eine heftige Schlacht verwickeln. Der Grund für die Unterbrechung der Perseus-Episode durch die Buchgrenze gerade an dieser Stelle dürfte in folgendem liegen: Die im vierten Buch geschilderten Ereignisse lassen sich als eine Art "Odyssee" des Perseus verstehen, der an verschiedenen Orten (bei Medusa, bei Atlas, bei Cepheus) Gefahren zu bestehen hat, sich von einem Ort zum nächsten bewegt und sich schließlich in einem Gelage befindet, in dem er von seinem ersten, auktorial nicht dargestellten Abenteuer in einer Binnenerzählung berichten $\operatorname{kann}^{66}$ - damit sind alle Kriterien für einen "odysseischen" Werkteil erfüllt. Der Inhalt des neuen Buchs wird dagegen hauptsächlich bestimmt durch kriegerische Auseinandersetzungen an dem von Perseus erreichten Bestimmungsort (am Hof des Cepheus); die Art, wie Cepheus die Auseinandersetzung zuerst verhindern will, aber sich dann schließlich zurückzieht, erinnert an das Verhalten des zwischen Aeneas und Turnus stehenden Latinus im siebenten Aeneis-Buch ${ }^{67}$. Die Buchgrenze scheint also einen Einschnitt zwischen einem odysseischen und einem iliadischen Teil der ovidischen "Perseis" zu bilden ${ }^{68}$, wobei diese beiden Teile im Vergleich zum vorschwebenden vergilischen Vorbild enger ineinander verwoben sind: Bei Vergil erfolgen der Bericht über den Anfang von Aeneas' Irrfahrt (bei Dido in Carthago) und die schließlichen Kämpfe (gegen Turnus in Latium) an verschiedenen Orten, während in der ovidischen "Perseis" odysseischer und iliadischer Teil zumindest teilweise zusammenfallen, insofern das Gelage mit dem intradiegetischen Bericht über die früheren Abenteuer und der Kampf um die Gattin lokal koinzidieren. Perseus kommt nach dem Ende seiner Erzählung über das Medusen-Abenteuer kaum zum Luftholen, und schon muß er den Kampf gegen Phineus bestehen.

\section{5. met. $\mathrm{V}$}

Mit dem Hochzeitskampf ist der episch gefärbte, erste Großteil des fünften Buchs abgeschlossen. Der Übergang zum zweiten Großteil ergibt sich durch die Bewegung der Göttin Minerva, die, nachdem sie ihrem Halbbruder Perseus seit dem Beginn des Hochzeitskampfes offenbar persönlich beigestanden hat, sich nunmehr von ihm

\footnotetext{
${ }^{66} \mathrm{Zu}$ dieser „odysseischen“ Situation vgl. — unter etwas anderem Gesichtspunkt — Rosati 2002, 289.

${ }^{67} \mathrm{Vgl}$. etwa Galinsky 1999, 308 f., der allerdings parodistische Züge in den Mittelpunkt stellt.

${ }^{68}$ Holzberg 1998, 80 bringt etwas anders die beiden durch die Buchgrenze getrennten Abschnitte der ovidischen „Perseis“ mit Irrfahrten und Freiermord in der Odyssee in Verbindung.
} 
entfernt und zum Musenberg Helicon begibt. Das Motiv des vom Hufschlag des Pegasus neuentstandenen Musenquells ermöglicht einen relativ organischen Übergang vom Perseus-Teil zur Musenepisode. Die von den Musen der Minerva berichtete Geschichte vom Frevel des Pyreneus eröffnet das Thema "Frevel Sterblicher gegen Gottheiten", welches in dieser allgemeinen Form im sechsten Buch weitergeführt werden wird. Doch die viel breiter ausgeführte Episode vom Gesangeswettstreit zwischen den Musen und den Pieriden inauguriert die speziellere Motivausprägung "Sterbliche beanspruchen in ihrer Kunstfertigkeit Überlegenheit über Götter", die diejenigen Episoden bestimmt, welche einander durch die Symmetrieachse zwischen Buch V und Buch VI widerspiegeln: die Pieriden-Erzählung und die ArachneGeschichte.

Der Gesang der Pieriden, den Ovid nur teilweise in Oratio recta wiedergibt ${ }^{69}$, diskreditiert sich schon durch die Diskrepanz mit der von Ovid innerhalb der Metamorphosen geschilderten Faktizität. Es handelt sich um eine blasphemische Version des Gigantenkampfs, nach welcher die olympischen Göttern vor den Giganten nach Aegypten geflohen sein und sich in verschiedene Tiere verwandelt haben sollen ${ }^{70}$. Ovid hat ebendiesen Mythos im ersten Buch behandelt ${ }^{71}$, und zwar in einer fast gleichlangen Partie, und aus dieser ovidischen Version (nach der sich die olympischen Götter durchsetzten) geht die faktische Verkehrtheit der Pieriden-Fassung klar hervor $^{72}$. Bei weitem ausführlicher wiedergegeben wird der Gesang der echten Musen

\footnotetext{
${ }^{69} \mathrm{Zu}$ dieser — ihrerseits diskreditierenden — Darstellungstechnik vgl. ausführlich Rosati 2002, 299301. Eine ähnliche selektive Darstellungstechnik findet Hardy 1995, 143 in der auktorialen Wiedergabe von Arachnes Gewebe in met. VI.

${ }^{70}$ Vgl. hierzu Spahlinger 1996, 116: „Unwürdigen Gestalten den ihnen nicht zukommenden Ruhm zu verleihen, dafür den angestammten Göttern den Rang streitig zu machen, dies ist die Absicht des Liedes, damit entspricht es genau der Situation des Wettstreites selbst“.

${ }^{71}$ met. I $151-162$.

72 Anders Ludwig 1965, 34, der versucht, die Pieriden-Version mit dem traditionellen Ablauf der Gigantomachie in Einklang zu bringen: „Die Pieriden sangen vom Gigantenkampf, jedoch nicht vom $\mathrm{s} \mathrm{c} \mathrm{h} \mathrm{l}$ i e $\beta 1 \mathrm{i}$ c h e $\mathrm{n}$ S i e g d e r G ö t t e r, sondern von der anfänglich bedrohlichen Rebellion ...". Ovid hebt ausdrücklich hervor, daß die Pieriden-Version die Giganten f ä $1 \mathrm{~s} \mathrm{chlich} \mathrm{zu-}$ ungunsten der olympischen Götter bevorzugt (met. V 319 f. f a l s o que in honore Gigantas/ Ponit), und diese Tatsache schlägt sich möglicherweise gerade darin nieder, daß in dieser Version a $11 \mathrm{e}$ Götter fliehen (met. V 322), während in Ovids mutmaßlicher Vorlage (Nikander bei Anton. Lib. 28, 2 , fr. 59 Schneider) Athene und Zeus ausdrücklich von der Flucht ausgenommen werden (vgl. Guthmüller 1964, 16). Hinds 1987, 131 sieht in der Niederlage der Pieriden im Gesangeswettstreit zugleich eine Kritik an der konventionell kriegerisch-epischen Art ihrer Dichtung (,,.. there is some reason to think that the Pierid Gigantomachy incurs the Muses' displeasure not just because it is impious, but because it is the „wrong kind“ of poetry“); ähnlich Hofmann 1986, 228, der den Pieriden-Gesang als ,a carmen perpetuum - a traditional piece of epic in its structure and content" auffaßt. Solche Deutung des Pieriden-Gesangs wirft jedoch verschiedene Probleme auf: 1. Wie ließe sich diese Deutung vereinbaren mit der Feststellung, daß Ovid seinen Leser geradezu auffordert zu einem Vergleich mit seiner eigenen Behandlung des Gigantomachie-Mythos innerhalb der Metamorphosen? Auch im Prooemium des Orpheus-Gesangs (met. X 150 f.) erfolgt eine poetologische Auseinandersetzung mit dem Gigantenthema, das jedoch nicht abgelehnt, sondern als etwas zuvor oft Behandeltes dargestellt wird (in Übereinstimmung mit der Tatsache, daß sich Ovid mit dem Thema im ersten Buch befaßt hat — und in indirekter Form auch im fünften). 2. Die im Text implizierte Kritik am Pieriden-Gesang konzentriert sich auf sachliche Aspekte, insbesondere die faktisch-mythologische Falschheit des von den Pieriden Erzählten; das zeigt nicht nur der Vergleich mit der ovidischen Gigantomachie im ersten Buch, sondern auch der Beginn des Musen-Gesangs, der mit seiner beiläufigen Anspielung auf den Typhoeus-Mythos geflissentlich die herkömmliche Version (Sieg der olympischen Götter) restituiert (vgl. hierzu Guthmüller 1964, 18; Zissos 1999, 110). Eine poetologische Kritik kann hierneben allenfalls eine untergeordnete Rolle spielen (zu diesem Einwand gegen Hinds' Deutung vgl. P. J. Johnson 1996/97, 8). 3. Die — sehr kurze und teilweise indirekte — Wiedergabe des Pieriden-Gesangs
} 
(321 Hexameter), der eine erotische Begebenheit, nämlich den Raub der Proserpina durch den Totengott Dis $^{73}$ in Sizilien und einige hiermit zusammenhängende Ereignisse zum Gegenstand hat; diese Begebenheit unterscheidet sich von anderen göttlichen Liebesaffairen in den Metamorphosen insbesondere dadurch, daß der eigentliche Akt des gewaltsamen Zugriffs in ungeheuer komprimierter Form dargestellt wird (met. V 395 f. Paene simul visa est dilectaque raptaque Diti:/ Usque adeo est properatus amor) und in der Erzählung vor allem die Folgen des Raubs in den Mittelpunkt gerückt werden.

Relativ deutlich abgesetzt von diesem Haupthandlungsstrang innerhalb der Binnenerzählung ist die Geschichte von Alpheus und Arethusa, die Arethusa der verzweifelt nach ihrer Tochter suchenden Ceres zunächst erspart, aber für einen späteren Zeitpunkt, wenn Ceres "besserer Stimmung" sei, ankündigt ${ }^{74}$; diese Ankündigung wird gegen Ende des Binnengesangs verwirklicht. Die so recht kunstvoll neben die Erzählung von Proserpina und Dis plazierte Episode über die Flucht der Arethusa vor dem Flußgott Alpheus steht in subtiler impliziter Beziehung zur Haupthandlung des Binnengesangs: Zunächst steht sie der Erzählung über den Raub der Proserpina supplementär gegenüber, insofern hier die Flucht der Arethusa vor Alpheus wieder in Einklang mit dem üblichen Schema einer Erzählung göttlicher Liebesaffairen —

(von Schmitzer 1990, 205 f. so ausgedeutet, daß ,dem Leser ein langes und vor allem langweiliges Großepos erspart“ wird) läßt dessen poetologische Qualitäten nicht recht transparent werden. Das Schwergewicht scheint aber nicht auf der — herkömmlichen — Kampfhandlung, sondern vielmehr auf der Flucht und Selbstverwandlung der Olympier zu liegen, worin kaum ein herkömmliches episches Element zu erblicken ist. Gegen eine Auffassung des Pieriden-Gesangs als ein Beispiel für „poetologisch falsche Dichtung“ vgl. auch Rosati 2002, 293. Spahlinger 1996, 129 f. wendet sich gegen die Deutung von Schmitzer 1990, 201 ff., der hinter dem Pieriden-Gesang das obsolete mythologisch-politische Großepos, hinter dem Lied der Calliope dagegen ein hellenistisches „Musterepyllion“ sieht; demgegenüber betont Spahlinger den am Anfang deutlich werdenden hymnischen Charakter des Calliope-Gesangs und findet hinter dem ganzen Wettstreit folgende poetologische Lehre: „Richtige Dichtung ist Dichtung im Dienste der Götter und mit den Göttern, falsche Dichtung und damit scheiternde Dichtung ist Dichtung gegen die Götter“ (Spahlinger 1996, 130). Diese Lehre trifft im Falle der Musen-Pieriden-Episode durchaus zu, insofern Ovid, wie seine eigene Gigantomachie-Darstellung in met. I zeigt, hier sachlich (d.h. im Rahmen der fiktiven mythischen Faktizität seines Gesamtwerks) auf der Seite der Götter steht. Problematisch wird die Deutung Spahlingers dagegen im Falle der Arachne-Episode (vgl. unten Anm. 89), wo das Götterbild der unterlegenen Künstlerin enge Entsprechungen zu dem ovidischen aufweist. P. J. Johnson stellt die Pieriden wie Spahlinger ebenfalls in die Nähe Arachnes, sieht in ihrem Gesang aber eine poetologische Stellungnahme gegen enkomiastische Dichtung (1996/97, 14): „The Emathides' solution to the problem of praise poetry, like Ovid's, is not recusatio, or avoidance of the genre; instead they embrace the genre and the topic, but subvert it, to the great dismay of the Muses: falsoque in honore Gigantas/ Ponit et extenuat magnorum facta deorum (5.319-20)“. Auch gegen diesen Ansatz ist anzuführen, daß der Pieridengesang bei Ovid nicht poetologisch als Verstoß gegen dichterische Konventionen, sondern inhaltlich als faktische Falschheit dargestellt wird, wie gerade die von P. J. Johnson als Titel gewählte Stelle dartut. Wegen dieser faktischen Falschheit des Inhalts, die offenkundig besonders vor dem Hintergrund der Gigantomachieschilderung in met. I diskreditierend wirken soll, kann man die Pieriden von vorneherein nicht — im Gegensatz zu Arachne, deren Gewebe sachlich mit Ovids Götterbild übereinstimmt — als sympathisch gezeichnete poetologische Spiegelbilder Ovids ansehen.

${ }^{73}$ Zur Parallelität zwischen Dis im Calliope-Gesang und Jupiter in der Callisto-Episode in met. II, die beide während eines Inspektionsgangs von kosmischer Bedeutung (Dis nach der Gigantenschlacht, Jupiter nach dem durch Phaethon verursachten Weltbrand) in Liebe entbrennen, vgl. Wheeler 2000, 57. Durch diese parallele Gestaltung wird jeweils eine erotische Episode mit einem erhaben-epischen Geschehen (Weltbrand durch Phaethon bzw. Gigantomachie) verknüpft.

${ }^{74}$ Solche Reflexionen ovidischer Erzähler über die Länge der Erzählung, die sie ihrem (intradiegetischen) Publikum zumuten, werden gesammelt bei Rosati 2002, 284 f. Der hier vorliegende Fall ist der einzige, in dem das Motiv eine „Auslagerung“ einer ganzen Erzählung aus dem Zusammenhang bewirkt, innnerhalb dessen sie eigentlich gehalten werden sollte. 
breiten Raum einnimmt, während dieses Element in der Proserpina-Episode betont kurz abgehandelt wurde.

Wichtig und sinnhaltig sind aber auch andere Korrespondenzen: Arethusa begibt sich wie Proserpina in das von einer Gottheit (Diana bzw. Dis) auf zauberhafte Weise geöffnete Erdreich ${ }^{75}$, doch für Proserpina bedeutet dieser Gang in die Erde das endgültige Gelingen der Entführung und damit ihr Unglück, für Arethusa dagegen ihr glückliches Entkommen nach Sizilien und damit den Erhalt ihrer Keuschheit ${ }^{76}$. Aber nicht nur diese implizite Kontrastbeziehung verbindet die beiden Episoden, sondern vor allem ermöglicht es nur der von Diana geöffnete unteriridische Flußlauf der Arethusa, ihre entscheidende Rolle in der Proserpina-Geschichte als Denunziantin des Totengotts zu spielen: Nur weil sich ihr Flußlauf unter der Erde befindet, vermag sie Ceres Auskunft über den Verbleib ihrer Tochter zu geben. Die Arethusa-Geschichte scheint also von Ovid mit beträchtlichem kompositorischen Geschick als ein wenn auch quantitativ kürzeres Pendant der Proserpina-Erzählung gegenübergestellt zu $\operatorname{sein}^{77}$. Eine solche strukturelle Zweiteilung des zweiten, erotisch-episodischen Buchteils ließ sich bereits im ersten (Daphne/ Io) und im dritten (Narcissus/ Pentheus) Metamorphosenbuch beobachten. Die für die ersten drei Metamorphosenbücher typische Dichotomie (1. geschlossener epischer Großteil/ 2. episodischer elegischer Großteil) läßt sich im fünften Buch ziemlich genau wiedererkennen - insofern der Minerva-Musen-Großteil quantitativ durch die prinzipiell erotische Erzählung über den Raub der Proserpina beherrscht wird und die Proserpina-Erzählung durch die Arethusa-Geschichte ein zwar episodisches, aber kompositionell sorgfältig abgewogenes erotisches Pendant erhält.

\section{6. met. VI}

Das sechste Buch ist, wie bereits angedeutet, spiegelsymmetrisch zum fünften angelegt: Die Arachne-Episode korrespondiert als ein zweites „Duell menschlicher Künstler mit Gottheiten" mit dem Gesangeswettstreit zwischen Musen und Pieriden, welcher den zweiten Großteil des fünften Buchs fast vollständig bestimmte. Diese Entsprechung kommt auch durch den formalen Anschluß der Arachne-Episode ans Vorige zum Ausdruck. Der Dichter beschreibt die gedankliche Reaktion der Minerva auf das von den Musen berichtete Vorgehen gegen die Pieriden: Minerva billigt die Bestrafung der frevelhaften Pieriden und fühlt sich dadurch wiederum animiert, ihrer-

\footnotetext{
${ }^{75}$ met. V 423 f.; 639.

${ }^{76}$ Vgl. Zissos 1999, 104. Cahoon 1996, 60 findet in der Arethusa-Episode gerade das, was in der Proserpina-Erzählung fehlt, nämlich die subjektiven Erfahrungen der von einem unabweisbaren Liebhaber verfolgten Frau: "What Calliope had suppressed emerges with Arethusa from watery depths“. Dieser Unterschied müßte jedoch im Zusammenhang mit dem weiteren Gesichtspunkt gesehen werden, daß der in der Proserpina-Erzählung narrativ stark verkürzte Akt des erotischen Zugriffs in der Arethusa-Episode wieder breit thematisiert wird. Ferner wäre der entscheidende Unterschied $\mathrm{zu}$ berücksichtigen, daß der Zugriff des Alpheus auf Arethusa (im Gegensatz zu dem des Dis auf Proserpina) letztlich erfolglos bleibt.

${ }^{77}$ Weiteres zur Parallelität zwischen Proserpina- und Arethusa-Erzählung: Wheeler 1999, 188. Hinds 1987, 91-93, der gemäß seinem methodischen Ansatz die ovidischen Proserpina-Erzählungen (sowohl in den Metamorphosen als auch in den Fasten) vor allem unter dem Gesichtspunkt der Imitation des homerischen Demeter-Hymnus betrachtet, faßt die Erzählung der Arethusa als ein strukturelles Pendant zum Bericht der Persephone über ihre Entführung auf (hymn. 406 ff.). Weitere Entsprechungen zwischen Proserpina- und Arethusa-Erzählung in met. V bespricht Hinds 1987 in Anm. 46 zu S. 92 (S. 157 f.).
} 
seits vorzugehen gegen die Lydierin Arachne ${ }^{78}$. Doch bei allen äußeren Parallelitäten zwischen Musen-Pieriden-Wettstreit und Arachne-Episode (Hybris von Sterblichen führt zur Herausforderung von Göttern; Schilderung des Wettkampfs durch paarweise Wiedergabe von Gesangestexten/Bildinhalten ${ }^{79}$; abschließende Verwandlung der hybrishaften Sterblichen in Tiere) gibt es auch wichtige Diskrepanzen zwischen den beiden Wettkampfschilderungen ${ }^{80}$ : Zunächst ist es im Falle der Musen eine übergeordnete Instanz (nämlich ausgewählte Nymphen), welche das Urteil fällt; dagegen findet in der Arachne-Episode kein eigentliches Urteil statt, sondern Minerva zerreißt einfach das Gewebe der Arachne (obwohl es nach Ovid nicht einmal der personifizierte Neid tadeln könnte ${ }^{81}$ ), schlägt auf die Künstlerin ein und verwandelt sie später in eine Spinne. Dies läßt Minervas Verhalten willkürlich erscheinen ${ }^{82}$; die Musen dagegen werden durch die Nymphen zunächst als Sieger im Wettkampf bestätigt und reagieren dann mit der Verwandlung erst auf vorausgegangene Unverschämtheiten der besiegten Pieriden ${ }^{83}$.

$\mathrm{Zu}$ ähnlichen, für Minerva ungünstigen Ergebnissen führt auch ein Blick auf die „Kunstwerke” der jeweils unterlegenen Sterblichen: Im Falle der Pieriden handelte es sich, wie bereits ausgeführt, um eine Darstellung der Gigantomachie, welche der Darstellung Ovids im ersten Buch kontradiktorisch widersprach; dagegen handelt es sich bei dem Arachne-Gewebe um Liebesaffairen von Göttern in verwandelten Gestalten, wie sie in den Metamorphosen allenthalben vorkommen ${ }^{84}$. Insbesondere die erste Episode, die Liebe des in einen Stier verwandelten Jupiter zu Europa, bestätigt sich durch einen Vergleich mit dem Schluß des zweiten Metamorphosenbuchs, wo der Mythos als Vorgeschichte zur thebanischen Stadtgründung erzählt wird ${ }^{85}$. Der malerische Zug, daß die vom Stier verschleppte Europa zum verlassenen Ufer zurückblickt, ist auffälligerweise beiden Schilderungen gemeinsam ${ }^{86}$.

\footnotetext{
${ }^{78} \mathrm{Da}$ Minerva bei ihrer Strafaktion größere Eigeninitiative zeigt als die Musen, wird hervorgehoben bei von Albrecht 2000, 84.

${ }^{79} \mathrm{Vgl}$. Rosati 2002, $292 \mathrm{f}$.

${ }^{80}$ Vgl. Harries 1990, 66 f.; Rosati 2002, 297: „The differing motivations for the outcomes of the two contests, not coincidentally juxtaposed, raise questions about justice“.

${ }^{81} \mathrm{Vgl}$. Hofmann 1986, 230: „Her eventual reaction is not aesthetic but purely moral“; 234: „It was not lack of ,poetic“ qualities, then, but immoral content (caelestia crimina) which led to Arachne's metamorphosis“. Ähnlich von Albrecht 2000, 88, der Arachne als ,,perfekte Künstlerin“ bezeichnet.

${ }^{82}$ Bernsdorff 1997, 353 verweist zusätzlich auf eine gewisse Gewalttätigkeit Minervas sowohl innerhalb als auch außerhalb der bildlichen Darstellung, die sich im zweimaligen Vorkommen von percutere $(80 ; 133)$ niederschlägt. Zur Maßlosigkeit von Minervas Reaktion vgl. auch Pöschl 1999, 429.

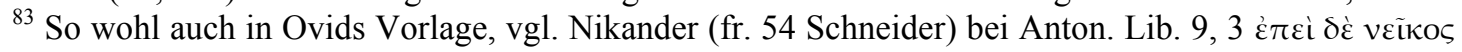

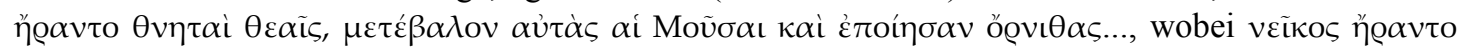
offenbar nicht auf den eigentlichen Wettstreit geht.

${ }^{84}$ Einige vergleichbare durch Verführungsabsichten motivierte Szenen göttlicher Selbstverwandlung in den Metamorphosen sammelt W. R. Johnson 1997, 367. Heinze 1960, 384 f. (zu seiner Grundthese vgl. oben Anm. 20) meint, der Dichter habe die Darstellungen Arachnes in der Tat ,als Verstoß gegen göttliche Würde empfunden“, und versucht die offenkundigen zahlreichen Parallelen im Gesamtwerk der Metamorphosen mit recht künstlichen Argumenten wegzuinterpretieren.

${ }^{85}$ Vgl. Nagle 1988, 102 mit Anm. 6.

${ }^{86}$ met. VI $105 \sim$ met. II 873 f. Vgl. Guthmüller 1964, 36 Anm. 2; Schmidt 1991, 121 Anm. 19. Zum rückverweisenden Charakter des Europa-Motivs vgl. auch Lausberg 1982, 113. In ähnliche Richtung gehende Überlegungen zur Funktion dieses Rückverweises bei Wheeler 2000, 99; Segal 2001/2002, 92: „Ovid is self-referentially harking back to his own poem“. Tsitsiou-Chelidoni 1999, 295 sieht in der Bildbeschreibung eine „Fortsetzung“ der Schilderung am Ende von met. II, insofern „die Verzweiflung des Mädchens und seine Angst erst auf dem ... Teppich ... thematisiert“" werden. Wenn die Europa-Erzählung im zweiten Metamorphosenbuch auch die einzige Verwandlungsgeschichte auf dem Gewebe der Arachne ist, welche Ovid auch ,in eignem Namen erzählt“ (Heinze 1960, 384), so
} 
Insofern scheint die inhaltliche Tendenz des Arachne-Gewebes durch die Gesamttendenz der Metamorphosen bestätigt zu werden ${ }^{87}$. Man muß sich fragen: Konnte der Verfasser der Metamorphosen, in denen Götter tatsächlich ständig in ähnlichen Situationen wie auf dem Arachne-Gewebe dargestellt werden, die Verdammung der Arachne durch Minerva ernstgemeint und im eigenen Namen gebilligt haben? Hinzu kommt die offenkundige Doppeldeutigkeit der Junktur caelestia crimina ${ }^{88}$, was aus der Perspektive der Minerva (die der Dichter an dieser Stelle einnimmt) sicher "Beschuldigungen gegen die Götter" heißt, aber rein sprachlich die Deutung "Verbrechen der Götter" mindestens genauso nahelegt ${ }^{89}$.

liegt doch ohne Zweifel eine besondere Bedeutung darin, daß ge rade di e e rste Episode der Arachne eine durch wörtliche Anklänge betonte Parallele in der auktorialen Erzählung hat.

${ }^{87}$ Im Gegensatz zu der hier gegebenen metamorphosen-immanenten Deutung versucht Harries eine biographistische Interpretation, deutet den Inhalt von Arachnes Gewebe auf die Ars amatoria hin $(1990,70)$ und versteht Arachne als ,a prototype of the exiled poet“ (a.a.O. 65). Hofmann 1986, 230 ff. sieht hinter dem Wettstreit eine poetologische Auseinandersetzung zwischen dem klassischen carmen perpetuum (Gewebe der Minerva) und dem alexandrinischen carmen deductum (Gewebe der Arachne). Noch genauer legt sich Glei 1998, 95 ff. fest, der hinter dem Gewebe der Minerva die vergilische Aeneis, hinter dem der Arachne dagegen die Metamorphosen sieht. Gegen derlei Deutungen wendet sich zurecht Bernsdorff 1997, 349 f., der sowohl der direkten Identifikation zwischen Arachne und Ovid skeptisch gegenübersteht als auch bezweifelt, daß sich das komplexe Gesamtwerk Metamorphosen „entweder auf „,klassische“ oder auf „moderne“ Züge reduzieren ließe“. Eine solche direkte Identifikation zwischen Arachne und Ovid wäre vor allem auch unter dem Gesichtspunkt des Inhalts der Gewebe problematisch: Die Abstrafungen hybrishafter Sterblicher durch Götter (im Minerva-Gewebe) gehören genauso zum Erzählkosmos der Metamorphosen wie die die Liebesaffairen der Götter (im Arachne-Gewebe), vgl. Lausberg 1982, 114-116 (die ihre poetologische Ausdeutung der beiden Gewebe durch das bT-Scholion zu Il. 3, 126 f. zu erhärten sucht, a.a.O. 117 ff.); Feeney 1991, 192; Spahlinger 1996, 80; Pöschl 1999, 423 f. (der jedoch letztlich wieder Arachnes Gewebe den Vorzug gibt, und zwar unter dem ,menschlichen Aspekt“ [426]: „Dem Solipsismus der Göttin steht ... bei Arachne die Hinwendung zu den Frauen gegenüber, die Opfer göttlicher Willkür geworden sind“ [427]; jedoch spielen die Frauen in den meisten von Arachne dargestellten Episoden — abgesehen von der Europageschichte - überhaupt keine irgendwie profilierte Rolle, vgl. Hardy 1995, 144 f.: „After the opening detailed description of Europa, there is a marked shift of focus away from the victims involved, and near the end of the ecphrasis they start to disappear from the description altogether"). Die Gegenüberstellung der beiden Gewebe konfrontiert gewissermaßen pointiert zwei Momente, die auch innerhalb der Metamorphosen miteinander kollidieren (anders Glei 1998, 97 f.): Götter einerseits als ernste Wahrer der Weltordnung und Bestrafer von Übermütigen, andererseits als triebgesteuerte Liebhaber (vgl. z.B. met. I, wo Jupiter zunächst als Wahrer der Weltordnung und dann als vor seiner Ehefrau zitternder Liebhaber der Io figuriert). $\mathrm{Zu}$ einem befriedigenden Ausgleich werden diese beiden inhaltlichen Momente auch innerhalb der Arachne-Episode nicht gebracht: Diejenige Sterbliche, welche in ihrer Darstellung den für die Götter unvorteilhaften Aspekt (Götter als triebbestimmte Liebhaber) gegenüber dem vorteilhaften (Götter als Wahrer der Ordnung) in den Vordergrund stellt, wird wiederum von einer ordnungswahrenden Gottheit abgestraft und schließlich ausgelöscht. Es fehlt vor dem Hintergrund der Auseinandersetzung zwischen Pieriden und Musen vor allem eine dritte, objektive Instanz.

${ }_{88}^{8}$ met. VI 131.

${ }^{89}$ Dieser Ambivalenz nicht gerecht wird die Deutung von Spahlinger, der Arachne einfach als eine

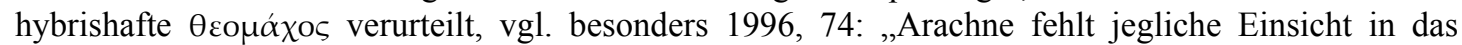
Heilsame göttlichen Wirkens, ihre Anklage ist zu allgemein und darum ungerecht." Die deutliche Querverbindung zwischen Arachnes Europa-Bild und Ovids eigener Schilderung derselben Episode macht es schwer, hier an ein verkanntes ,heilsames Wirken“ Jupiters (wie es Ovid in anderen, nicht erotischen Episoden durchaus auch schildert) zu denken, und die von Spahlinger hervorgehobene Bezeichnung Minervas als flava virago (VI 130) berührt sich nicht mit dem Bildinhalt, insofern Arachne der Minerva selbst keine Verhältnisse mit Sterblichen unterstellt; das Gebaren der männlichen Götter in dem Gewebe hat so viele Parallelen in den ovidischen Metamorphosen, daß hier kein Leser einen Widerspruch zwischen der Ekphrasis und der fiktiven Wirklichkeit innerhalb von Ovids Erzählkosmos empfinden wird. 
Im ganzen ist die "Abstrafung" der Arachne durch Minerva also mit einigen fragwürdigen Zügen ausgestattet ${ }^{90}$. Der Leser fragt sich, ob Minerva gegenüber Arachne das ihr von den Musen gegenüber den Pieriden vorgegebene Verhaltensparadigma $^{91}$ wirklich in korrekter Weise übernimmt, und eng verbunden damit ist die Frage, ob das Götterbild auf Arachnes Gewebe aus Ovids Sicht tatsächlich so verkehrt ist wie die Gigantomachieversion der Pieriden.

Während also die Arachne-Episode mit signifikanten Korrespondenzen an die im Gesangeswettstreit zwischen Musen und Pieriden begonnene Thematik des Künstlerwettstreits zwischen Sterblichen und Göttern anknüpft, wird das allgemeinere Thema „Hybris von Sterblichen gegen Götter”, welches im fünften Buch durch die Pyreneus-Erzählung nur kurz angedeutet wurde, in den folgenden Episoden des sechsten Buchs breit entfaltet. Es zeigt sich eine chiastische Spiegelsymmetrie mit jeweils konträren Quantitätsverhältnissen: Der kurzen Pyreneus-Erzählung entspricht jetzt eine ausführliche Gestaltung der Niobe-Episode und der ihr beigeordneten Erzählungen (s.u.), während der Arachne-Abschnitt im Vergleich zum Gesangeswettstreit im vorigen Buch geradezu knapp gehalten ist.

Die Niobe-Episode ist deutlich als Hauptgeschichte des ersten Großteils von met. VI profiliert: Die vorausgehende Arachne-Geschichte wird in Hinsicht auf Niobe instrumentalisiert, insofern Arachne in der Überleitungspartie als ein mögliches warnendes Paradigma für Niobe dargestellt wird. Die beiden auf Niobe folgenden Erzählungen, die Lykischen Bauern ${ }^{92}$ und die Marsyas-Geschichte, werden von Ovid eingeführt als Erzählungen dritter im Umfeld Niobes, welche die (mythologische) Vergangenheit im Lichte des neulichen Geschehens um Niobe neudeuten; somit sind sie kompositorisch in gewisser Weise der Niobe-Erzählung untergeordnet. In der Marsyas-Geschichte wird der Aspekt des Künstlerwettstreits (den Ovid bereits im Gesangeswettstreit der Musen und in der Arachne-Erzählung erschöpfend behandelt hat) kaum profiliert: Von den künstlerischen Qualitäten der Darbietungen beider Kontrahenten erfährt man jedenfalls keinerlei Detail, und die narratologische Besonderheit der Marsyas-Episode besteht gerade darin, daß sie erst mit den Schmerzbekundungen des Satyrn einsetzt ${ }^{93}$ und somit das im Falle der Pieriden- und Arachne-Erzählung zentrale Darstellungselement, die Charakterisierung der kon-

\footnotetext{
${ }^{90}$ Es ist durchaus möglich, daß in Ovids Quelle Minerva die eindeutige Siegerin des Agons war (wie es in solchen Auseinandersetzungen zwischen Sterblichen und Menschen naturgemäß naheliegt) und daß erst Ovid der Minerva ihre technische Überlegenheit nahm, um so die fragwürdigen Züge von Arachnes „Abstrafung“ zu verstärken, vgl. Pöschl 1999, 427 f. mit dem Verweis auf Servius zu Verg. georg. IV 247. Allerdings gibt der Ovidtext auch keine Handhabe, mit Pöschl von einem „Sieg Arachnes“ zu sprechen (ähnlich Segal 2001/2002, 93: „The goddess has in fact been defeated in artistry and is a sore loser"); der technische Aspekt tritt in der Schlußszene eben völlig zurück gegenüber dem Zorn Minervas.

${ }^{91}$ met. VI $1 \mathrm{ff}$.

${ }^{92}$ In der Parallelversion, die bei Anton. Lib. 35 auf Menekrates von Xanthos (FGrHist 769 F 2) und Nikander (FGrHist 271/2 F 23 = fr. 61 Schneider, der Bedenken äußert, ob die Details der Erzählung für Nikander in Anspruch genommen werden können) zurückgeführt wird, kommt Leto einerseits an den Fluß Xanthos, der ihr Zugang gewährt und dafür dem Apollo heilig wird $(35,3)$, und andererseits an die Quelle Melite, zu der ihr der Zugang verwehrt wird von Hirten, die schließlich bestraft werden. Ovid verabsolutiert in seiner — der Niobe-Erzählung beigeordneten - Version den Aspekt menschlichen Vergehens (in der Parallelversion beanspruchen die Hirten die Quelle selbst als ihre Rindertränke, bei Ovid sind sie einfach nur boshaft und trüben sogar mutwillig das Trinkwasser) und folgerichtiger göttlicher Bestrafung. Die quellenanalytische Behandlung der Episode bei Clauss 1989, 310 ff. ist stark beeinträchtigt von seiner exzentrischen poetologischen Gesamtdeutung, die das von den Bauern getrübte Wasser mit kallimacheischer Dichtungsmetaphorik in Verbindung bringt.

${ }^{93}$ met. VI $385 \mathrm{ff}$.
} 
kurrierenden Kunstwerke, völlig ausgespart bleibt. Die hervorgehobene herausragende Bedeutung der Niobe-Erzählung im ersten Großteil von met. VI erhellt übrigens auch daraus, daß der Übergang zum zweiten Großteil von Niobes Vater Pelops ausgeht, den die Fürsten sämtlicher Griechenstädte nach dem Verlust seiner Tochter trösten mit Ausnahme der athenischen, die durch einen aktuellen Krieg daran gehindert werden.

Die den zweiten Großteil dominierende Erzählung, welche durch diese Überleitung vorbereitet wird, ist die Geschichte von dem Thrakerfürsten Tereus und seiner athenischen Frau Procne. Das in dieser Geschichte zentrale Motiv des heimtückisch erzwungenen Kannibalismus wird bereits in der Überleitungspartie praepariert ${ }^{94}$ : Im Zusammenhang mit Pelops' Trauer um Niobe wird auf dessen elfenbeinerne Schulter und damit auch auf die Geschichte des Tantalusmahls hingewiesen. An die weitausgreifende Geschichte von Tereus und Procne schließt sich noch im zweiten Großteil des sechsten Buchs die relativ kurze Erzählung vom Raub der Erechtheus-Tochter Orithyia durch den thrakischen Nordwind (Boreas) an. Die Parallelität dieser Geschichte zur Tereus-Procne-Episode unter dem Gesichtspunkt, daß sich jeweils thrakische Geschlechtslust an jungen Frauen aus dem kultivierten Athen vergreift, wird in der ovidischen Darstellung nicht verschleiert ${ }^{95}$. Der Grund, warum Ovid diese kleine Parallelerzählung (welche für sich keine Metamorphose enthält) der großen Tereus-Procne-Geschichte hinterherschiebt ${ }^{96}$, dürfte vor allem in dem leichten Anschluß liegen, welchen die Boreaden Calais und Zetes an das nächste große Motiv, die Argonautenfahrt, ermöglichen.

Das sechste Buch setzt sich also zusammen aus einem inhomogenen und episodischen ersten Großteil, der jedoch keine erotischen Begebenheiten zum Gegenstand hat wie die entsprechenden Großteile in met. I-V, sondern sich auf den thematischen Schwerpunkt hybrishafter Vergehen von Sterblichen gegen Götter konzentriert. Diese Thematik entsteht prinzipiell durch den spiegelsymmetrischen Anschluß an den zweiten Großteil von met. V, wo dieselbe Thematik in der PyreneusErzählung und in dem Gesangeswettstreit vorlag. Dort war jedoch durch die quantitative Dominanz des Musengesangs über Proserpina und Dis die erotische Komponente noch bestimmend, während im ersten Großteil von Buch VI der erotische Aspekt nur noch im Gewebe der Arachne eine Rolle spielt. In umgekehrter Proportionalität zum Zurücktreten des erotischen Aspekts im ersten, episodischen Großteil tritt dieser im zweiten, eine wesentlich geschlossenere Erzählung (Tereus und Procne) bietenden

\footnotetext{
${ }^{94} \mathrm{Vgl}$. Hofmann 1971, 103.

95 met. VI 682 ff. (vgl. Hofmann 1971, 106 f.). Dieser Anknüpfungspunkt innerhalb der Metamorphosen dürfte von Ovid selbst geschaffen sein, denn in der dem Tereus-Stoff entsprechenden Erzählung über Polytechnos und Aedon, welche bei Anton. Lib. 11 auf die Ornithogonia des Boios zurückgeführt wird, wird das Handeln des Mannes, der sich die Schwester seiner Gattin gefügig macht, gerade nicht durch dessen - typisch thrakische - erotische Erregbarkeit motiviert, sondern ist Teil einer systematischen Racheintrige: Polytechnos kommt zum Vater seiner Gattin von vorneherein mit der Absicht, sich an dessen anderer Tochter zu vergreifen (und diese danach seiner Gattin als Sklavin zu übergeben), und der Auftrag der Aedon, ihr diese Schwester zuzuführen, ist bloße Fiktion $(11,4)$. Gegenüber dieser Fassung betont die ovidische Version (die in wesentlichen Zügen auf den Tereus des Sophokles zurückgeführt wird, vgl. Bömer zu met. VI/ VII, S. 117) viel deutlicher den erotischelegischen Aspekt plötzlich und gewaltsam aufbrausender Liebe, und gerade dieses Motiv verbindet die ovidische Erzählung mit der zunächst stehenden Geschichte um Boreas und Orithyia. Zu den Quellen der ovidischen Tereus-Erzählung vgl. auch Hofmann 1971, 93 ff., der in den bei Ovid nicht berücksichtigten Parallelversionen vom Leser zu decodierende Querverbindungen zu den umgebenden Erzählungen der Metamorphosen findet.

${ }^{96}$ Vgl. Newlands 1997, 204: die Orithyia-Episode ,generally regarded as a lighthearted appendage to the myth of Procne, Philomela, and Tereus“".
} 
Großteil wiederum stärker in den Vordergrund, als es in den homogenen Erzählpartien der ersten Metamorphosenbücher (Weltschöpfung; Phaethon; Gründung von Theben; Perseus) der Fall war. Das kompositorische Verhältnis von met. VI zu met. V (Aufgreifen des zweiten Großteils des alten im ersten Großteil des neuen Buchs) entspricht dem zwischen met. IV und met. III; dort war das Bacchus-Motiv das über die Buchgrenze hinaus verbindende Element, hier ist es das Thema "hybrishaftes Vergehen Sterblicher gegen Götter”.

\section{7. met. VII}

Das siebente Buch scheint mit einem typisch epischen Stoff zu beginnen ${ }^{97}$, nämlich der Argonautensage, die von Ovid bei näherer Betrachtung jedoch sehr selektiv behandelt wird: Die ereignis- und abenteuerreiche Hinfahrt wird - ebenso wie die Rückreise - äußerst summarisch abgehandelt, im Mittelpunkt stehen dagegen die erotische Reaktion Medeas auf die Notlage Jasons, als ihm die von Aeetes geforderten Arbeiten mitgeteilt werden, und die Art der Bewältigung dieser Arbeiten (die u.a. mit einer sich aus ausgesäten Drachenzähnen ergebenden Metamorphose verbunden ist). Letzterer Schwerpunkt ist bedingt durch die kompositorische Notwendigkeit des Metamorphosenmotivs, ersterer durch das psychologische Interesse Ovids an der erotischen Ausnahmesituation Medeas. Auch nach der Rückkehr nach Thessalien bleibt der Fokus der Darstellung bei Medea: Die Verjüngung von Jasons Vater Aeson gibt Gelegenheit zu einer breit ausgeführten Zauberszene. Die in diesem Falle im Sinne der pietas eingesetzte Zauberkraft Medeas entfaltet in der nächsten Episode verbrecherische Wirkung ${ }^{98}$ : Medea schmeichelt sich bei den Töchtern des Pelias ein und erbietet sich, auch diesen verjüngen zu wollen, den sie in Wirklichkeit durch eine hinterhältige Intrige von seinen eigenen Töchtern zu Tode bringen läßt. Nachdem Medea aus dieser Situation mit dem Schlangenwagen entkommen ist, folgt der üblicherweise zentrale Teil des Medea-Mythos, die Rache an Jason wegen desser neuer Hochzeit und der Kindermord. Es scheint, als behandele Ovid diesen Abschnitt bewußt am komprimiertesten ${ }^{99}$ : Er steht innerhalb einer längeren Reihe von Lokalmetamorphosen, welche Ovid anläßlich einer topographischen Ekphrasis von Medeas Reise mit dem Schlangenwagen in höchst kursorischer Form jeweils nur andeutet; durch die Einbettung in diese Umgebung macht Ovid seinen Entschluß, den Kindermord nur äußerst summarisch und episodisch (in vier Hexametern ${ }^{100}$ ) zu behandeln, fast provozierend deutlich ${ }^{101}$. In der literarischen Tradition außerhalb und innerhalb Ovids ist dieser Abschnitt am stärksten „vorbelastet”; gäbe Ovid hier eine ausführliche Neufassung, so müßte das ausführliche Psychogramm einer Frau, welche sich durch einen Mord an den eigenen Kindern am Ehemann rächt, fast notwendig zu motivischen Dubletten mit der Tereus-Procne-Erzählung führen ${ }^{102}$. Schließlich begibt sich Medea in Übereinstimmung mit dem herkömmlichen Mythos nach Athen zu

\footnotetext{
${ }^{97}$ Vgl. Holzberg 1997, 138 und 1998, 92.

${ }^{98}$ Vgl. Wilhelm 1990-92, 56.

${ }^{99}$ Vgl. hierzu Binroth-Bank 1994, 143 ff., die die ähnliche Raffung der Dido-Tragödie in met. XIV vergleicht (a.a.O. 145).

${ }^{100}$ met. VII 394-397.

${ }^{101}$ Vgl. Newlands 1997, 190: „Corinth, the focal point of so much suffering in Euripides’ play, is simply one stopping point in a long, learned journey“.

${ }^{102} \mathrm{Zu}$ den Parallelitäten zwischen Medea und Procne vgl. Newlands 1997, 192 ff.
} 
Aegeus, wo sie dessen Sohn Theseus mit Gift zu töten sucht; der Anschlag mißlingt im letzten Moment, und Medea muß wieder fliehen.

Die Erzählung, die sich anfangs wie eine systematische Darstellung des Argonautenmythos ausnimmt, konzentriert sich in ihrem Verlauf völlig auf die erotische Ausnahmesituation Medeas und ihre sich hieraus sukzessive ergebenden Handlungen. Es ergibt sich das Bild einer pathologisch liebenden und dieser Liebe von Anfang an - wie aus dem Entscheidungsmonolog zu Beginn von met. VII hervorgeht - alle vernünftigen Erwägungen opfernden Frau, die von einem Verbrechen ins nächste getrieben wird (Verrat der Heimat — indirekte Tötung des Pelias - Kindermord Anschlag gegen Theseus), wobei die genauen Motive ihres Handels zumindest im Falle der Anschläge gegen Pelias ${ }^{103}$ und Theseus ${ }^{104}$ weitgehend im Dunkeln bleiben. Medea erscheint nicht wie in isolierten Darstellungen des Muttermords (z.B. in den Tragödien des Euripides und Seneca) ${ }^{105}$ als eine verzweifelte Frau, die durch ihre Verlassenheit zum äußersten gedrängt wird, sondern als eine ursprünglich durch ihre pathologische Gefühlssituation motivierte Gewohnheitsverbrecherin ${ }^{106}$, die nach immer neuen Verbrechen immer wieder fliehen muß ${ }^{107}$. Der epische Argonautenstoff

${ }^{103}$ Vgl. Rosner-Siegel 1982, 241; Wilhelm 1990-92, 56; Binroth-Bank 1994, 125; Newlands 1997,
188: „Medea seemingly acts alone purely for malice's sake“. Glaser 2001, 53 zur Pelias-Szene: „Es
tritt ... eine Medea auf, die sich beträchtlich von jener skrupulösen Mutter, wie wir sie bei Euripides,
und von der keuschen Tochter, wie wir sie bei Apollonius kennengelernt haben, unterscheidet. Wir
sehen eine Schlächterin und Hexenmeisterin, die mitleidlos ihren Interessen nachgeht und bedenkenlos
ihren und Jasons politischen Plänen das Leben anderer Personen aufopfert.“
${ }^{104}$ Vgl. Wilhelm 1990-92, 56; Binroth-Bank 1994, 147.
${ }^{105}$ Zum Unterschied der ovidischen Medea-Episode gegenüber Schilderungen „with their focus on one ${ }^{105}$ Zum Unterschied der ovidischen Medea-E
time and place“ vgl. Newlands 1997, 178.

${ }^{106}$ Rosner-Siegel (1982) betont im Vergleich zu der hier gegebenen Darstellung eher das Moment der Entwicklung Medeas von einer liebenden Frau zu einer böswilligen Hexe (ähnlich Wilhelm 1990-92, 54, 56), doch bereits in Medeas Entscheidungsmonolog zu Anfang des VII. Buches findet sich deutliches Unrechtsbewußtsein (Binroth-Bank 1994, 125 sieht hinter diesem Unrechtsbewußtsein ein immerhin noch verhandendes „Bewußtsein moralischer Werte“ und sucht aufgrund dieser Tatsache Medeas Haltung in ihrer ersten Phase zu differenzieren von den späteren Phasen ihres Handelns in den Metamorphosen, wo ihre inneren Motive von Ovid nicht mehr beleuchtet werden; vgl. zusammenfassend auch Binroth-Bank 1994, 153 f.). Rosner-Siegels Aufsatz ist beeinflußt von Anderson 1963, der den Metamorphosenbegriff sehr weit faßt und vor allem auch auf psychische Entwicklungen ausdehnt (ein sehr stark verengter Metamorphosenbegriff findet sich dagegen etwa bei Schmidt 1991, 15 ff., der beispielsweise der Kosmogonie und der Weltzeitalterabfolge in met. I den Metamorphosencharakter abspricht). - Etwas anders sieht Newlands (1997) bei Ovid zwei konträre Medea-Bilder nebeneinanderstehen, einerseits ,the sympathetic girl“ (in der Entscheidungsszene am Anfang von met. VII) und andererseits ,the wicked sorceress“; insofern ergebe sich eine ,dissonant structure“ (Zitat von S. 180). Hiergegen ist wiederum das sich bereits am Anfang im Entscheidungsmonolog manifestierende Unrechtsbewußtsein anzuführen. Newlands 1997, 183 wertet die Kongruenz zwischen met. VII 20 f. video meliora proboque,/ Deteriora sequor und den (zu einer interpolierten Partie gehörigen) Versen 1078 f. der euripideischen Medea im Sinne ihrer These aus: „Euripides [vielmehr der — gleichwohl stark rezipierte - Interpolator] makes Medea speak these words before she kills her children; her failure to do what she clearly sees is reasonable and right is therefore appalling. But the transferal of these words to the youthful, untested Medea makes them disarming, a sign of her love rather than her barbarism“. Näher liegt jedoch die Deutung, daß die zu furchtbarem Verbrechen führende Vernunftfeindlichkeit der Kindsmörderin der griechischen Tragödie bei Ovid bereits auf die junge Medea übertragen wird, also das affektbedingte verbrecherische Verstoßen gegen vernünftige Erwägungen von Anfang an zum Kern ihres Wesens gehört.

${ }^{107}$ Vgl. Binroth-Bank 1994, 150: „Ovid erweckt ... den Eindruck, daß sich die Aneinanderreihung von Gewalttat und Flucht noch endlos fortsetzen ließe und daß somit Medea niemals zur Ruhe komme“; 151: Es ,wird ... angedeutet, daß sie ... immer weiter mordet und flieht — ihr Dasein sich auf eine endlose Flucht reduziert. Der Erzähler folgt ihr an einem bestimmten Punkt der Handlung nicht mehr weiter, sondern bleibt gleichsam zurück und wendet sich einer anderen Figur [Theseus] und damit 
wandelt sich unter den Händen Ovids zu einer Chronik erotisch motivierten weiblichdaemonischen Verbrechens ${ }^{108}$.

Trotz dieser ovidischen Umgestaltung bildet der erste Großteil des siebenten Buchs den bei weitem erzähltechnisch homogeneren, eben durch die Person Medeas geeinten $^{109}$ Abschnitt dieses Buchs. Denn der zweite, sich an Aegeus und Theseus knüpfende ,athenische” Großteil findet zu keiner beständigen inneren Einheit. An die Feierlichkeiten des Wiedersehens zwischen Aegeus und Theseus (in die als Ersatz für eine systematische Tatenschilderung ein Festgesang über die heroischen Leistungen des Theseus eingelegt ist, ähnlich wie Hercules in seinem langen Monolog in met. IX seine eigene Aretalogie im Angesicht des Todes ausspricht und damit eine systematische Darstellung überflüssig macht) schließt sich als Kontrast der Krieg Athens gegen den Kreter Minos an. Im Zusammenhang mit den Rüstungen zu diesem Krieg kommt es zu einer Begegnung zwischen dem (eingeheirateten) Athener Cephalus und den salaminischen Fürsten, welche Anlaß gibt zu den Binnenerzählungen, die den zweiten Großteil des siebenten Buchs fast vollständig ausmachen. Zunächst berichtet Aeacus über die wundersame Regeneration seines Volkes aus Ameisen nach einer verheerenden Pest, ein Thema, welches sowohl eine Metamorphose enthält als auch in einer gewissen funktionalen Beziehung zum Zweck der Gesandtschaft des Cephalus (der Einholung von Bündnern aus dieser neuen Population) steht. Dagegen verliert sich die Binnenrede des Cephalus in der Erklärung der Herkunft eines außergewöhnlichen Wurfspießes und erweitert dieses an sich schon abgelegene Thema, um im Sinne des Dichters eine Metamorphosengeschichte zu integrieren, noch eigenmächtig um einen ihm von Procris zusammen mit dem Wurfspieß geschenkten Jagdhund. Der Hauptteil der Cephalus-Erzählung hat das Scheitern der Liebesbeziehung zu seiner Gattin Procris unter dem ungünstigen Einfluß der von Cephalus verschmähten Göttin Aurora zum Gegenstand, ist also wieder dezidiert erotischer Natur ${ }^{110}$.

Im siebenten Buch stehen sich also zwei Großteile gegenüber, die zumindest ansatzweise epischen Charakter haben (Argonautenfahrt bzw. Krieg zwischen Aegeus und Minos), sich aber in ihrem Verlauf eher erotischen Themen zuwenden (den erotisch motivierten Verbrechen Medeas bzw. dem intradiegetisch dargestellten Liebesverhältnis zwischen Cephalus und Procris).

einer neuen Thematik zu“ (vgl. auch Newlands 1994, 192: „The story of Medea in Metamorphoses 7 does not come to a definite conclusion“"). Zu der kontinuierlichen Steigerung des Erzähltempos von Etappe zu Etappe vgl. Binroth-Bank 1994, 155.

${ }^{108}$ Die verbrecherische Grundhaltung Medeas wird mehrfach betont: Im Zusammenhang von Aesons Verjüngung, der einzigen größeren nicht-verbrecherischen Handlungssequenz Medeas in met. VII, heißt es (VII 169 f.) mota est pietate rogantis (sc. Iasonis),/ Diss i mi l e mque a $n$ i mu m subiit Aeeta relictus (vgl. Rosner-Siegel 1982, 238; Binroth-Bank 1994, 107 f.); die Überleitung zur Pelias-Episode lautet (met. VII 297) Neve doli cessent (vgl. Rosner-Siegel 1982, 241; Wilhelm 199092, 55; Binroth-Bank 1994, 125; Newlands 1994, 188); die Hochzeit des Aegeus mit Medea wird kommentiert mit der zynischen, äußerst boshaft auf Medea abzielenden Bemerkung (met. VII 402 f.) Excipit hanc Aegeus facto damnandus in uno;/ Nec satis hospitium est: thalami quoque foedere iungit. ${ }^{109}$ Vgl. Binroth-Bank 1994, 153.

110 Pechillo 1990-91, 40 ff. analysiert die Erzählung über Cephalus und Procris als ein deutlich elegisch geprägtes Epyllion, welches in zwei Teile zerfällt, die wiederum durch die digressionsartig eingeschobene Geschichte des Jagdhunds Laelaps getrennt werden (zum Charakter dieses Einschubs: Segal 1978, 179 ff.). Zur Zweiteilung der erotischen Erzählung vgl. auch unten Anm. Error! Bookmark not defined. (Pöschl). In den Mittelpunkt seiner Analyse stellt Pechillo „Ovid's skill in juxtaposing genres“ (a.a.O. 44). 


\section{8. met. VIII}

Das achte Metamorphosenbuch bleibt thematisch bei der militärischen Auseinandersetzung zwischen Aegeus von Athen und Minos von Kreta, wechselt jedoch gewissermaßen die Seite: Während die Perspektive des Erzählers sich im zweiten Großteil des siebenten Buchs zunehmend auf die athenische Seite, nämlich die Gespräche des athenischen Gesandten Cephalus auf Aegina, verengte, steht am Anfang des achten Buchs jetzt die kretische Partei und besonders die Person des Minos im Mittelpunkt. Minos will seine Kriegsmacht, die sich hauptsächlich gegen Athen richten soll, zunächst an der kleinen Stadt Megara "vorerproben"111, die unter der Herrschaft des Königs Nisus steht. Während der langdauernden Belagerung von Megara verliebt sich Scylla, die Tochter des Nisus, in den ihr nur vom Sehen bekannten Minos. Die verliebte Scylla hält einen Entscheidungsmonolog wie Medea zu Beginn des siebenten Buchs. In beiden Fällen hat eine Frau die Möglichkeit in der Hand, einen Feind ihres Vaters in für ihre Heimatstadt katastrophaler Weise zu begünstigen, Medea durch ihre magischen Fähigkeiten, Scylla durch das Wissen um die schicksalshafte purpurne Locke. Der Anfang von Buch VIII ist also in offenkundiger Analogie zum Anfang von Buch VII komponiert ${ }^{112}$.

Allerdings übertrifft Scylla Medea erheblich an krimineller Energie ${ }^{113}$. Denn während Medea eigentlich nur einem ungerecht behandelten Fremdling gegen ihren Vater Hilfe verschafft, wendet sich Scylla direkt gegen die Herrschaft ihres Vaters und stürzt zugleich ihre ganze Heimatstadt ins Unglück. Obwohl die Situation Scyllas mit der Medeas vergleichbar ist (und gemäß der parallelen Gestaltung des Auftakts von met. VIII und met. VII im Sinne Ovids wohl auch verglichen werden soll), trägt das Handeln ersterer wesentlich deutlichere Züge von Verrat (Medea stürzt weder ihren Vater noch ihr Heimatland ins Verderben). Insofern hat Scylla im Vergleich zu Medea gleich mit ihrer ersten (und einzigen) Tat das Vollmaß des Verbrechens erreicht, was sich auch in der Reaktion des Minos auf Scyllas erotischen Antrag drastisch niederschlägt, der die von Scylla für ihn erbrachte Leistung (im Gegensatz zu Jason im siebenten Buch) in keiner Weise anerkennt. Insofern scheint das sofortige Scheitern Scyllas nach einem einzigen Verbrechen das schließliche Scheitern Medeas ${ }^{114}$ nach einer Vielzahl von etappenweise geschilderten verbrecherischen Handlungen ${ }^{115}$ gewissermaßen in konzentrierter Form nachzuvollziehen ${ }^{116}$. Scylla gelangt nach ihrer einen Tat in genau dieselbe verzweifelte isolierte Situation, die Medea erst nach ihrem Zerwürfnis mit Jason in Korinth erreicht.

Die Auseinandersetzung zwischen Kreta (Minos) und Athen (Aegeus) bildet jedoch nicht den erzählerischen Leitfaden eines homogen-episch gestalteten ersten Großteils von met. VIII, wie man zunächst erwarten könnte. Denn als nächstes beschreibt Ovid, wie Minos seine Heimat Kreta erreicht. Zwischen der Belagerung von Megara, die als eine bloße „Vorerprobung” der militärischen Kräfte des Minos bezeichnet wurde, und der Rückkunft muß noch die Belagerung von Athen gelegen haben, die mit der Vereinbarung endete, daß die Athener regelmäßig einen Menschen-

\footnotetext{
111 met. VIII 7.

112 Ausführlich zur Analogie zwischen Scylla und Medea vgl. Newlands 1994, 196 ff.

${ }^{113}$ Vgl. Newlands 1994, 197.

114 Zum letztlichen Scheitern Medeas vgl. Rosner-Siegel 1982, 242.

115 Vgl. oben Anm. 107.

${ }^{116}$ Etwas anders wird das Verhältnis zwischen Scylla und Medea dargestellt bei Crabbe 1981, 2278 : „In fact Scylla is no more than a romantic schoolgirl superficially and catastrophically aping her mythological betters“; 2304: „Scylla's words a comic pastiche of her more serious predecessor's“.
} 
tribut an den Minotaurus, den stiergestaltigen Stiefsohn des Minos, entrichten mußten. Doch diese Ereignisse übergeht Ovid, obwohl das Motiv des Menschentributs später bei der Geschichte von Theseus und Ariadne vorausgesetzt wird. Dies zeigt, daß es Ovid überhaupt nicht um den eigentlichen Ablauf der miltärischen Auseinandersetzung zwischen Minos und Athen ankam, sondern auf bestimmte hiermit mythologisch verknüpfte Ereignissequenzen.

Die nächste solche Sequenz ist das Geschick des begnadeten athenischen Handwerkers und Künstlers Daedalus. Minos verbirgt nach seiner Rückkunft in Kreta Minotaurus, die Schande seines Hauses, in einem von Daedalus angefertigten Labyrinth. Als die Athener zum dritten Mal ihren Menschentribut zur Speisung des Ungeheuers leisten, kommt Theseus nach Kreta, bezwingt den Minotaurus im Labyrinth mit Hilfe des Fadens der Ariadne, Tochter des Minos, und verläßt Kreta zusammen mit seiner neugewonnenen Geliebten. Er dankt Ariadne dieses Verdienst schlecht, indem er sie auf Naxos zurückläßt. Der Weingott Bacchus nimmt sich Ariadnes als neuer Geliebter an und versetzt ihre Krone als Gestirn an den Himmel. Diese Ereignissequenz wird nur sehr umrißhaft erzählt; insbesondere die Psychologie der Ariadne, die sich gegen ihren Vater Minos und ihre Heimat Kreta wendet und für den Fremdling Theseus eintritt, würde bei ausführlicher Ausgestaltung zu Doppelungen mit Medea bzw. Scylla führen. Der Theseus-und-Ariadne-Stoff steht nicht im Mittelpunkt des Interesses des Metamorphosendichters, sondern dient ausschließlich als eine kurze Anknüpfung der im folgenden wesentlich breiter ausgeführten DaedalusEpisode.

Als Daedalus seinen ins Meer gestürzten Sohn Daedalus bestattet (soweit bleibt die Erzählung ohne Metamorphose ${ }^{117}$ ), sieht ihm ein Rebhuhn voller Schadenfreude zu. Dabei handelt es sich um eine Verwandlungsform von Daedalus' hochbegabtem Neffen Perdix, der von ihm aus Neid um seine Erfindungsgabe von der Burg der Minerva gestürzt und von dieser Göttin in ein Rebhuhn verwandelt wurde. Offenbar soll der Sturz des Icarus als eine Art gerechter Ausgleich für den von Daedalus in verbrecherischer Weise herbeigeführten Sturz des Perdix aufgefaßt werden. Dementsprechend fällt ein Schatten auf die Person des Daedalus (anders in der Paralleldarstellung in der Ars amatoria, wo die Perdix-Erzählung völlig beiseite bleibt) $)^{118}$.

Im folgenden wird wieder zur athenischen Seite des (nur am Rande interessierenden) Kriegs übergegangen: Der Ruhm des Theseus verbreitet sich in Griechenland schnell, was zur Folge hat, daß Theseus als einer von vielen Helden zur Calydonischen Jagd eingeladen wird. Diese breit ausgeführte Geschichte hat die Verliebtheit des Meleager in die Mitjägerin Atalante, die Tötung seiner beiden Onkel und seine Bestrafung durch den schicksalshaften Holzscheit der Althaea zum Gegenstand ${ }^{119}$.

\footnotetext{
117 Eine Doxographie der vergeblichen Versuche, in die Daedalus-Icarus-Erzählung eine Metamorphose hineinzulesen, bietet Hoefmans 1994, $137 \mathrm{f}$.

${ }^{118}$ Vgl. hierzu (neben Schubert 1992, 27) die Abhandlung von Faber, welche die Bedeutung der im Rahmen des Daedalus-Komplexes oft vernachlässigten Perdix-Episode für das Daedalus-Bild in den Metamorphosen betont und insbesondere die Unterschiede zum Bild desselben Künstlers im Prooemium zum zweiten Buch der Ars amatoria hervorhebt. A.a.O. 89: „The husteron proteron arrangement of the narrative chronology enhances the meaning of the first episode by adding a moralistic tone in the second“. Ferner Pavlock 1998, 154: „Daedalus is now clearly associated with a moral flaw“.

${ }^{119}$ Im Vergleich zu der auf Nikander (fr. 51 Schneider) zurückgeführten Version bei Anton. Lib. 2 hätte Ovid die elegischen Elemente verstärkt durch das Motiv, daß sich Meleager bei der Jagd in Atalante verliebt und Atalante (nicht Diana) den Streit verursacht (Bömer zu met. VIII/ IX, S. 99, sieht in dieser Änderung mythengeschichtlich ,ein Werk des attischen Dramas“), und andererseits epische Aspekte zurücktreten lassen, insofern von einem Krieg zwischen Cureten und Calydonieren bei ihm
} 
Die bislang behandelten drei ausgestalteten Themenbereiche des achten Buchs (Scylla, Daedalus, Calydonische Jagd) gruppieren sich sehr locker um das epische "Hauptthema" des ersten Großteils von met. VIII, die kriegerische Auseinandersetzung zwischen Athen und Kreta. Sie haben aber gemeinsam, daß jeweils eine Person für eine schwere Verfehlung gegen einen nahen Verwandten abgestraft wird: Scylla für den Verrat an ihrem Vater, Daedalus für den Mord an seinem Neffen ${ }^{120}$ und Meleager für die Tötung seiner beiden Onkel. Diese Schuld-Strafe-Thematik bleibt auch im zweiten Großteil des achten Buchs zentral, der in die verschiedenen Erzählungen beim Gelage des Flußgotts Achelous zerfällt, zu dem Theseus mit seinen Gefährten bei seiner Rückkehr von der Calydonischen Jagd eingeladen wird. Es handelt sich also (wie beim ersten Großteil von met. IV, den Minyadenerzählungen, und dem fast das gesamte zehnte Buch bestimmenden Orpheus-Gesang) um einen beinahe ausschließlich von intradiegetischen Erzählungen geprägten Großteil.

Schon die erste, von Achelous selbst erzählte Episode zeigt, daß Verwandlungen durchaus göttliche Strafen oder Belohnungen für tadelns- bzw. lobenswertes Verhalten sein können. Die Echinaden-Inseln entstanden strafweise aus Naiaden, welche Achelous nicht den gebührenden Respekt erwiesen, dagegen entstand die Insel Perimele aus einer ehemaligen Geliebten des Flußgotts, der Achelous durch diese von Neptun erwirkte Verwandlung seine besondere Zuneigung bekundet. Äußerlich gleiche Metamorphosen können demnach ein Ausdruck entweder göttlichen Zorns oder göttlicher Zuneigung $\operatorname{sein}^{121}$. Die erste Binnenerzählung des Gelages zeigt bereits deutlich die Möglichkeit beider Alternativen. Das Vergehen der Echinaden, welche Achelous im Gegensatz zu den übrigen Landgottheiten beim Opfer vernachlässigten, wird von Achelous explizit mit dem menschlichen Versäumnis in Verbindung gebracht, welches die Calydonische Jagd herbeiführte (der Vernachlässigung der Diana beim Opfer des Oeneus) ${ }^{122}$.

Wenn bereits durch die erste Erzählung in der Gelageszene der Aspekt menschlichen Verdiensts oder menschlicher Verschuldung ${ }^{123}$ in den Mittelpunkt rückt, so wird diese Tendenz durch den nach Achelous' Rede gemachten Einwand des Pirithous noch verfestigt ${ }^{124}$ : Pirithous behauptet, man überschätze die Macht der

keine Rede ist. Allerdings ist gerade in diesem Abschnitt die unmittelbare und vollständige Rückführbarkeit des Antoninus auf Nikander fraglich, vgl. W. Kroll, RE s.v. Nikandros 11, XXXIII 254, 60 ff.

${ }^{120} \mathrm{Vgl}$. Faber 1998, 81: ,The death of Icarus is for Daedalus punishment for hubris and retribution for the attempted murder of Perdix".

${ }^{121}$ Vgl. Crabbe 1981, 2291: „... mercy replaces revenge“. Erbse 328 betont den Zusammenhang nur der Perimele-Episode mit der folgenden Philemon-und-Baucis-Erzählung unter dem Gesichtspunkt des „göttlichen Willens“.

${ }_{122}$ met. VIII 579.

${ }^{123} \mathrm{Zu}$ dem Thema ,Zorn und Strafe, Belohnung und Huld der Götter“ vgl. Schmidt 1991, 118 ff.

${ }^{124}$ Wheeler 1999, 167 ff. setzt sich ausführlich mit der Auffassung von Feeney 229 ff. auseinander, Pirithous und Lelex repraesentierten die beiden grundsätzlichen Möglichkeiten, die der Leser hat, die mythischen Erzählungen Ovids in den Metamorphosen zu rezipieren: entweder skeptizistisch oder moralistisch. Hiergegen ist jedoch einzuwenden, daß 1. Pirithous und Lelex nicht als gleichwertige Antagonisten charakterisiert werden, sondern Pirithous mit seiner blasphemischen Haltung wie ein Ausbund geschildert wird, Lelex dagegen als ein Vertreter der am Götterglauben festhaltenden, über die Äußerung des Pirithous bestürzten Allgemeinheit (VIII 617 Ante omnesque Lelex) und 2. sämtliche im Achelous-Symposion wiedergegebenen Erzählungen die moralistische Position zum Ausdruck bringen; wenn die Haltung des Pirithous als eine akzeptable mögliche Rezeptionshaltung dastehen sollte, müßte sie ebenfalls durch mindestens eine Erzählung gestützt sein, welche die skeptizistische Haltung des Pirithous zum Ausdruck brächte. Tatsächlich aber ist dessen Haltung (die Götter vermögen keine Metamorphosen menschlicher Gestalten herbeizuführen) mit dem im Prooemium bekundeten Programm der Metamorphosen unvereinbar und kann daher gar nicht in eine Meta- 
Götter ${ }^{125}$, wenn man ihnen die Fähigkeit zur beliebigen Veränderung menschlicher Gestalten zuspreche ${ }^{126}$. Die übrigen Gelageteilnehmer reagieren mit scharfem Widerspruch. Dadurch wird die Tendenz der folgenden Episoden und insbesondere der unmittelbar folgenden Erzählung des Lelex gewissermaßen schon im vorhinein fixiert: Es muß eine Episode folgen, die über jeden Zweifel beweist, daß Götter als Lohn oder Strafe für richtiges bzw. falsches Verhalten menschliche Gestalten ändern können. Damit wird gewissermaßen die Kernthese des Metamorphosenprogramms explizit zum Gegenstand einer symposiastischen Erörterung ${ }^{127}$; es handelt sich sozusagen um eine mikrokosmische Spiegelung des Gesamtthemas, welche genau im symmetrischen Mittel, im achten Metamorphosenbuch, plaziert ist ${ }^{128}$.

In Anbetracht dieses symposiastischen Themas (Können Götter beliebig die Gestalten von Sterblichen verändern?) ${ }^{129}$ erscheint eine inzwischen weithin akzeptierte konjekturale Textänderung im Prooemium bedenklich. Die erklärende Begründung der an die Götter gerichteten Bitte, sie möchten die dichterische Darstellung der Verwandlungssagen begünstigen, mit den Worten nam vos mutastis et illas ${ }^{130}$ sc. formas, soll nach Lejay (und einer mittelalterlichen Variante ${ }^{131}$ ) abgeändert werden in

morphosengeschichte umgesetzt werden. Pirithous ist also ein Vertreter einer Position, welche der Gesamtanlage der Metamorphosen radikal entgegengesetzt ist (insofern enthält seine Äußerung mehr als nur ,a denial and a rejection of the hospitable values which the Philemon-Baucis story presents“, Griffin 1991, 52). Wenn er mit seiner Position recht hat, sind die Metamorphosen von vorne bis hinten Fiktion, und ein Leser mit dieser Haltung müßte dem Dichter der Metamorphosen dieselben Worte entgegenhalten wie Pirithous dem Achelous: Ficta refers .... (met. VIII 614). Ovid setzt sich mit dieser grundsätzlichen Gegenposition zu seinem Werk nicht wirklich auseinander, sondern antwortet nur mit einer weiteren Metamorphosengeschichte, und zwar derjenigen, welche die moralistische Position wohl im gesamten Werk am nachdrücklichsten zum Ausdruck bringt. Poetologisch bekundet Ovid damit nichts anderes, als daß er weiß, daß man ihm den Vorwurf Ficta refers machen kann. Wenn er besonderen Wert auf die theologische Wahrhaftigkeit seiner Metamorphosenbehandlungen legte, würde er die Position des Pirithous wohl argumentativ im Zusammenhang des Symposions auf einer methodisch tieferen Ebene als durch eine erneute Metamorphosenerzählung (der man mit Pirithous wieder Ficta refers entgegenhalten könnte, trotz der abschließenden Autoritätsversicherung des Lelex, met. VIII 721 ff.) bekämpfen und die Person des Pirithous wohl auch in irgendeiner Weise im Rahmen seiner Erzählung für ihre Blasphemie bestraft werden lassen. Wenn er dagegen die Position des Pirithous als Rezeptionshaltung besonders empfehlen wollte, würde er ihr im Rahmen des Symposions ein besseres „Standing“ verschaffen. Wheeler selbst äußert einige Bedenken gegen eine Auffassung der Pirithous-Figur als eine mögliche Rezeptionshaltung des Metamorphosenlesers (a.a.O. 170). Die Position des Pirithous dürfte wohl weniger eine mögliche Rezeptionshaltung als einen potentiellen, von Ovid vorweggenommenen Einwand gegen seine Metamorphosendichtung als solche repraesentieren. Offenbar hat Ovid diesen Einwand nicht als einer ernsthaften Auseinandersetzung würdig erachtet: Der Einwand Ficta refers gegen den Metamorphosendichter ist zwar sachlich kaum zu bestreiten, aber andererseits doch trivial, insofern er Ovids künstlerischen Ehrgeiz nicht berührt. Dementsprechend erscheint Pirithous im Achelous-Symposion nicht als jemand, der wirklich widerlegt oder sogar abgestraft wird, sondern einfach als jemand, dessen Einwand durch die Fülle der weiteren Erzählungen überschüttet wird.

${ }^{125}$ Die Macht der Götter ist in intradiegetischem Zusammenhang bereits im Gespräch der Minyaden (IV 271-273) Thema, allerdings wird dort dieses Thema nicht explizit mit dem Metamorphosenmotiv in Verbindung gebracht. Wheeler 1999, 183 sieht das Gespräch der Minyaden als „forerunner“ des Achelous-Gelages an.

${ }^{126}$ met. VIII $614 \mathrm{ff}$.

127 Vgl. Feldherr 2002, 166 Anm. 5 (über met. VIII 614 f.): „lines that refer back to the Metamorphoses' programmatic description of its subject matter".

128 Ansatzweise erkannt bei Griffin 1991, 53.

${ }^{129}$ Vgl. Gordesiani 1985, 200: Die Erzählungen im Achelous-Gelage ,realisieren die These „Götter können die Formen verwandeln““،.

${ }^{130}$ met. I 2.

${ }^{131}$ Vgl. Tarrant 1982, $350 \mathrm{f}$. 
nam vos mutastis et illa sc. coepta; dann wären die Götter nicht mehr Urheber der dichterisch dargestellten Metamorphosen, sondern nur noch Gewährsleute von Ovids dichterischem Gattungswechsel von der Elegie zum Epos ${ }^{132}$. Gemäß der hier herausgearbeiteten Korrespondenz zwischen der Gesamtthematik der Metamorphosen und dem durch den Pirithous-Einwand fixierten symposiastischen Thema ist jedoch der Aspekt, daß Gestaltveränderungen d u r ch göttliches Wollen be d in g t sind, zentral.

Es dürfte in den Metamorphosen in der Tat wohl keine zweite Geschichte geben, die so klar den Zusammenhang zwischen menschlicher Gottgefälligkeit und einer ehrenden Metamorphose erweist wie die von Lelex vorgetragene Erzählung über Philemon und Baucis. Bei dieser Erzählung handelt es sich offenbar um ein Gegenstück zur Lycaon-Erzählung im ersten Buch $^{133}$ : Hier wie dort inspiziert Jupiter in sterblicher Gestalt die Erde; hier wie dort ergibt sich als Resultat der Inspektion eine alle Erwartungen übertreffende allgemeine Versündigung. In der LycaonEpisode ist der Frevel des Lycaon gewissermaßen die Spitze des Eisbergs, in der Philemon-und-Baucis-Episode bildet das Verhalten der Greise dagegen die rühmliche Ausnahme. Lycaon wird durch eine Metamorphose (Verwandlung in einen Wolf) bestraft, die Greise werden dagegen belohnt. Die Philemon-Baucis-Episode, die zentrale Erzählung in dem auf mikrokosmischer Ebene mit der Gesamtthematik korrespondierenden und in der arithmetischen Werkmitte stehenden Achelous-Symposion $^{134}$, enthält vielfache und sinnhaltige Kontrastbezüge zur ersten Individualmetamorphose im ersten Buch (Lycaon). Auf diese Weise wird die Polarität zwischen den beiden Möglichkeiten „Metamorphose als Bestrafung“ und „Metamorphose als Belohnung“, welche in der Achelous-Erzählung über die Echinaden und Perimele unmittelbar greifbar war, in der Philemon-Baucis-Episode intertextuell durch die offenkundige Kontrastbeziehung zum Lycaon-Thema in met. I ins Spiel gebracht.

In der folgenden Erzählung, deren Sprecher wieder der Flußgott Achelous ist, wird das Metamorphosenmotiv weiter differenziert: Von der einmaligen, irreversiblen Verwandlung (gewissermaßen dem Grundtyp der Metamorphose) unterscheidet sich die Gabe multipler Selbstverwandlung, wie sie beispielsweise dem Meergreis Proteus gegeben war $^{135}$; daß Achelous derartig prinzipiell auf die typologische Verschieden-

\footnotetext{
${ }^{132}$ Vgl. die ausführliche Argumentation bei Kenney 1976, 46-50 zugunsten von illa[s]. Ähnlich auch Kovacs, der allerdings - anders als Kenney — das Metamorphosen-Prooemium nach die Verbannung Ovids setzt und annimmt, ,that the parenthesis in the proem is meant to imply that his change of fortunes has wrought a change in the kind of poetry he writes“ (1987, 462). Das et, welches den Hauptanstoß an der Überlieferung nam vos mutastis et illas bildet, wird neuerdings von Harrauer 2001, 302 erklärt durch den Hinweis auf die hymnische Parallelstelle Arat. Phain. 4 f. $\pi \dot{\alpha} v \tau \eta ~ \delta \dot{~} \Delta$ เò $\kappa \varepsilon \chi \varrho \eta ́ \mu \varepsilon \theta \alpha$

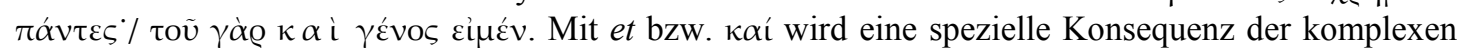
Allmacht göttlichen Wirkens nachdrücklich als etwas ,,a u c h (neben anderen Manifestationen dieser Allmacht) Vorhandenes“ hervorgehoben.

${ }^{133}$ Einige Kontrastbezüge werden zusammengestellt von Crabbe 1981, 2315 ff. Segal 1999, 405 betont den Gegensatz unter dem Gesichtspunkt der narrativen Einbettung: „,The Lycaon story, told by Jupiter himself, emphasizes the remoteness, wrath, and power of the ruler of the gods, whereas the PhilemonBaucis episode offers the perspective of a reverent older man seeking to oppose a cynical ,scorner of the gods" (8.611-19) and so has a deliberately pietistic tone“.

${ }^{134}$ Schmidt 1991, 84 wendet sich in Auseinandersetzung mit Otis gegen die Auffassung, die Philemonund-Baucis-Episode enthalte entsprechend ihrer strukturellen Stelle im Werkganzen eine besonders „zentrale“ Aussage. Andererseits hebt Schmidt selbst (120) hervor, daß es sich bei dieser Erzählung um „die erste eigentliche Geschichte göttlicher Belohnung“ handelt und verweist seinerseits auf die zentrale Position im Werkganzen.

${ }^{135} \mathrm{Zu}$ dieser typologischen Unterscheidung verschiedener Metamorphosen vgl. Schmidt 1991, $13 \mathrm{f}$. Die Gabe zur multiplen Verwandlung entspricht dem „Zweiten Ausnahmetyp“ bei Schmidt. Den „,self-
} 
heit mehrerer Metamorphosenarten reflektiert, bestätigt wiederum, auf wie grundsätzlich-poetologischer Ebene die ovidische Metamorphosenthematik im AchelousSymposion aufgegriffen wird. Als ein weiteres Beispiel für die Gabe multipler Selbstverwandlung wird Mnestra, die Tochter des Erysichthon, angeführt, der diese Gabe ebenfalls von einem Gott, nämlich Neptun, als Lohn für ihre - in diesem Fall sexuelle - Willfährigkeit verliehen wurde. In die Mnestra-Erzählung ist die Episode von ihrem Vater Erysichthon eingeschachtelt.

Insgesamt betrachtet, gliedert sich auch das achte Buch in zwei Großteile. Der erste scheint prima facie in typischer Weise an einem epischen Erzählfaden, nämlich der athenisch-kretischen Auseinandersetzung, orientiert zu sein, zerfällt aber bei genauerem Hinsehen in verschiedene Episoden, die mit diesem Erzählfaden nicht allzu eng verknüpft sind. Der zweite Großteil (die Binnenerzählungen bei Achelous) ist a limine episodisch, ähnlich wie der aus den Minyaden-Erzählungen bestehende erste Hauptteil des vierten Buches. Durch die blasphemische Bemerkung des Pirithous wird ein bestimmtes, eng mit dem Gesamtprogramm der Metamorphosen korrespondierendes Thema (Verwandlungen als Werk von Göttern im Sinne einer Belohnung oder Bestrafung) fixiert. Dieses Thema erfährt seinen klarsten Ausdruck in der einzigen nicht von Achelous stammenden Rede, der Erzählung des Lelex über Philemon und Baucis. Das den zweiten Großteil von met. VIII beherrschende Achelous-Symposion trägt mithin in Hinsicht auf das Gesamtwerk ausgesprochen programmatischen (man könnte auch sagen: metapoetischen) Charakter.

\section{9. met. IX}

Im neunten Buch wird das im achten begonnene Symposion noch weitergeführt und durch eine abschließende Erzählung des Flußgotts Achelous beendet. Achelous geht von der Fähigkeit der Mnestra zu multipler Verwandlung über zu dem Ringkampf, den er selbst in verschiedenen Gestalten mit Hercules um den Preis der Ehe mit Deianira führte und der damit endete, daß Hercules ein Horn des Flußgotts von dessen Stiergestalt abriß. Diese Erzählung fügt sich nicht mehr in das gedankliche Schema "Verwandlung der Gestalt als Belohnung oder Bestrafung von göttlicher Seite", welches, wie gezeigt, die im achten Buch wiedergegebenen Erzählungen des Symposions beherrschte. Die hinter dieser letzten Erzählung stehende auktoriale Intention liegt vielmehr darin, das Thema des ersten Großteils von Buch IX einzuführen: den Herculesstoff. Insofern erklärt sich die Verlegung der letzten Erzählung des Gastmahls in das neue Buch nicht primär aus dem Bestreben, scharfe Buchgrenzen zu vermeiden, sondern beruht auf der Absicht, thematisch Zusammengehöriges in ein geschlossenes Buch zu integrieren.

Die ovidische "Herculeis" besteht hauptsächlich aus drei Episoden, welche den Weg des Hercules in seinen Untergang (bzw. zu seiner Vergöttlichung) nachvollziehen: 1. die Gewinnung der Deinaira im Ringkampf gegen Achelous, 2. anläßlich der Rückkehr mit Deianira die Bezwingung des Nessus (mündend in der Übergabe des tödlichen Gifts an Deianira) und 3. der eigentliche Tod des Hercules und seine Vergöttlichung durch Jupiter. Auffälligerweise wird in all diesen Abschnitten mittelbar oder unmittelbar hingeleitet zum Untergang des Hercules. Seine Aretalogie

transformers" in den ovidischen Metamorphosen wird eine eigene Abhandlung gewidmet von Elaine Fantham 1993. 
wird nur angedeutet in einer Aufzählung in dem verzweifelten Monolog vor seinem Tod, in welchem er sich fragt, ob er noch derselbe sei, der all jene großen Taten vollbringen konnte ${ }^{136}$. Die Episode 2 wird in sehr ungewöhnlicher Weise an die Erzählung über den Ringkampf gegen Achelous im Munde des Flußgottes angeschlossen. Ovid "entläßt" die Teilnehmer des Symposions in wenigen Versen ${ }^{137}$, ehe er dann mit seiner weiteren Erzählung unmittelbar an die direkte Rede des Achelous anknüpft ${ }^{138}$ : Während Achelous nur durch den Verlust eines Horns betroffen war, mußte Nessus das Verlangen nach Deianira mit dem Leben bezahlen. Ovid knüpft also in diesem Fall mit seiner auktorialen Darstellung unmittelbar an die intradiegetische Erzählung des Achelous an.

Auf diesen thematisch geschlossenen ersten Großteil des neunten Buchs folgt wiederum ein zweiter höchst episodischer. Im Gespräch zwischen Hercules' Mutter Alcmene und der schwangeren Gemahlin von Hercules' Sohn Hyllus, Iole, werden eine herkömmliche Tiermetamorphose (Galanthis) und eine Pflanzenmetamorphose (Dryope) abgehandelt ${ }^{139}$. Es folgen zwei Altersmetamorphosen, zunächst die Verjüngung von Hercules' Kamerad Iolaus, an welche sich dann über eine komplizierte Götterverwicklung eine andere Altersmetamorphose aus einem völlig verschiedenen Sagenkreis (dem der Alcmaeoniden) anschließt. Wiederum paarweise fügen sich zwei das neunte Buch beschließende erotische Episoden an: zunächst die pathologische Liebe der Miletos-Tochter Byblis zu ihrem Bruder Caunus ${ }^{140}$ und dann die Geschichte von der wundersamen Geschlechtsumwandlung der Iphis durch die Göttin Isis. Die Geschichten kontrastieren dadurch, daß die erste erwartungsgemäß katastrophal, die zweite wider Erwarten glücklich ausgeht. Sie stehen in keinem engeren mythologischen Zusammenhang. Der Übergang von der Byblis-Geschichte zur IphisErzählung ${ }^{141}$ kaschiert kaum, daß es sich um eine bloße Aneinanderreihung zweier erotischer Monstrositäten handelt.

Das neunte Buch restituiert also im wesentlichen die ursprüngliche, in den ersten Metamorphosenbüchern praktizierte Dichotomie zwischen einem epischgeschlossenen und einem erotisch-episodischen Großteil.

\footnotetext{
${ }^{136}$ met. IX $182 \mathrm{ff}$.

${ }^{137}$ met. IX $93 \mathrm{ff}$.

138 met. IX $98 \mathrm{ff}$.

139 Von Erbse 2003, 329 zusammengebracht unter dem Aspekt „unmenschlich harte Strafen für menschlich verständliche Verfehlungen“".

${ }^{140}$ Mythengeschichtlich hatte Ovid hier wohl zwei Versionen zur Auswahl, in denen entweder Caunus oder Byblis die Initiative ergriff (vgl. Bömer zu met. VIII/ IX, S. 411 f.; Jenkins 2000, 440: „Ovid had even his choice of protagonists“; a.a.O. 441 zeigt Jenkins, wie Ovid auf die von ihm verworfene Alternativversion anspielt); er entschied sich für letztere, wohl wegen seiner Vorliebe für pathologisch liebende Frauen und besonders in Anbetracht der Parallelität zur Myrrha-Geschichte in met. X. Gegenüber der wichtigsten Paralleldarstellung dieser Version (Nikander [fr. 46 Schneider] bei Anton. Lib. 30), wo Byblis auf ihre unheilbare Liebessehnsucht sogleich mit einem Selbstmordversuch reagiert $(30,3)$, hat Ovid die elegische Situation der Werbung und des verzweifelten Versuchs einer (zunächst brieflichen) Kontaktaufnahme herausgearbeitet. Zu Parallelen der elegischen Werbesituation in anderen Versionen des Mythos und der ovidischen Besonderheit des Briefschreibens vgl. Jenkins $2000,440 \mathrm{f}$.

${ }^{141}$ met. IX 666 ff.
} 


\subsection{0. met. $X$}

Den Übergang vom neunten zum zehnten Metamorphosenbuch bildet die Bewegung des Hochzeitsgotts Hymenaeus von der glücklichen Hochzeit zwischen Iphis und Ianthe (welche durch die von Isis an Iphis vollzogene zauberhafte Geschlechtsumwandlung in letzter Minute ermöglicht wurde) $\mathrm{zu}$ der von vorneherein unter schlechten Vorzeichen stehenden Hochzeit zwischen Orpheus und Eurydice ${ }^{142}$. Dieser kontrastive Übergang ${ }^{143}$ ist nicht nur punktuell wirkungsvoll, sondern durchaus auch in bezug auf die gesamten Episoden sinnhaltig ${ }^{144}$ : Die Iphis-Geschichte scheint zunächst (vor der Geschlechtsumwandlung, als Iphis noch eine Frau ist) auf eine pathologische homosexuelle Liebesbeziehung zwischen den beiden Frauen Iphis und Ianthe hinauszulaufen ${ }^{145}$; durch die Geschlechtsumwandlung und die dadurch möglich gewordene Hochzeit wird diese Beziehung aber im letzten Moment doch noch auf glückliche Bahnen geleitet. Dagegen beginnt die Beziehung zwischen Orpheus und Eurydice als eine normale Ehe; die Liebe zwischen beiden scheint zunächst sogar den Tod der Eurydice überwinden zu können; aber nach der endgültigen Trennung orientiert sich Orpheus in homosexueller Richtung. Einer glücklichen Umbiegung eines ursprünglich homosexuellen Verhältnisses in eine normale Ehe (Iphis - Ianthe) steht also die geradezu aitiologische Mutation einer normalen heterosexuellen Beziehung (des Orpheus zu Eurydice) zu einer homosexuellen Ausrichtung entgegen ${ }^{146}$.

Auf den letztlich vergeblichen Gang in die Unterwelt folgt der Gesang des Orpheus inmitten der thrakischen Bäume und Tiere, der mit fast 600 Versen die umfangreichste Oratio recta der gesamten Metamorphosen bildet. Als Thema dieses "Binnengesangs" werden im Prooemium 1. die Liebesverhältnisse von Knaben zu Göttern und 2. die unerlaubten, sträflichen Liebesaffairen von Mädchen genannt ${ }^{147}$. Demnach scheint sich dieser Binnengesang als eine programmatische Bekräftigung der Homosexualität verstehen zu lassen, der sich Orpheus nach dem endgültigen Verlust der Eurydice zuwandte: Die Liebesaffairen zwischen Knaben und Göttern werden scheinbar als beispielhaft empfohlen, die Liebe zu Frauen muß man scheinbar in Anbetracht von deren "unerlaubten Liebesfeuern" als etwas Verabscheuungswürdiges ablehnen. In dieser Weise scheinen zumindest die Maenaden, die Orpheus zu Beginn des elften Buchs töten, seinen Gesang aufzufassen: Sie sehen Orpheus als einen habituellen "Verächter" des weiblichen Geschlechts an ${ }^{148}$.

\footnotetext{
${ }^{142}$ Vgl. Holzberg 1998, 85.

143 Erbse 2003, 330 betont, etwas anders, den Kontrast zwischen Byblis und Iphis: „Dort versagen die Götter ihre Hilfe einer unnatürlichen Neigung. Hier schaffen sie durch ein Wunder natürliche Verhältnisse".

${ }^{144}$ Vgl. Coleman 1971, 470: „The thematic links are considerable“; Ludwig 1965, 52 spricht dagegen von einem ,künstlich wirkenden Kontrast“.

${ }^{145}$ Diesen Zug hat Ovid wahrscheinlich seiner bei Anton. Lib. 17 greifbaren Quelle (Nikander, fr. 45 Schneider) hinzugefügt, vgl. Guthmüller 1964, 67 f. Gerade das Motiv einer beinahe zustandegekommenen pathologischen Liebesbeziehung einer Frau zu einer anderen schafft eine Parallelität zur vorausgehenden Byblis-Geschichte (pathologische Liebe einer Schwester zu ihrem Bruder) und einen Kontrast zur folgenden Orpheus-Erzählung (glückliche Umbiegung des sich anbahnenden homosexuellen Liebesverhältnisses der Iphis in ein normales heterosexuelles gegenüber der unglücksbedingten Mutation der ursprünglich heterosexuellen Neigung des thrakischen Sängers zu einer homosexuellen).

146 Ähnlich Makowski 1996, 32, der in der Iphis-Geschichte ,a comment on the superiority of heterosexuality over homosexuality and of marriage over tribadism" sieht.

${ }^{147}$ met. X $152 \mathrm{ff}$.

148 met. XI 7.
} 
Überblickt man jedoch den Gesang des Orpheus im einzelnen, so erscheint es durchaus fragwürdig, ob sich die hier gegebenen Darstellungen von Liebesaffairen in diesem "kontextuell-funktionalen" Zweck des Gesangs (Profilierung von Orpheus als Frauenhasser und Freund der Homosexualität ${ }^{149}$ ) erschöpfen: Ein Liebesverhältnis zwischen einem Gott und einem Knaben liegt nur in der ersten, bloß andeutungshaften Erzählung über Jupiter und Ganymedes vor und in der breiter ausgestalteten zweiten über Apollo und Hyacinthus. Derselben Tendenz entspricht auch die vor dem eigentlichen Binnengesang gegebene Erzählung über die Vorgeschichte der als Teil des Auditoriums gedachten Zypresse, die Liebesgeschichte zwischen Apollo und Cyparissus. Das zweite im Prooemium angekündigte Hauptthema des Binnengesangs, die "unerlaubten" Liebesbegierden von Mädchen, wird dagegen nur in der MyrrhaEpisode thematisiert ${ }^{150}$, welche freilich den Binnengesang quantitativ dominiert und insofern den Gesamteindruck, den ein Zuhörer von dem Orpheus-Gesang behält, nachhaltig prägt. Die übrigen Geschichten passen genaugenommen nicht zu den beiden im Prooemium angekündigten Themen, und die Pygmalion-Episode steht sogar in einem gewissen Widerspruch zu der scheinbaren homosexuellen Gesamttendenz des Binnengesangs. Pygmalion sieht den schändlichen Lebenswandel der Propoetides, entschließt sich deshalb zu einem ehelosen Leben ${ }^{151}$ und könnte somit auf den ersten Blick als ein intradiegetisches Ebenbild zu Orpheus erscheinen ${ }^{152}$, der sich wegen des Verlusts der Eurydice ebenfalls von den Frauen abwendet. Doch die Verkommenheit der Propoetides eignet sich trotz der Junktur obscenae ... Propoetides $^{153}$ schwerlich als ein Exempel für die natürliche Verdorbenheit von Frauen, insofern diese von Venus zur Prostitution gezwungen wurden, weil sie die Göttlichkeit der Venus bestritten (welchen Hintergund diese Bestreitung hatte, ob die Propoetides sich wirklich von sich aus in irgendeiner Weise „obszoen“ verhielten oder ob dieses Attribut nur proleptisch auf ihre Bestrafung durch Prostitution zu beziehen ist, und ob die Propoetides vielleicht Venus sogar aus Gründen der Keuschheit ablehnten — in welchem Falle die Prostitution eine besonders passende Strafe wäre -, läßt sich in Ermangelung mythologischer Parallelquellen zu Ovid nicht sagen). Vor allem aber wird die Abwendung des Pygmalion von Frauen durch den Fortgang der Geschichte deutlich falsifiziert, denn Pygmalion verliebt sich schließlich in das von ihm als "Ersatz" für eine leibliche Frau geschaffene Kunstwerk so heftig, daß er Venus bitten muß, es in eine leibhaftige Frau zu verwandeln ${ }^{154}$. Demnach scheint man der Pygmalion- und vielleicht auch der Propoetides-Episode eher eine Tendenz zugunsten der durch Venus repräsentierten herkömmlichen, heterosexuellen Liebe entnehmen zu

\footnotetext{
${ }^{149}$ Vgl. Makowski 1996, 35, der die Themen des Gesangs mit den Begriffen ,pederasty and female immorality“ beschreibt.

${ }^{150}$ Anderson 1989a, 4 bezweifelt zurecht, daß sich die Episoden um die Propoetides und um Atalante unter den zweiten Dispositionspunkt subsumieren lassen.

${ }^{151}$ Döpp 1992, 141 betont den Kontrast zwischen Propoetiden- und Pygmalion-Episode.

152 Zur Parallelität zwischen Pygmalion und Orpheus unter diesem Gesichtspunkt vgl. Fränkel 1945, 96 f.; Guthmüller 1964, 72 f.; Coleman 1971, 468; Anderson 1989a, 4 f.; Schmidt 1991, 128; Spahlinger 1996, 137 (der in Orpheus den artifex infelix, in Pygmalion dagegen den artifex felix verkörpert sieht); Schönbeck 1999, 302.

153 met. X 238.

${ }^{154}$ Vgl. Anderson 1982, 45: Die Pygmalion-Episode „starts from supreme misogyny and ends with perfect romantic love“; 48: „Pygmalion's failure as an artist and his success as a human lover are Ovid's potent response to the myth of Orpheus“; Döpp 1992, 139: ,... er, der vom schamlosen Treiben der Propoetiden abgestoßen wurde und daraufhin allen Frauen abschwor, ist jetzt von tiefer Liebe erfaßt und fühlt sich aufs stärkste zu einer Frau hingezogen.“
} 
dürfen ${ }^{155}$. Eine konsequent durchgehende frauenfeindliche, homosexuelle Tendenz wird man den im Binnengesang versammelten, zum Teil auf der Inzeln Zypern spielenden Liebesepisoden nicht zusprechen dürfen, zumal die den Abschluß machende Liebe der Venus zu Adonis (also ein heterosexuelles Verhältnis zwischen einer Göttin und einem Sterblichen) ein Gegengewicht $\mathrm{zu}$ den homosexuellen Exempla am Anfang bildet ${ }^{156}$ und auch die in die Adonis-Geschichte eingeschachtelte Episode von Atalante und Hippomenes kein wirklich überzeugendes Exempel gegen die Ehe bildet, insofern die Katastrophe von Hippomenes selbst durch sträfliche Undankbarkeit gegenüber Venus herbeigeführt wird ${ }^{157}$, welche einer erfolgreichen

${ }^{155} \mathrm{Zu}$ ähnlichen, deutlicher im Sinne einer anti-homosexuellen Haltung des Autors artikulierten Ergebnissen hinsichtlich der Tendenz der Pygmalion-Erzählung kommt Anderson: „... Ovid consistently makes love for boys silly and unsatisfying, whereas love between male and female serves as his principal topic in the Metamorphoses ... we fault Orpheus for turning against women for boys, and we sympathize with Pygmalion as the morally mistaken artist who lets himself be drawn back into the natural world by recognizably human feelings“ (1989a, 5); „Ovid suggests that the anti-feminine argument of the great poet Orpheus is artistically and humanly false“" (a.a.O. 6). Gegen eine allzu nachdrückliche Betonung der anti-homosexuellen Tendenzen in Ovid's Gesamtwerk wendet sich andererseits Verstraete (a.a.O. 79: „The poet's rejection is not quite as sweeping and vehement as some scholars would have us believe“; zum Orpheus-Abschnitt in den Metamoprphosen vgl. a.a.O. 80 f.). Die der Orpheus-Geschichte gegenläufige Tendenz der Pygmalion-Erzählung macht übrigens die von Bartenbach 1990, 186 ff. hervorgehobene „Trostfunktion“ der Episoden des Orpheus-Gesangs im Sinne einer „Selbsttröstung“ fraglich. Wenn sich „die Trauer des Erzählers Orpheus in der Trauer derjenigen, von denen Orpheus erzählt,“ widerspiegeln soll (Bartenbach a.a.O. 190), welche Funktion kann dann die Geschichte des Pygmalion haben, der — im Gegensatz zum Schicksal des Orpheus seine frauenfeindliche Haltung überwindet und mit der ersehnten Geliebten schließlich glücklich vereint wird?

${ }^{156}$ In Anbetracht des offenkundig homosexuellen Hintergrunds (met. X 83-85) und des Auftakts des Gesangs mit Ganymedes und Hyacinthus wird man den Dispositionspunkt pueros .../ Dilectos superis (met. X 152 f.) kaum mit Knox 1986, 51 auf die Geschichte von Venus und Adonis ausdehnen dürfen.

${ }^{157}$ Gauly stellt zunächst sehr zurecht „,die Frage, inwiefern dieser Ausgang der Geschichte [die Verwandlung der Liebenden in Löwen] eine plausible Folge der vorausgehenden Ereignisse ist“; die Metamorphose ist ,nicht die unvermeidliche Konsequenz der Vereinigung der Liebenden, da sie ja nur durch Hippomenes' Nachlässigkeit verursacht wird“ (446). Jedoch erscheint der Versuch Gaulys, in dem „Thema Liebe“ die ,innere Einheit“ der Atalante-Geschichte zu finden (448), fragwürdig, da Hippomenes nicht wirklich ,übergroßer Leidenschaft erliegt“, insofern Venus den das Cybele-Heiligtum befleckenden Beischlaf willentlich herbeiführt, um Hippomenes für die Unterlassung der ihr geschuldeten Dankopfer zu bestrafen. Es liegt also letztlich eine menschliche Fehlhandlung gegen eine Gottheit vor (ähnlich wie in der Episode der Calydonischen Jagd, wo Oeneus der Diana die geschuldeten Opfer versagt), und man kann nicht sagen, daß die Götter „keine wesentliche Rolle spielen“ (Gauly 1992, 448). Entsprechend seiner Gesamtdeutung der Episode als einer reinen ,erotischen Geschichte“ sieht Gauly den einzigen Widerspruch zum Prooemium des Orpheus-Gesangs in der Tatsache, daß es sich um die „unerlaubte Liebe“ eines Mannes (Hippomenes) und nicht eines Mädchens handelt (452 f.). Auch Gaulys Parallelisierung des Hippomenes mit Orpheus (453) ist problematisch, insofern Orpheus Eurydice nur erneut verliert, weil er sich aus purer Liebe nach ihr zu früh umdreht, wohingegen Hippomenes sein Unglück in wesentlich schuldhafterer Weise herbeiführt, indem er seiner erfolgreichen göttlichen Helferin den geschuldeten Respekt versagt. Hippomenes eignet sich als Exempel höchstens dafür, wie ein Mensch seine mühsam errungene Liebe durch eine schuldhafte Respektlosigkeit gegenüber der hilfreichen Liebesgottheit wieder verspielt (der Ausdruck Pro thalamis celebrant silvas, met. X 703, im Munde der zürnenden Liebesgottheit läßt sich trotz der Verweise bei Gauly 1992, 447 f. nur schwer als Ausdruck eines glücklichen Zusammenseins in Löwengestalt fassen). Als ein Exempel für das Nicht-Gelingen heteroerotischer Liebesverhältnisse, wie es der Tendenz des Prooemiums des Orpheus-Gesangs entspräche, taugt er schwerlich: Denn seine Liebe zu Atalante hätte — im Gegensatz zu der von vorneherein unter unglücklichem Vorzeichen stehenden des Orpheus zu Eurydice - den Segen der zuständigen Gottheit (Venus) gefunden, wenn er sich nur dankbar gezeigt hätte. - Etwas anders als Gauly sucht Guthmüller 1964, 77 die Atalante-Erzählung mit der Themenangabe des Orpheus-Gesangs zu harmonisieren: In der von Atalante empfundenen Liebe zu 
Ehebeziehung zuvor den Weg gebahnt hat. Im Binnengesang des Orpheus kann man also bei genauerer Betrachtung nur eine recht heterogene Zusammenballung erotischer Episoden erkennen ${ }^{158}$.

$\mathrm{Da}$ im zehnten Buch ein größerer epischer Erzählfaden fehlt, ist schon durch die quantitative Dominanz des Binnengesangs in diesem Buch vorbestimmt. Auf die anti-epische Tendenz des Ganzen scheint der Dichter in dem poetologischen Prooemium des Orpheus-Gesangs (wo eine herkömmliche epische Darstellung im Stile der Gigantenkämpfe programmatisch abgelehnt wird) sogar zu reflektieren. Durch diese programmatische Hinwendung des Orpheus zur levior lyra ${ }^{159}$ und zu erotischen Themen - welche zu der unglücklichen Stimmung eines Orpheus nach dem Verlust der Eurydice zunächst schlecht zu passen scheint ${ }^{160}$ — wird die singuläre elegischepisodische Bauweise des zehnten Metamorphosenbuchs (welches vom OrpheusGesang quantitativ dominiert wird) gewissermaßen auktorial angekündigt: Es soll nicht mehr um Gigantenkämpfe (wie im Weltschöpfungsteil des ersten Buchs) gehen, sondern das erotisch-elegische Element soll in met. X verabsolutiert werden.

\subsection{1. met. XI}

Am Anfang des elften Buchs wird auf geographischem Wege von Thrakien über Phrygien nach Troja übergeleitet. Bacchus bestraft zunächst die thrakischen Maenaden für die Zerreißung des Orpheus, dann bestraft er Midas durch eine eigentlich als Belohnung konzipierte Wunscherfüllung, indem er ihm nämlich die Gabe verleiht, jeglichen Gegenstand in Gold zu verwandeln. Die Torheit des Midas bildet den Übergang zur nächsten Strafaktion, die Apollo an Midas vornimmt (Eselsohren). Als sich dann Apollo von Phrygien nach Troja begibt, ist ein um die Torheit des Midas angelegter axial-symmetrischer Übergang zum Trojamythos geschafft. Der Leser könnte nun wieder einmal eine längere zusammenhängende Erzählung epischer Prägung erwarten, doch die sich um Troja entspinnende politisch-militärische Handlung bildet zunächst einmal nur den Anknüpfungspunkt für recht locker angefügte Einzelepisoden, ähnlich wie die Auseinandersetzung zwischen Aegeus und Minos im siebenten und achten Buch.

Die mit der eigentlichen Stadtgründung verbundenden trojanischen Betrügereien werden sehr kursorisch erzählt. Insbesondere eine nähere Ausführung von Hercules' Kampf gegen das von Neptun gesandte Seeungeheuer, welcher zur Rettung der an einen Fels angeketteten Tochter des Laomedon führt, würde wohl zu einer nicht wünschenswerten Dublette mit dem Kampf des Perseus um Andromeda in met. IV führen. Auch die erste Eroberung Trojas durch Hercules findet nur summarische

\footnotetext{
Hippomenes liege wegen des warnenden Orakels (met. X 564 ff.) ein inconcessus amor. Dabei wird jedoch übersehen, daß ein Verstoß der Atalante gegen die Warnung bereits innerhalb des Orakels angekündigt wird (met. X 566).

${ }^{158} \mathrm{Vgl}$. Anderson 1982, 46: „The stories of this supposedly incomparable bard fail to prove his points: boy-love ends in lamentation, not happiness; girl-love refuses to be reduced to a simple formula of libido and punishment“. Anders Makowski 1996, 25: „We may consider the narrative from 9.666 to 11.66 as the Metamorphoses' homoerotic or bisexual sequence“.

${ }^{159}$ met. X 152.

${ }^{160}$ Vgl. Neumeister 1986, 178 mit Anm. 37, der den ,überraschenden“ Charakter von Orpheus’ Hinwendung zur levior lyra hervorhebt. Diese Interpretationsschwierigkeit erklärt sich möglicherweise dadurch, daß das Prooemium des Orpheus-Gesangs zumindest partiell auch als Aussage des Dichters über den bevorstehenden Werkteil zu verstehen ist.
} 
Behandlung: Die Übergabe der Hesione an Telamon dient als Überleitung zu einer ausführlicheren Darstellung der Liebe des anderen Trojakämpfers Peleus zu der Meergöttin Thetis. Die sexuelle Verbindung zwischen beiden nimmt bei Ovid jedoch nicht die Form einer Hochzeitsschilderung an, sondern besteht in der bloßen ringerischen Überwindung eines zur multiplen Verwandlung befähigten Wesens, deren literarischer Archetyp die Bezwingung des Proteus durch Menelaos in der Odyssee und deren engste Parallele in den Metamorphosen der Ringkampf des Hercules gegen Achelous ist. Der Charakter der Geschichte ist folglich kaum erotisch-elegisch geprägt (dieser Aspekt beschränkt sich völlig auf die Schlußperikope confessam amplectitur heros/ Et potitur votis ingentique inplet Achille ${ }^{161}$ ); es handelt sich vielmehr um die kämpferische Eroberung einer Frau, die der kriegerischen Erbeutung der Hesione durch Telamon passend an die Seite tritt.

An der Person des Trojakämpfers Peleus (und am eher epischen Charakter der Erzählung) wird festgehalten: Die Verbindung mit Thetis bildet gewissermaßen die

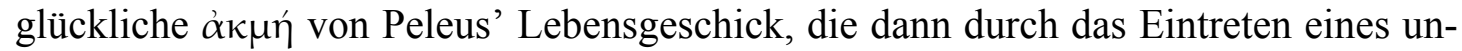
glücklicheren Lebensabschnitts überschritten wird, ähnlich wie das scheinbare Glück des thebanischen Stadtgründers Cadmus dem anschließenden Unglück durch die Katastrophen seiner Nachfahren entgegengesetzt wurde ${ }^{162}$. Dieser neue, unglücklichere Lebensabschnitt bildet den nächsten Erzählgegenstand: Peleus gelangt, wegen der Tötung seines Halbbruders Phocus aus der Heimat verbannt, zum trachinischen König Ceyx. Dessen persönliches Umfeld wird durch eine Binnenerzählung näher beleuchtet. Als Ceyx dann dem Peleus zum Schutz seiner Herden gegen einen riesigen Wolf hilfreich zur Seite springen will, wirft sich dem trachinischen König seine Gattin Alcyone in halbfrisiertem Zustand entgegen und bittet ihn, an dieser gefährlichen Unternehmung nicht persönlich teilzunehmen; er solle "zwei Seelen in einer retten" "163; Peleus bezeichnet diese Furcht der Alcyone um Ceyx wie um eine "zweite Seele" als "schön und liebevoll"164. Bereits durch diese eher beiläufige Szene wird noch innerhalb der Peleus-Episode angedeutet, daß zwischen Alcyone und Ceyx ein besonders liebevolles Pietätsverhältnis besteht ${ }^{165}$; ein Übergang zu einer eher elegischen Erzählung deutet sich an.

Dieses tiefe Liebesverhältnis wird in der folgenden Episode über die Trennung des Ceyx von Alcyone, seinen Tod im Seesturm, das Erscheinen seines Traumbilds vor Alcyone, die Anschwemmung seiner Leiche und die Verwandlung beider Eheleute in Eisvögel verabsolutiert unter völliger Preisgabe des (epischen) Peleus-Fadens. Diese Erzählung hat einen solchen Umfang (über 330 Verse), daß man sie als einen

\footnotetext{
${ }^{161}$ met. XI $264 \mathrm{f}$.

162 met. XI 266-268 Felix et nato, felix et coniuge Peleus,/ Et cui, si demas iugulati crimina Phoci,/ Omnia contigerant met. III 131-137 Iam stabant Thebae: poteras iam, Cadme, videri/ Exilio felix: soceri tibi Marsque Venusque/ Contigerant; huc adde genus de coniuge tanta,/ Tot natas natosque et, pignora cara, nepotes,/ Hos quoque iam iuvenes, sed scilicet ultima semper/ Exspectanda dies homini est, dicique beatus/Ante obitum nemo supremaque funera debet.

163 met. XI 388. Tränkle 1963, 471 bezeichnet diese Formulierung als „Leitmotiv für die ganze Geschichte" und weist den elegischen Ursprung des Gedankens nach. Zu dieser Exposition der Liebesbeziehung zwischen Ceyx und Alcyone vgl. auch Fantham 1979, 336.

${ }^{164}$ met. XI $389 \mathrm{f}$.

${ }^{165} \mathrm{Da}$ Alcyones Gefühle von Ceyx erwidert werden, wird explizit gesagt in met. XI 445; vgl. auch die Wiedergabe seiner Gedanken während des Seesturms met. XI 544 ff.; 562 ff. Haywood deutet das die Verbundenheit der Liebenden zum Ausdruck bringende Motiv, daß der Name Alcyones während des Seesturms ständig auf den Lippen des Ceyx ist, in kaum zwingender Weise als eine geistreich-witzige Anspielung auf den Topos, daß der als alycone bezeichnete Seevogel umgekehrt Ceyx ruft (vgl. etwa Sen. Ag. 681 ff.).
} 
eigenen Großteil des elften Metamorphosenbuchs betrachten kann, der mit seiner erotisch-elegischen Tendenz ein Pendant zu den umliegenden, an Helden des kriegerischen Trojamythos orientierten Erzählpartien bildet.

An diese unglückliche Liebesgeschichte schließt die unter strukturellem Gesichtspunkt äußerst interessante Aesacus-Erzählung an. Irgendein älterer Mann lobt die eheliche Treue der durch die letztgenannte Metamorphose entstandenen Eisvögel. Daraufhin schließt ein anderer oder vielleicht derselbe Sprecher (Ovids Übergangstechnik ist scheinbar so beliebig, daß er sich nicht einmal in der Identität des Sprechers festlegt ${ }^{166}$ ) die Geschichte von Aesacus an. Das Übergangsmotiv ("auch dieser Vogel war ursprünglich ein Königskind" ${ }^{, 67}$ ) ist also die bloße gedankliche Assoziation eines beliebigen Sprechers, auf dessen Identität Ovid nichts anzukommen scheint ${ }^{168}$. Einziges explizit genanntes Verbindungsmotiv ist die Vogelmetamorphose.

Bei genauerer Betrachtung dieser Episode wird jedoch klar, daß die Verbindung dieser (wesentlich kürzeren) Geschichte zur Alcone-Ceyx-Episode viel komplexer ist, als es der anonyme Erzähler der Aesacus-Geschichte ausspricht. In beiden Fällen stürzt sich ein verzweifelter Liebender (Alcyone bzw. Aesacus) auf eine über das Meer emporragende Erhöhung ${ }^{169}$ und wird schließlich durch das Mitleid der Götter ${ }^{170}$ in einen Vogel verwandelt; so wird der Sturz durch die neuartige Bewegung des Fliegens gebremst. Einem Musterbild weiblicher pietas (Alcyone) tritt ein ebensolches männlicher (Aesacus) entgegen.

Doch andererseits gibt es auch Antithesen zwischen beiden Erzählungen: Während Alcyone mit ihrem Geliebten in der neuen Gestalt glücklich vereint wird, bleibt dem Aesacus eine solche glückliche Vereinigung verschlossen, und er behält sein Verlangen nach dem Selbstmord - zumindest nach Ovids dichterischer Fiktion - auch nach der Verwandlung bei: Denn der Tauchvogel, in den Aesacus verwandelt wird, taucht immer wieder gewaltsam kopfüber ins Wasser ein, was Ovid dichterisch als immer neue Selbstmordversuche ausdeutet ${ }^{171}$.

Einerseits finden sich also in beiden Episoden vergleichbare Charaktereigenschaften (pietas) und vergleichbare Metamorphosen (Verwandlung in einen Vogel

\footnotetext{
${ }^{166}$ Vgl. Rosati 2002, 290, der darin eine Opposition gegen den alexandrinischen Anspruch auf die Wahrheit des berichteten Mythos sieht.

${ }^{167}$ met. XI $751 \mathrm{ff}$.

${ }^{168}$ Latacz 1979, 148 f. resümiert die bisherige Forschung zu dieser Übergangstechnik und vermag die Einführung einer zweiten beliebigen Zuschauerfigur nur als „komisch“ zu betrachten. Dieser „komische“ Übergang hat nach Latacz die Funktion, einen seinerseits komischen Troja-Abschnitt einzuleiten.

${ }^{169}$ Alcyone stürzt sich im Gegensatz zu Aesacus nicht von dieser Erhöhung mit dem Ziel des Selbstmords ins Meer, sondern sie will über die moles den herantreibenden Leichnam des Ceyx erreichen und wird auf diesem Weg verwandelt. Tränkle 1963, 467 ff. erschließt für die Ovid mutmaßlich vorliegende Version, daß sich dort Alcyone (wie Aesacus in der folgenden Geschichte) ins Meer stürzte; Ovid habe die Rückkehr der Leiche des Ceyx an den Strand von Trachis und die g e m e i n s a m e Verwandlung beider geneuert und dabei das ursprüngliche Sich-Ins-Meer-Stürzen der Alcyone abgewandelt. Auch Fantham 1979, 342 nimmt an, daß die Bedeutung von Alcyones Sprung ursprünglich der Selbstmord war und daß erst Ovid diese Version änderte.

${ }^{170}$ met. XI 741; 784.

${ }^{171}$ Vgl. Schmidt 1991, 132. Aesacus repräsentiert in Porods Typologie den „Typus 5“: Ovid bestimmt „den letzten Moment des Lebens zum die Verwandlung überdauernden Element ... Auf diese Weise wird die letzte Lebensäußerung, der letzte Gedanke bzw. Wunsch einer Person oder auch die letztmalige Körperhaltung eines beliebigen Tieres oder Menschen unmittelbar vor der Verwandlung durch das Ergebnis der Metamorphose sinnfällig zum Ausdruck gebracht. Häufig wird auf diese Weise ein besonders heftiger Affekt (insbesondere der des Leidens) gleichsam wie in einer Momentaufnahme eingefangen und dauerhaft festgehalten“" (a.a.O. 124).
} 
während des Sturzes von einer Erhöhung ins Meer), aber andererseits ist der jeweilige Gefühlszustand nach der Verwandlung diametral verschieden: Aesacus bleibt auch als Vogel erfolglos und verzweifelt; dagegen bleiben Alcyone und Ceyx in ihrer neuen Gestalt glücklich vereint. Bei der kurzen Aesacus-Erzählung handelt es sich also nicht um ein zufällig-belangloses Anhängsel in Gestalt irgendeiner anderen Vogelmetamorphose, sondern um ein motivisch genau abgewogenes (wenn auch quantitativ unproportionales) Pendant zur Alcyone-Ceyx-Episode ${ }^{172}$ - zu vergleichen ist etwa das oben herausgearbeitete Verhältnis der Arethusa-Episode zum Raub der Proserpina in met. $\mathrm{V}$.

Zugleich hat die Aesacus-Episode aber auch noch eine andere kompositorische Funktion: Sie lenkt zurück zum Troja-Faden, der mit Peleus zugunsten der AlcyoneCeyx-Erzählung aufgegeben wurde. Denn Aesacus wurde von Ovid als ein Sohn des Priamus vorgestellt, der dem berühmten Trojakämpfer Hector vielleicht nicht nachgestanden hätte, wenn ihm ein längeres Leben vergönnt gewesen wäre ${ }^{173}$. Damit wird die im nächsten Buch beginnende Darstellung des eigentlichen Trojanischen Kriegs (genaugenommen müßte man von der zweiten Eroberung sprechen) vorbereitet und zugleich - mit dem Tod des Priamiden Aesacus - ein Anknüpfungspunkt für eine Erwähnung des anderen Priamiden Paris zu Beginn des folgenden Buches geschaffen. Die einleitende Charakteristik des Aesacus - als eines einerseits gegenüber Hector nicht minderwertigen Helden, der jedoch andererseits eine Lebensform abseits des trojanischen Königshofes bevorzugt ${ }^{174}$ — verdeutlicht mit symbolischer Ausdruckskraft, daß es sich zwar im Gegensatz zur Alcyone-und-Ceyx-Erzählung wieder um einen mit Troja zusammenhängenden Sagenstoff, nicht jedoch um eine epischkriegerische Episode handeln wird: Wie Aesacus als eine vom Hof abgewandte „Ausnahmeerscheinung“ neben seinem Bruder Hector, dem Kämpfer $\kappa \alpha \tau^{\prime} \dot{\varepsilon} \xi o \chi \eta ́ v$, und den übrigen Priamiden steht, so kontrastiert die erotische Aesacus-Erzählung mit den übrigen, militärisch geprägten Troja-Episoden.

Die Gesamtkomposition des elften Metamorphosenbuchs ist vor allem geprägt durch das starke kompositionelle Eigengewicht der Alcyone-und-Ceyx-Episode, deren elegischer Charakter ${ }^{175}$ dadurch besonders deutlich wird, daß sie beidseitig eingeschlossen wird durch Episoden, die in enger Verbindung mit einem epischen Stoff, nämlich dem Trojakrieg, stehen. Die abschließende kurze Aesacus-Episode hat eine gewisse Zwitterfunktion sowohl als elegisch-erotisches Pendant zur Alcyone-undCeyx-Erzählung als auch als motivische Überleitung zum eigentlichen Trojanischen Krieg.

\subsection{2. met. XII}

Das zwölfte Buch wird mit dem typischen Motiv der singulären Abwesenheit einer bestimmten Person begonnen: Paris fehlt bei der Totenfeier für seinen Bruder Aesacus, da er sich gerade in Griechenland befindet. Eine Totenfeier für den in einen Vogel verwandelten Aesacus ist natürlich strenggenommen unangebracht. Aber der

\footnotetext{
${ }^{172}$ Primmer 1979, 137 betont dagegen die Parallelitäten zwischen Aesacus und Orpheus.

173 met. XI $759 \mathrm{f}$.

${ }^{174}$ met. XI $764 \mathrm{ff}$.

${ }^{175}$ Hierzu vgl. Tränkle 1963, 470 ff. Holzberg 1997, 146 sieht dagegen in der ausführlichen Sturmbeschreibung innerhalb der Alcyone-und-Ceyx-Erzählung bereits eine „Einstimmung des Lesers auf die Welt des Epos“.
} 
Dichter hilft sich mit dem Motiv, daß Priamus eben nicht Bescheid weiß um die Verwandlung seines Sohnes, ebenso wie Inachus in met. I $583 \mathrm{ff}$. nichts von der Vergöttlichung der Io und Cadmus in met. IV $563 \mathrm{ff}$. nichts von der Verwandlung von Ino und Melicertes in Seegottheiten wußte.

Die Darstellung des (zweiten) Trojanischen Kriegs beginnt mit einer summarischen Erzählung einiger Ereignisse in Aulis. Die eigentliche Kriegsschilderung (soweit sie in met. XII gegeben wird) beschränkt sich auf genaugenommen auf drei Tötungsszenen: 1. Hector tötet Protesilaus; 2. als Ausgleich hierfür tötet Achill Cygnus $^{176}$; 3. als unmittelbare Vergeltung hierfür bewirkt wiederum Cygnus' Vater Neptun, daß Paris mit Apollos Hilfe Achill tötet ${ }^{177}$. Die beiden mit 1 und 2 bezifferten Tötungen finden nach Ovids Darstellung unmittelbar nach dem Kriegsbeginn statt; dagegen erfolgt die Racheaktion Neptuns erst, als die zehn Kriegsjahre beinahe vorüber sind, wie in Ovids Darstellung ausdrücklich vermerkt wird ${ }^{178}$.

In diese eigentliche Schilderung trojanischer Kriegsereignisse (die man als ersten Großteil bezeichnen könnte) ist als zweiter, quantitativ ungefähr entsprechender Großteil eine Binnenerzählung Nestors bei einem nächtlichen Gelage nach der Tötung des Cygnus eingeschachtelt. Nestor mit seinem „,biblischen“ Alter bildet - wie schon bei Homer - ein Bindeglied zum vortrojanischen Zeitalter ${ }^{179}$. Seine umfängliche Erzählung nimmt ihren Ausgangspunkt bei der körperlichen Unverwundbarkeit des Cygnus; an dieser Eigenschaft des Cygnus drohte Achill im Kampf zu verzweifeln: Er zweifelte an der Stärke seiner eigenen Hand, die sich doch bei so vielen früheren Gelegenheiten bewährt hatte ${ }^{180}$ (damit gibt Achill weggangs im Moment des augenblicklichen Versagens seine eigene Aretalogie, ähnlich wie Hercules in met. IX im Angesicht seines Todes); schließlich gelang es Achill, Cygnus mittels Ersticken durch dessen Helmgurt zu töten.

Nestor weist darauf hin, daß es in früheren Zeiten auch andere solche Unverwundbaren gegeben habe. Zum Beleg erzählt er die Geschichte der thessalischen Jungfrau Caenis. Diese wurde von Neptun vergewaltigt und durfte daraufhin einen Wunsch äußern. Sie wünschte sich, fortan ein Mann zu sein, damit ihr derartiges nicht mehr zustoßen könne ${ }^{181}$. Dieser Wunsch wurde von Neptun sogleich erfüllt. Als eine

\footnotetext{
${ }^{176}$ Ellsworth 1980, 27 betrachtet diese Szene als ein Substitut für die bei Ovid erzählerisch ausgesparte Tötung Hectors.

${ }^{177}$ Möller 2003, 63 sieht im Tod Achills ,ein unrühmliches, beinahe nebensächliches Ende“. Diesem Eindruck beugt schon die buchüberschreitende Bedeutung vor, die Achill durch das Buch XIII eröffnende Armorum iudicium — und seine im Zusammenhang dieser Reden erfolgenden Erwähnungen (vgl. vor allem XIII 128 ff.) — erhält. Vgl. überdies noch im XII. Buch den auf Achills Tod bezüglichen Vers 617 (im Gegensatz zur Vergänglichkeit der Asche): At vivit totum quae gloria conpleat orbem. Die Dominanz Achills in der ovidischen Troja-Erzählung — die weit über seinen Tod hinausgeht — wird treffend herausgearbeitet von Ellsworth 1980, 28. Vgl. auch Dippel 1990, 22 über Achill als ein die ganze Kriegserzählung zusammenhaltendes Moment; im übrigen beurteilt Dippel das ovidische Achill-Bild ebenfalls (wie Möller) als ungünstig (59 ff.; a.a.O. 66 ist die Rede von einer ausgewogenen Mischung aus „Ernst und Komik“, a.a.O. 69 von einem „,antiepischen Charakter“, einer „,vollkommenen Karikatur des Iliashelden“; sogar der zitierte Vers met. XII 617 wird a.a.O. 68 in die achill-kritische Deutung miteinbezogen: „Damit wird der Leser aufgefordert, darüber nachzudenken, durch welche Leistungen Achill denn das Übermaß an Ruhm verdient hat").

178 met. XII 584.

${ }^{179}$ Vgl. Dippel 1990, 34 f. (der den ovidischen Nestor jedoch als „Persiflage“ des homerischen ansieht, a.a.O. 36).

${ }^{180}$ Möller, welche die ganze Cygnus-Episode poetologisch auszudeuten sucht, sieht hinter diesem temporären Versagen des herkömmlichen Kämpfers Achill das Versagen traditioneller Epik $(2003,56)$.

${ }^{181}$ Schmidt 1991, 108 hebt die poetologische Verwirklichung dieses Wunsches hervor: Es ist die letzte Vergewaltigung in den Metamorphosen.
} 
„Zugabe” erhielt Caeneus (so der Name des neu entstandenen männlichen Wesens) körperliche Unverwundbarkeit. Damit ergibt sich nicht nur die obligatorische Metamorphose, sondern die intradiegetische Nebenhandlung erhält auch als Pendant zu der in diesem Buch nahezu ausschließlich militärisch angelegten extradiegetischen Haupthandlung zumindest ein deutlich ausgeprägtes erotisches Element ${ }^{182}$. Diese erotisch-elegische Komponente wirkt in Gestalt der sexistischen Schmähreden der feindlichen Centauren gegen Caeneus, die in ihm immer noch eine Frau zu sehen vorgeben, ${ }^{183}$ bis weit in die - quantitativ dominanten - episch-kriegerischen Abschnitte der Caeneus-Episode hinein.

Noch wichtiger ist aber, daß der eigentliche Kampf, in dem sich die dem Caeneus verliehene Unverwundbarkeit bewähren kann (die Auseinandersetzung zwischen Lapithen und Centauren), von Nestor unabhängig von der Person des Caeneus in ca. 250 Hexametern ausgeführt wird. In dieser langen Schlachtbeschreibung wird — ganz nach Art antiker Kampfschilderungen ${ }^{184}$ — eine Vielzahl von Einzelkämpfen aneinandergereiht. Eine solche Kumulation von Einzelkämpfen - aus denen sich epische Schlachten in der Regel zusammensetzen - fehlt dagegen in der extradiegetischen, auf den Trojanischen Krieg bezüglichen Haupthandlung, wo das gesamte Kriegsgeschehen im zwölften Buch auf die oben angeführten drei Tötungen reduziert wird. Insofern die Binnenerzählung Nestors nun gerade in der Position (zwischen dem Tod des Cygnus und dem Tod Achills) steht, wo vom Dichter in der extradiegetischen Haupthandlung die überwiegende Masse militärischer Details weggelassen wird, ergibt sich der Eindruck, daß die ausführliche Kampfschilderung in Nestors Erzählung ein Substitut für die von Ovid verkürzend ausgelassene Kampfhandlung des Trojanischen Kriegs darstellt ${ }^{185}$; es handelt sich zwar um keinen eigentlichen Kampf, sondern eher um eine Prügelei bei einem Gelage, aber die als Supplement zur Lapithen-und-Centauren-Episode zu verstehende, als Reaktion auf den Einwand des Tlepolemus nachgeschobene Periclymenus-Erzählung Nestors trägt dieses fehlende Element (Gemetzel bei der kriegerischen Einnahme einer Stadt) gewissermaßen nach: Hier findet sich ein genaues intradiegetisches Pendant zu den fehlenden trojanischen Kampfszenen, nämlich die Niedermetzelung von elf Brüdern Nestors bei der Einnahme von dessen Heimatstädten durch Hercules. Zu einer solchen Ausdeutung der Binnenerzählung Nestors stimmt, daß die durch die verkürzende Auslassung auf der Ebene der erzählten Zeit gelassene Lücke (zwischen den Toden von Cygnus und von Achill) andererseits auf der Ebene der Erzählzeit ausgeglichen wird durch den geradezu überproportional langen Bericht Nestors über die Schlacht

\footnotetext{
${ }^{182}$ Vgl. Möller 2003, 63: „Soeben weidete man sich noch an dem Sieg Achills ..., und nun schließt sich unmittelbar eine hermaphroditische Metamorphose an“. Ob durch diesen spannungsreichen Kontrast aber zugleich „,die virtus als oberstes Ziel allen Heldentums relativiert“ wird, bleibt fraglich.

183 met. XII $470 \mathrm{ff}$.; $498 \mathrm{ff}$.

${ }^{184}$ Coleman 1971, 474, Latacz 1979, 150 ff., Ellsworth 1980, 28, Dippel 1990, 40 ff. (Doxographie: a.a.O. 45) und Möller 2003, 63 finden in dieser Kampfschilderung parodistische Züge. Hiergegen ist daran zu erinnern, daß die exzentrische Grausamkeit in der Lapithen-und-Centauren-Episode literaturgeschichtlich den Weg bahnt zu den grotesk-grausamen Kampfschilderungen der Dichtung der silbernen Latinität. Etwa die lucanischen Kampfschilderungen mag man genausogut aus klassizistischer Sicht als Degeneration der herkömmlichen Epik ansehen, doch dienen sie kaum ausschließlich dem subversiven Zweck, die Werthaftigkeit ihrer klassischen Vorläufer ad absurdum zu führen, wie dies Möller 2003, 63 unter alleiniger Berufung auf die „,besondere Grausamkeit“ für die ovidische Schilderung des Lapithen-und-Centauren-Kampfs annimmt.

185 Ähnlich Dippel 1990, 19; Holzberg 1997, 147 f.; Musgrove 1998a, 224 f.; Papaioannou 2002, 213; 223; ferner Latacz 1979, 151, der jedoch parodistische Aspekte in den Mittelpunkt seiner Interpretation stellt.
} 
zwischen Centauren und Lapithen ${ }^{186}$. Diese „Substitution“ der trojanischen Kampfhandlung durch ein intradiegetisches Pendant (einige andere weggelassene Kampfdetails werden übrigens in der rhetorischen Antilogie am Anfang von met. XIII also ebenfalls intradiegetisch — berührt) macht die makrostrukturelle Bedeutung der als ein autonomer - in diesem Fall eingeschachtelter - Großteil zu verstehenden Binnenerzählung Nestors aus. Als mikrostrukturelle Entsprechungen sind bestimmte Einzelparallelen wie z.B. die Gemeinsamkeit, daß der Unverwundbare (Caeneus bzw. Cygnus) nach seinem Tod in einen Vogel verwandelt wird, zu notieren.

Die Besonderheit des Aufbaus von met. XII liegt also in der E in$\mathrm{sch}$ a c h t e l ung des einen, ansatzweise erotisch-elegisch geprägten Großteils in den anderen, rein militärisch-epischen.

\subsection{3. met. XIII}

Das dreizehnte Metamorphosenbuch wird eröffnet durch die rhetorische Auseinandersetzung zwischen Aiax und Odysseus vor den Fürsten des griechischen Heers um die Waffen Achills, deren Szenerie bereits am Ende von met. XII angelegt worden ist. Diese rhetorische Auseinandersetzung, die übrigens viele in met. XII überhaupt nicht behandelte Details der militärischen Ereignisse berührt ${ }^{187}$, bildet den ersten Großteil des zwölften Buchs. Im Anschluß daran wird der Abschluß des eigentlichen Kriegs sehr summarisch dargestellt.

Die erste wieder ausführlich dargestellte Ereignissequenz ist das Geschick der Hecuba: Ihrer Verhundung gehen zwei Geschehnisse voraus, die zuerst Euripides in seiner Hekabe miteinander verknüpft hat: die Opferung ihrer jüngsten Tochter Polyxena und dann - als eine weitere Komplikation, die sich (ebenfalls gemäß Euripides) bei der Säuberung von Polyxenas Leichnam ergibt - die Anschwemmung der Leiche des Polydorus, welche zu einer grausamen Rache der Hecuba an dem Thrakerkönig Polymestor führt; der Anschluß an Euripides geht so weit, daß sogar die kompositionell das Polyxena-Geschehen umklammernde Stellung des PolydorusAbschnitts beigehalten wird (das dem chronologisch früheren Polyxena-Geschehen vorausgehende Segment des Polydorus-Abschnitts wird bei Euripides durch die Prologrede von Polydoros' Totenschatten gewährleistet, bei Ovid dagegen durch die exponierende Vorstellung des Schauplatzes Thrakien, in welche die Erzählung von der Ermordung des Polydorus integriert ist ${ }^{188}$ ).

Mit dieser euripideischen Sequenz über das Leid der Hecuba wird durch das gängige Anschlußmotiv ,,alle nehmen Anteil, nur nicht XY“189 eine andere Sequenz parallelisiert, welche in dieser Weise nur um den Preis einer beträchtlichen chronologischen Inkonsequenz angeschlossen werden $\operatorname{kann}^{190}$ : die Trauer der Aurora um ihren im Kampf für Troja gefallenen Sohn Memnon und die mit Hilfe des Göttervaters Jupiter eingesetzte jährliche Ehrung seines Grabes durch die aus seiner Asche

\footnotetext{
186 Ähnlich Ellsworth 1980, 26; Dippel 1979, 33; Musgrove 1998a, 229.

${ }^{187}$ Vgl. Ludwig 1965, 65: „Das Geschehen der Ilias erscheint jetzt in einer doppelten und zwar gegensätzlichen, subjektiven Schilderung, gesehen von zwei Augenzeugen, den beiden Helden Aias und Odysseus“; Dippel 1979, 92. Ellsworth 1980, 25 hebt hervor, daß die in der ovidischen Haupthandlung weitgehend fehlenden Anspielungen auf die Ilias „occur primarily in the debate between Ajax and Ulysses over the arms of Achilles“.

${ }^{188}$ met. XIII $429 \mathrm{ff}$.

${ }^{189}$ Vgl. hierzu Herter 1983, 315 f.

${ }^{190}$ Vgl. Dippel 1979, 120 mit Anm. 3.
} 
hervorgegangenen Vögel. Insofern der Tod Memnons vor dem Tod Achills erfolgt sein muß, der am Ende von met. XII geschildert wurde, versteht man nicht recht, warum die Totentrauer seiner Mutter chronologisch hinter das Kriegsende und ferner hinter die Verhundung der Hecuba verlegt wird ${ }^{191}$ (in der Aithiopis stand der Bittgang der Eos zu Zeus natürlicherweise unmittelbar hinter dem Tod des Memnon ${ }^{192}$ ): Im Mittelpunkt steht offenbar Ovids kompositorisches Bestreben, die Trauer zweier Mütter, die ihre Kinder im Trojanischen Krieg verloren haben, zu parallelisieren und gewissermaßen in konzentrierter Form die menschlichen Folgen dieser zerstörerischen Auseinandersetzung darzustellen.

Diese Tendenz bestätigt sich durch die ovidische Fortführung der Erzählung: Obwohl mit den Irrfahrten des Aeneas ein völlig neues Kapitel ${ }^{193}$ — welches von der sich in Aeneas manifestierenden „Hoffnung“ (spes) auf einen Fortbestand Trojas ausgeht ${ }^{194}$ — begonnen wird, hat doch die erste ausführlicher gestaltete Episode dieses neuen Themenkreises wieder das Leid von Eltern der Opfer des Trojanischen Kriegs zum Gegenstand: Der delische Priesterkönig Anius berichtet dem Aeneas über das Geschick seiner vier Töchter, die durch ein Geschenk des Bacchus mit der Gabe ausgestattet waren, alles, was sie berührten, in Getreide und Wein zu verwandeln, wegen dieser für die Versorgung eines Heeres höchst nützlichen Eigenschaft von dem griechischen Heerführer Agamemnon verfolgt und schließlich von Bacchus in Tauben verwandelt wurden. Auch der Gegenstand dieser Binnenerzählung wird explizit als eine Folge des Trojanischen Kriegs herausgestellt. Anius sagt zu Aeneas ,... damit du nicht etwa glaubst, daß nicht auch wir zu einem gewissen Teil euer Unglück zu spüren bekommen hätten“،195. Die in Form einer Bildbeschreibung eingeführte Erzählung über die thebanischen Coroni, zwei junge Männer, welche aus der Asche der sich für ihre Heimatstadt Theben opfernden Orion-Töchter hervorgingen und die toten Frauen durch eine feierliche Prozession ehrten, ist offenkundig von Ovid als mikrokosmische Spiegelung der Memnoniden-Episode konzipiert ${ }^{196}$ und somit auch noch zum zweiten Großteil von met. XIII gehörig, welcher sich mit dem Titel „die

\footnotetext{
${ }^{191}$ Ellsworth 1980, 27 sieht dahinter ein ovidisches Substitut für die Bestattung Hectors am Ende der Ilias.

${ }^{192}$ p. 47, 17-19 EGF Davies. Allerdings bittet Eos dort für Memnon nicht wie Aurora bei Ovid (met. XIII 598) um ,,irgendeine Ehre als Trost für den Tod“", sondern um Unsterblichkeit.

${ }^{193}$ Die verschiedenen Forschungspositionen zur „ovidischen Aeneis“ werden deutlich in den Arbeiten von Döpp 1991, der die Problematik des Parodie-Begriffs in Hinsicht auf Ovids Vergilbenutzung herausarbeitet (1991, 330) und am Ende zu dem Ergebnis kommt, Ovid bleibe ,im Atmosphärischen, mehr noch in der geistigen Aura ... der Vergilischen Aeneis näher, als es nach den jüngsten Interpretationen scheinen könnte“ (a.a.O. 342) und die Größe des Aeneas werde ,nicht etwa ausgeblendet oder demontiert, sondern umrißhaft sichtbar“ (a.a.O. 344), und andererseits Glei, der von „Bagatellisierung“ und ,dekonstruktivistischer Verflachung des historischen Tiefgangs“ (a.a.O. 101) spricht.

${ }^{194}$ met. XIII 623 f. Non tamen eversam Troiae cum moenibus esse/ Spem quoque fata sinunt. Vor dem Hintergrund der vergilischen Fatumsvorstellung fällt auf, daß die ovidischen fata nur $\mathrm{H}$ o f f n u $\mathrm{n} g$, aber keine $G$ e w i $\beta$ h e i t eines Fortbestehens von Troja implizieren.

195 met. XIII 656 f. Döpp 1991, 336 sieht in der Anius-Geschichte ein Pendant zur Polydorus-Episode im dritten Aeneis-Buch: Die Aeneaden werden ,gleich zu Beginn ihrer Fahrt noch einmal mit dem Leid Trojas konfrontiert“. Ähnlich Guthmüller 1964, 83; von Albrecht 2000, 189: „die Erzählung von den Töchtern des Anius als Epilog“" zum Troja-Teil.

${ }^{196}$ Die Verwandlung in junge Männer, die dann einen Grabkult betreiben, findet sich nur bei Ovid. Nach der einzigen mythologischen Parallelerzählung, die Anton. Lib. 25 auf Nikander (fr. 57 Schneider) und Korinna (PMG 656) zurückführt, werden die Leichen in Gestirne, sogenannte Kometen, verwandelt $(25,4)$.
} 
Folgen des Trojanischen Kriegs für die hinterbliebenen Anverwandten der Kriegsopfer" überschreiben ließ $\mathrm{e}^{197}$.

Ein dritter Großteil schließt sich an, der einen Ausgleich gegenüber den ersten beiden auf den Trojanischen Krieg und seine Folgen konzentrierten Großteilen von met. XIII schafft: Die Weiterfahrt des Aeneas nach Sizilien gibt Anlaß zur Erwähnung der Seeungeheuer Scylla und Charybdis, woran sich wiederum eine Erzählung von Scyllas Geschichte anschließt. Diese ist genauso erotischer Art wie die in Form einer Binnenerzählung in die Scylla-Episode eingeschachtelte GalateaEpisode $^{198}$. Das Gespräch zwischen Scylla und Galatea antizipiert in ironischer Weise die auf Scylla eindrängenden Ereignisse ${ }^{199}$ : Scylla berichtet Galatea über die zahlreichen von ihr abgewiesenen Verehrer, und Galatea antwortet seufzend (in Hinblick auf ihr eigenes Geschick, die Zudringlichkeit des Kyklopen Polyphem), daß es Scylla ja wenigstens noch möglich sei, unerwünschte Liebhaber abzuweisen. Doch der nächste Liebhaber, der Scylla bedrängen wird (der neugeschaffene Meergott Glaucus), wird sich eben auch nicht mehr abweisen lassen, sondern Scylla durch seine Herbeiziehung der Zauberin Circe ins Unglück stürzen. Insofern werden die beiden Liebesgeschichten in eine subtile Querbeziehung zueinander gebracht: Beide Episoden zeigen, wie furchtbar sich die Verschmähung eines ungeheuerähnlichen Liebhabers (Polyphem bzw. Glaucus) auswirken kann. Der Zorn des Verschmähten äußert sich in der Galatea-Episode in stumpfer Gewalt gegen den durch einen Steinwurf erschlagenen Konkurrenten Acis. In der Scylla-Episode ergibt sich dagegen eine kompliziertere Verwicklung ${ }^{200}$, insofern Glaucus sich erst, um einen Liebeszauber für Scylla ersuchend, zu der Zauberin Circe begibt, die sich dann selbst in Glaucus verliebt und — ihrerseits verschmäht - eine furchtbare Rache an ihrer vermeintlichen Nebenbuhlerin Scylla nimmt ${ }^{201}$. Die unschuldig geschädigte Person Acis $^{202}$ bzw. Scylla — wird jeweils in eine Wassergottheit verwandelt, wobei die Verwandlung des Acis in einen Flußgott eher tröstlicher Natur zu sein scheint, während Scyllas Verwandlung in ein hundetragendes Seemonster von ihr selbst gemäß ihrer ersten Reaktion ${ }^{203}$ — als furchtbar empfunden wird. Möglicherweise darf man in dieser schmerzhaft empfundenen Metamorphose eine gewisse Strafe für die am Anfang der Episode von Scylla an den Tag gelegte spröde Ablehnung gegen ihre vielen Freier sehen (ähnlich wie in der Narcissus-Episode in met. III).

Das dreizehnte Metamorphosenbuch ist das letzte, welche eine derart klare Scheidung in kriegerisch-epische und erotisch-elegische Großblöcke zuläßt. In den

\footnotetext{
197 Von Döpp 1991, 337 wird die Coroni-Episode ebenfalls noch mit dem Troja-Komplex in Verbindung gebracht; vgl. auch Guthmüller 1964, 89 f.

${ }^{198}$ Eine separate Behandlung dieses Abschnitts unter dem Gesichtspunkt von Intertextualität und Narratologie bietet Musgrove 1998b, die in dem ganzen Exkurs vor allem ein Substitut sieht für eine Schilderung von Achaemenides' Rettung durch die Aeneaden, wie sie bei Vergil gegeben wird: „Only then [in met. XIV $167 \mathrm{ff}$.] do we realize that Achaemenides really has been on Aeneas' ship since Aetna, i.e., since about 13.730, the beginning of the Scylla episode. The gap created by the omission of an account of Achaemenides' rescue in Book 13 has been filled by an inset narrative ..." (a.a.O. 101).

${ }^{199}$ Vgl. Brenk 176.

${ }^{200}$ Vgl. Guthmüller 104.

${ }^{201}$ Ellsworth 1986, 30 sieht in der Circe-Glaucus-Konstellation kaum überzeugend ein Substitut für die vergilische Erzählung über Dido und Aeneas.

${ }^{202}$ Schwerlich entspricht der ovidischen Darstellungstendenz die Deutung von Griffin 1983, 196, der Acis als ein die Sympathien für den monströsen Polyphemus steigerndes Requisit betrachtet: „Ovid's introduction of Acis, the successful rival, into the story increases the reader's feeling of pity for Polyphemus as the underdog. When Acis and Galatea, locked in an embrace, watch and listen to Polyphemus as he exposes his emotional and sexual distress, their behaviour smacks of voyeurism“".

${ }^{203}$ met. XIV $61 \mathrm{ff}$.
} 
beiden Schlußbüchern zeigen sich — bedingt wohl durch den Ovids freie Komposition hier ein wenig einschränkenden Stoff — andere Dispositionsweisen.

\subsection{4. met. XIV}

In met. XIV ist als erste Auffälligkeit hervorzuheben, daß die - oben bereits vollständig paraphrasierte - Scylla-Episode noch deutlich (über 70 Hexameter) in den Beginn des neuen Buchs hineinragt: met. XIV beginnt mit dem Aufbruch des von Scylla abgewiesenen Glaucus zur Zauberin Circe. Der Grund für diese Zerteilung des durch Einschachtelung der Galatea-Episode kunstvoll strukturierten erotischen Großteils dürfte in der Rolle der Circe liegen, die sich unerwarteterweise in Glaucus verliebt und dann ihre vermeintliche Nebenbuhlerin Scylla in höchst skrupelloser Weise durch ihre Magie und eine hinterhältige Intrige ins Unglück stürzt. Ganz ähnlich wirkt Circe in der ebenfalls im vierzehnten Buch innerhalb der Erzählung des Macareus dargestellten Picus-Episode, wo sie sich ebenfalls verliebt und mit verheerender Grausamkeit ihre Zurückweisung ahndet ${ }^{204}$. Die Zerteilung des Scylla-GalateaKomplexes auf zwei verschiedene Bücher ermöglicht es, die Parallelität von Circes Verhalten in beiden Fällen durch die Zusammenstellung beider Episoden innerhalb eines Buchs zu betonen ${ }^{205}$. Insbesondere die von Macareus an Aeneas gewendete emphatische Warnung vor Circe und ihrer Insel ${ }^{206}$ kann der Leser des vierzehnten Metamorphosenbuchs bereits kraft seiner eigenen Leseerfahrung nachvollziehen; ferner erhält die Einleitung der an Macareus gerichteten Picus-Erzählung einer Dienerin Circes (Accipe ..., Macareu, dominaeque potentia quae sit/ Hinc $q$ ио qu e disce meae ${ }^{207}$ ) für den Leser, der zu Beginn des XIV. Buches über das Vorgehen der Circe gegen Scylla erfahren hat, eine tiefere Verständnisdimension.

Was die weiteren im vierzehnten Metamorphosenbuch dargestellten Ereignisse betrifft, so war es hier für Ovid - im Vergleich zu den ersten Büchern - weitaus weniger leicht, kontinuierlich-narrative Großteile epischer Prägung und solche erotisch-elegischer Natur nebeneinanderzustellen. Denn in den ersten Büchern konnte Ovid bei der Disposition der einzelnen Bücher im wesentlichen frei schalten und walten, da er in den meisten Fällen mythische Begebenheiten hintereinanderreihte, die in der vorgängigen Tradition kaum jemals geradeso miteinander kombiniert wurden. Dagegen im Schlußteil war die Ereignisabfolge von vorneherein relativ rigide festgelegt: An der Aufeinanderfolge von Aeneas' Reiseepisoden, seinen Kämpfen in Italien und der Chronologie von Aeneas' Nachfolgern in Latium und den römischen

\footnotetext{
${ }^{204}$ Vgl. Fränkel 1945, 104 f. Allgemein zum ovidischen Circe-Bild vgl. Segal 1968, besonders 436 ff.: Ovid verweigert der Circe (wie Vergil) ,, a really effective male counterpart. Ovid's Glaucus and Picus flee her advances, and his Ulysses is a pallid lover at best“" (a.a.O. 428; etwas anders sieht Ellsworth 1988, 338 in Glaucus und Picus Abbilder des homerischen Odysseus: „In both cases, the man rejects her in favor of another woman ..., just as Odysseus ultimately rejects her to return home to Penelope“; zu undifferenziert urteilt Schubert 1989b, 123, bei der ovidischen Circe trete das ,erotische Element“" zurück, welches wenn auch nicht bei Odysseus, so doch bei Glaucus und Picus - in zwei deutlich parallelisierten Geschehenskonstellationen — nachhaltig hervortritt). $\mathrm{Zu}$ der Tatsache, daß die Gegenfiguren Circes von recht untergeordneter Bedeutung im Ganzen der Metamorphosen sind, vgl. auch Segal 1968, 437. Andererseits übernimmt Circe bei Ovid ,a more active initiative and a more aggressive role“, insofern ihr räumlicher Aktionsradius weit über ihre Insel hinausgeht (a.a.O. 441).

${ }^{205}$ Erkannt in der bei von Albrecht 2000, 266 beschriebenen Buchillustration von met. XIV.

${ }^{206}$ met. XIV $245 \mathrm{ff}$.

${ }^{207}$ met. XIV $318 \mathrm{f}$.
} 
Königen war nichts Wesentliches zu ändern, und die darstellerische Freiheit Ovids erstreckte sich hier nicht auf die Disposition, sondern höchstens auf die Möglichkeit, bestimmte Episoden wegzulassen bzw. sehr knapp zu behandeln, andere dagegen breit auszugestalten oder exkursartig zu erweitern. Etwa eine Buchhälfte ausschließlich mit erotisch-elegischen Erzählungen zu gestalten wäre hier nur möglich gewesen, wenn Ovid den Haupthandlungsfaden (Erlebnisse des Aeneas bzw. Chronologie seiner Nachfolger) völlig suspendiert hätte. Dementsprechend vermag Ovid hier eine Auflockerung des politisch-militärischen Stoffes durch erotische Begebenheiten nicht in Form separater Großteile, sondern nur in Gestalt kleinerer Anhängsel zu bestimmten mythisch-historischen Etappen zu schaffen ${ }^{208}$.

Die Ereignisse der Aeneis-Bücher I (Ankunft der Aeneaden in Libyen infolge eines Seesturms), IV (Aufenthalt bei Dido), V (erneute Ankunft in Sizilien und Leichenspiele für Anchises) behandelt der Metamorphosendichter äußerst knapp. Offenbar meidet Ovid die Konkurrenz mit Vergil. Die in Aen. VI dargestellte Katabasis des Aeneas wird unter deutlicher Verschiebung der Schwerpunkte gegenüber Vergil beschrieben: Die Anbahnung und die Ausführung der Katabasis werden sehr summarisch dargestellt, breit ausgeführt dagegen ein Gespräch des Aeneas mit der Sibylle, mit dem die beiden sich den Rückweg verkürzen. Hierbei handelt es sich gewissermaßen um die erotische Aitiologie der Priesterin, die durch ihre Weigerung, dem Gott Apollo sexuell zu willfahren, eine bessere, götterähnlichere Existenz verspielt hat ${ }^{209}$. Charakteristisch ist hier die ovidische Hervorhebung von Nebenfiguren (Begleiterin des Aeneas bei Katabasis) und Nebenaspekten (Gespräch während des Rückwegs), die für den Haupthandlungsstrang entbehrlich sind, aber die Gelegenheit zur Einschiebung einer erotischen Episode bieten.

Die nächste Episode spielt vollständig zwischen zwei Nebenfiguren. Der unter die Aeneaden aufgenommene Grieche Achaemenides ist wohl eine vergilische Kreation, der Ovid hier den inzwischen nahe dem Unterweltsausgang sesshaft gewordenen Macareus gegenüberstellt ${ }^{210}$. Der Anteil des Achaemenides an dem langen, in Oratio recta wiedergegebenen Binnengespräch der beiden enthält sachlich wenig über Vergil Hinausgehendes ${ }^{211}$ und vor allem keinerlei Metamorphose. Dagegen bietet Macareus eine interessante neuartige Darstellung ${ }^{212}$ der von Circe vorgenommenen Verwandlung von Odysseus' Gefährten in Schweine aus der Perspektive eines unmittelbar Betroffenen ${ }^{213}$. Doch auch diese (sachlich aus der Odyssee bekannte) Geschichte scheint nur den Aufhänger bzw. Rahmen für das wirklich

\footnotetext{
${ }^{208}$ Döpp 1991, 341 f. bringt diese ovidische Kompositionsweise vage mit dem dritten Aeneis-Buch in Verbindung. Zum besonderen Einfluß von Aen. III auf die ovidische Gestaltung vgl. auch Tissol 1993, $70 \mathrm{ff}$.

${ }^{209}$ Hierzu im einzelnen vgl. Gärtner 2004.

${ }^{210}$ Vgl. Schade 2001, 529. Hinds 1998, 112 versteht die Begegnung zwischen Achaemenides und Macareus als ein Symbol des intertextuellen Dialogs Ovids mit seinem epischen Vorgänger Vergil: „Ovid thematizes his intertextual dialogue with his epic predecessor ... by putting an Odyssean stray of his own into conversation with the Odyssean stray through whom Virgil had thematized his intertextual dialogue with his epic predecessor [Homer]".

${ }^{211}$ Baier 1999, 448 sieht in dem ovidischen Achaemenides eine „Karikatur“ seines vergilischen Vorläufers.

${ }^{212}$ Vgl. Ellsworth 1988, 335: „Although Ovid's account includes elements from Vergil's Aeneid, scholars generally agree that the primary reason Ovid includes this conversation between the two Greeks is to tell, in summary form, the part of the Odyssey that extends from the Cyclops to Circe".

${ }^{213} \mathrm{Zu}$ dieser „Subjektivierung“ durch beteiligte Ich-Erzähler insbesondere in Parallelschilderungen zu homerischen oder vergilischen Szenen (in met. XII-XIV) vgl. Wheeler 1999, 164; 189 f. Speziell zur hier besprochenen Partie vgl. Schubert 1989b, 122; Döpp 1991, 338 f.; Baier 1999, 444 ff.
} 
Neuartige, bei Vergil nur rudimentär Vorhandene ${ }^{214}$ in Macareus' Rede zu bilden: die Geschichte über die Liebe der Circe zu dem italischen König Picus, die Macareus während des Aufenthalts des Odysseus bei Circe von einer Dienerin Circes erzählt wurde $^{215}$. Wieder ermöglicht eine Abwendung von den epischen Hauptpersonen Aeneas und Odysseus, verbunden mit einer Konzentration auf Nebenfiguren wie Achaemenides, Macareus und die Dienerin der Circe, die Gestaltung einer dem epischen Hauptstoff fremden, ein Gegengewicht bildenden erotischen Episode.

Die Korrespondenz des Verhaltens der Circe (die einen Sterblichen, der ihr nicht zuwillen ist, einfach zur Strafe in ein Tier verwandelt) mit dem Auftreten derselben Gottheit in der Scylla-Episode (wo sie an einer vermeintlichen Nebenbuhlerin, die in Wirklichkeit ihrerseits an Glaucus keinerlei Interesse hatte, furchtbare Rache nahm durch Verwandlung in ein Ungeheuer) ist bereits berührt worden ${ }^{216}$. Diese Korrespondenz wird betont durch die Plazierung beider Episoden in dasselbe Buch. Bei Circe handelt es sich offenkundig um eine gefährliche, zur Verwandlung anderer Personen befähigte Gottheit, die ihre Fähigkeit skrupellos einsetzt, um eigene erotische Abweisungen in willkürlicher Weise zu rächen ${ }^{217}$. Dieser Aspekt völlig autonomer göttlicher Willkür wird auch deutlich, wenn man die Circe-Picus-Episode (Göttin liebt einen seinerseits glücklich verheiraten Sterblichen) vergleicht mit der in der Cephalus-Erzählung am Ende von met. VII gegebenen Darstellung der typologisch ähnlichen — ebenfalls während einer Jagd entflammenden — Liebe der Aurora zu Cephalus: Auch hier wirkte sich der Ärger der zurückgewiesenen Gottheit offenkundig schließlich fatal aus auf die anfangs glücklichen Eheleute Cephalus und Procris, aber dort waren es doch deutlichermaßen auch die Eheleute selbst, die sich ins Unglück stürzten ${ }^{218}$ : zunächst Cephalus durch seinen Versuch, die Treue der Procris mit Hilfe der von Aurora gegebenen Verwandlungsgabe auszuforschen (was zum ersten Zerwürfnis führte), dann Procris durch ihre Bereitschaft, der Denunziation gegen ihren Gatten Glauben zu schenken, und ihre übertriebene Eifersucht auf „Aura“ (welche die schließliche Katastrophe herbeiführte) ${ }^{219}$. Während also dort das von

\footnotetext{
${ }^{214}$ Verg. Aen. VII 187 ff. Vgl. Baier 1999, 450.

${ }^{215} \mathrm{Zu}$ der Auffassung, daß die Picus-Episode den eigentlichen Zielpunkt der Macareus-Erzählung bildet, vgl. Schubert 1989b, 123 f. mit Anm. 20.

${ }^{216}$ Zur Parallelität der Erzählungen vgl. auch Guthmüller 1964, 122 ff.; Segal 1968, 437. Baier 1999, 451 ff. betont dagegen Parallelitäten zwischen der Picus-Canens-Circe-Episode und der LaviniaTurnus-Aeneas-Konstellation bei Vergil.

${ }^{217}$ Vgl. Segal 1968, 442: „As a goddess both of passion and of metamorphosis par excellence, both of love and of invincible magic, Ovid's Circe comes close to summing up the underlying spirit of his poem“; ähnlich Schubert 1989b, 122 f.

${ }^{218}$ Pöschl 1959, 337 = 286 zeigt, daß bei Ovid (im Gegensatz zu anderen Gestaltungen des Cephalusund-Procris-Mythos) „das Schwergewicht und die Hauptverantwortung für das Geschehen im menschlichen Bereich“ liegt. Vgl. auch Segal 1978, 190 f.: Aurora ,plants the seed of doubt in Cephalus' mind (7.712-13), but it is Cephalus' own meditation on the godess' words which leads him to his fatal mistrust of his wife (7.714-15)“; $194 \mathrm{f}$.: „By relating the catastrophe directly to the main emotional problem between the two lovers, viz. „faith“" and „,belief“, ... Ovid shows its roots in their character. Their tragedy, though out of proportion to their fault (and far more so in Procris' case since she treats her suspicions with greater restraint than Cephalus did his), is still a result of their own inner make-up. Their own disposition causes error to explode into desaster." $\mathrm{Zu}$ der nur äußerlichen Bedeutung der Anlässe zur Eifersucht in beiden Abschnitten der Erzählung (Aurora im ersten, der anonyme Denunziant im zweiten) vgl. a.a.O. 195 f. Zusammenfassend a.a.O. 196: „This symmetry ... suggests the repetition of a self-destructive mechanism, almost the unconscious reenactment of a neurotic pattern.“

${ }^{219}$ Zur bewußten Parallelisierung dieser beiden Abschnitte der ovidischen Erzählung (Eifersucht des Cephalus und Eifersucht der Procris) - die beide mit einer morgendlichen Jagd beginnen (met. VII 700 ff. 804 ff.; teilweise bedenkliche Ausdeutungen des Jagdmotivs bei Anderson 1990, 142 f., vgl.
} 
Aurora gestiftete Unglück sich erst allmählich entwickelte und die Beziehung zwischen Cephalus und Procris eine gewissene ungünstige Eigendynamik hatte (welche sich vor allem durch die Eifersucht der beiden Eheleute entfaltete), wird hier Picus sofort nach der Zurückweisung Circes verwandelt und unmittelbar nach ihm auch seine Gattin Canens. Daraus erhellt, daß hier — anders als in der Erzählung über Cephalus und Procris - ein völlig unschuldiger Sterblicher ins Unglück gestürzt wird, indem ihn eine willkürliche Zauberin verwandelt. Genau in diesem Aspekt der skrupellosen Willkür Circes besteht aber auch die Korrespondenz zu dem ins vierzehnte Buch verlagerten Schlußteil der Scylla-Episode. Ein weiterer nicht zu unterschätzender kompositorischer Aspekt der Picus-Canens-Episode ${ }^{220}$ besteht darin, daß bereits innerhalb des griechischen Stoffs der Übergang ins italische Milieu praepariert wird $^{221}$.

Die von Ovid im folgenden beschriebenen Ereignisse bilden im wesentlichen seine Paraphrase des iliadischen Aeneisteils. Dabei werden wieder bestimmte Nebenepisoden in den Vordergrund gerückt, z.B. der Hintergrund der Tatsache, daß Diomedes die Seite des Turnus nicht unterstützen kann, nämlich die Verwandlung seiner Gefährten in Vögel. Während dieser ovidische Schwerpunkt zumindest ein rudimentäres Pendant in der iliadischen Aeneishälfte hat ${ }^{222}$, ist ein anderer Höhepunkt der Darstellung sagenchronologisch hinter die Aeneishandlung gesetzt: die Vergöttlichung des Aeneas, eine politisch-kultisch relevante Art der Metamorphose, wie sie bereits im neunten Buch bei Hercules praefiguriert wurde und später in met. XIV bei Romulus und ganz am Werkende bei Caesar sich wiederholen wird ${ }^{223}$.

Im folgenden geht die darstellende Erzählung der Metamorphosen strukturell in eine Art von Herrscherliste über: Die verschiedenen Nachfolger von Aeneas' Sohn Ascanius bzw. Iulus als Herrscher in Latium werden aufgezählt. Die Gestaltungsfreiheit Ovids bei der Behandlung dieser mythologisch-historischen Etappen besteht im wesentlichen darin, ob er den jeweiligen Herrscher nur nennt oder eine Episode aus seiner Herrschaftszeit breit darstellt. Letztere Vorgehensweise wählt er im Falle der Regierungszeit des Proca, in welche Periode die ausführlich gestaltete Liebesgeschichte zwischen Vertumnus und Pomona fällt. In diese Liebesgeschichte wiederum eingeschachtelt ist als ein argumentatives Paradigma im Munde des — in eine Greisin verwandelten - Vertumnus die unglückliche Liebe des Iphis zu Anaxarete. Das rhetorische Paradigma bleibt wie die meisten anderen Paradigmata in den Metamorphosen (die fast immer eine ausgeschlagene Möglichkeit zu einer Verhaltensänderung markieren) erfolglos ${ }^{224}$, und somit war unter erfolgsoekonomischem Gesichtspunkt die ganze Binnenerzählung (wie überhaupt die Verwandlung des Ver-

\footnotetext{
auch die Monographie von Davis) — vgl. Pöschl 1959, 338 ff. = 287 ff. Pöschl erkennt hier einen „Gegensatz zwischen der unnachsichtigen Rohheit des Mannes, der in blindwütiger Eifersucht die Geliebte erniedrigt und das gemeinsame Glück entweiht und zerstört, und der milden Güte und Hoheit der Frau, deren Liebe sich in grenzenlosem Verzeihen äußert“ (a.a.O. $340=289$ ).

${ }^{220}$ Ellsworth 1986, 31 f. vermutet hinter dieser Episode kaum zurecht eine Anspielung auf die durch das Auftreten des Aeneas gestörte Beziehung zwischen Turnus und Lavinia.

${ }^{221}$ Vgl. Ludwig 1964, 68; Baier 1999, 450.

${ }^{222}$ Verg. Aen. XI 272 ff.

223 Zum Motiv Apotheose, „das seine Dominanzphase gegen Ende des Werkes hat“, vgl. Schmidt 1991, 129 f.; 133 ff.; Lieberg 1970.

${ }^{224}$ Vgl. Barchiesi 2002, 184, der das Scheitern der meisten intradiegetischen Argumentationen innerhalb der Metamorphosen konstatiert; ähnlich Myers 1993-94, 242.
} 
tumnus in eine Greisin) überflüssig. Doch schließlich beeindruckt die ureigene Jünglingsgestalt des Gottes Pomona derart, daß sie sich Vertumnus freiwillig hingibt ${ }^{225}$.

Der letzte in met. XIV behandelte Herrscher ist der erste eigentliche römische König, Romulus. Über ihn wird eine militärische Episode aus dem Krieg gegen den Sabinerkönig Tatius und die schließliche Apotheose zusammen mit seiner Gattin Hersilia berichtet.

Als charakteristische Eigenheit des vierzehnten Metamorphosenbuchs bleibt die relativ enge Orientierung an der mythologischen Vorlage (Aeneadenfahrt, Auseinandersetzung zwischen Aeneas und Turnus in Latium, römische Herrschergeschichte) zu nennen, die nur punktuell dem Hauptthema fremde, erotisch-elegische Einsprengsel ermöglicht, welche ihrerseits meist an Nebenfiguren anknüpfen. $\mathrm{Zu}$ großen, ganze Buchhälften okkupierenden blockartigen Einschüben erotischer Art, wie sie in den ersten Büchern beobachtet werden konnten, ergibt sich keine Gelegenheit mehr. Eine spezifische Eigenart, welche sich zur punktuellen Ausschmückung des fast annalistischen Stoffs eignet, ist die Gestaltung einer Apotheose, wie sie im Falle von Aeneas und Romulus ausgeführt wird. Die Methode, Erzählblöcke (die Darstellung von Aeneas' Geschick bzw. das gesamte vierzehnte Buch) mit einer solchen Apotheose zu beschließen, bereitet auf den endgültigen Schluß der Metamorphosen im fünfzehnten Buch vor.

\subsection{5. met. XV}

Das fünfzehnte Buch beginnt mit der Person des Numa, des zweiten eigentlichen römischen Königs ${ }^{226}$. Dieser König zeichnet sich durch ein besonderes philosphisches Interesse aus, welches Numa zu einer Reise in die griechische Pflanzstadt Croton veranlaßt, in der sich der griechische Philosoph Pythagoras aufhält. An eine relativ kurze Ausführung der Gründungsaitiologie dieser Stadt im Munde eines älteren Manns schließt sich eine mehr als 400 Hexameter umfassende Oratio recta des Pythagoras an, in welcher der Philosoph unter anderem seine Auffassung von einer steten Veränderung aller Dinge ausführt. Damit wird das ovidische Metamorphosenthema in naturphilosophischer Brechung mit einer umfangreichen Exempelsammlung behandelt. Der Numa-Abschnitt ist kaum mehr als das Gefäß zu einer als eigener Großteil zu betrachtenden naturphilosophischen Erörterung 227 .

\footnotetext{
${ }^{225} \mathrm{Zu}$ dieser - im Rahmen der Metamorphosen — ungewöhnlichen Freiwilligkeit der Hingabe vgl. Schmitzer 2001, 315; Holzberg 1997, 145 f. und 1998, 93 f.; ausführlicher 1999, 320-322, wo der Kontrast zwischen Vertumnus in met. XIV und Apollo in der Daphne-Geschichte (met. I) unter dem Gesichtspunkt der ovidischen Liebeslehre betont wird (die Korrespondenz zwischen der ersten und letzten Liebesepisode der Metamorphosen behandelt auch Myers 1993-94, 225 ff.; Johnson 1997, 374 sieht in der Vertumnus-Pomona-Geschichte eine Umkehrung der in den Metamorphosen üblichen „ugly rape stories“). Zum Ausnahmecharakter des Ausgangs der Liebesgeschichte vgl. ferner Wheeler 2000, 111. Heinze 1960, 385 (vgl. auch Myers 1993-94, 244) stellt Pomona neben Leucothea, die sich Sol ebenfalls freiwillig hingibt, als dieser seine ureigene Gestalt wieder annimmt (met. IV 230 ff.). Kaum überzeugend sieht Ellsworth 1988, 340 hinter dem für Vertumnus erfolgreichen Ausgang der Geschichte die Zurückgewinnung der Penelope durch Odysseus aufgrund von dessen „,self-revelation“ wirksam.

${ }^{226}$ Genau entsprechend dem Anschluß des zweiten Buchs der ennianischen Annalen an das erste, vgl. Hofmann 1986, 225; Holzberg 1998, 82.

227 Anders Buchheit 1993, der die - rein chronologisch unmögliche, aber durch alte Tradition bezeugte - Rolle Numas als eines Weitervermittlers des durch Pythagoras vermittelten philo-
} 
Der Übergang zum zweiten, politisch-historischen Großteil von met. XV (der wiederum die beiden Themenbereiche „Einholung des Heilgottes Aesculap von Epidauros nach Rom“ und „Apotheose Caesars“ enthält) erfolgt durch zwei recht künstlich angeschlossene Geschichten. Nach dem Tod des (abgesehen von seinen philosophischen Neigungen kaum charakterisierten) Numa trauert seine Frau Egeria. Sie hält sich im heiligen Hain der Diana auf und wird von dem dort in verwandelter Form (als Gott Virbius) lebenden Hippolytus getröstet. Die konsolatorische Wirkung ergibt sich aus dem Argumentationsprinzip, daß das die tröstende Person betreffende Leid eigentlich noch viel größer ist als dasjenige, welches die zu tröstende belastet ${ }^{228}$. Dieses Prinzip gibt Hippolytus die Gegelegenheit, die Geschichte von der falschen Denunziation seiner Stiefmutter und seinem anschließenden Tod durch den aus dem Meer entstiegenen Stier zu schildern. Diese Geschichte gehört als solche weder mythenchronologisch an diese Stelle (unter diesem Aspekt wäre sie in die Nähe des Theuseus-Mythos $\mathrm{zu}$ stellen) noch weist sie über das erwähnte konsolatorische Argumentationsprinzip hinaus besondere Nähe zum Geschick der Egeria auf ${ }^{229}$ noch enthält sie eine Metamorphose. Der Sinn dieser Geschichte an dieser Stelle der Metamorphosen ergibt sich ausschließlich aus der diesem griechischen Mythos angehängten ,italisch-römischen Appendix“: Hippolytus gelangt nach seinem Tod in die Unterwelt, wird aber von dem Heilgott Aesculap wieder zum Leben erweckt. Da eine solche Wiedererweckung notwendig mit der Mißgunst anderer Götter einhergeht, wird Hippolytus von seiner Schutzgottheit Diana in ihrem heiligen Hain versteckt; er erhält den neuen Namen Virbius und wird in eine der ,untergeordneten Gottheiten“ ${ }^{‘ 230}$ verwandelt. Diese Appendix dient offenkundig dem Zweck, den Heilgott Aesculap bereits als einen möglichen Retter im Falle einer Notsituation, wie sie sich in der wenig später geschilderten römischen Pest ergeben wird, zu profilieren. Diese Erwähnung vom machtvollen Eingreifen des Heilgotts läßt den Leser zugleich die Einführung dieser Gottheit als Sohn des Apollo und der Coronis und ferner die Prophezeiung über seine göttlichen Leistungen im Munde der Ocyroe in met. II rekapitulieren und bereitet damit den Boden für die den zweiten Großteil einleitende Erzählung über die Einholung des Heilgotts nach Rom.

Gleichermaßen der Überleitung zum Folgenden dient die Episode von Cipus, deren erzähltechnischer Anschluß noch künstlicher wirkt. Egeria trauert, unbeeindruckt von den konsolatorischen Bemühungen des Hippolytus-Virbius, weiter und wird schließlich von Diana aus Mitleid in einen Fluß verwandelt. Das Erstaunen des Hippolytus über diese Verwandlung wird durch ein dreifaches Gleichnis beleuchtet, welches Ovid die Gelegenheit gibt, drei weitere Metamorphosen in recht äußerlicher Weise und ohne organische Bindung an sein Erzählgefüge anzuschließen ${ }^{231}$ (die Technik, an das Erstaunen einer Person weitere Metamorphosen auf dem Wege eines Vergleichs mechanisch anzuschließen, hat Ovid bereits im zehnten Buch in der Orpheus-Erzählung praktiziert ${ }^{232}$ ). Von diesen drei Vergleichen wird nur der dritte zu

sophischen Guts an die Römer betont und eine vom Dichter intendierte Vorbildfunktion dieses Königs für Ovids Zeitgenossen und insbesondere Augustus annimmt.

${ }^{228}$ met. XV 530 f. Num potes aut audes cladi conponere nostrae,/ Nympha, tuam?

${ }^{229}$ Vgl. Bartenbach 1990, 295 ff., die herausstellt, daß Hippolytus äußeres Leid erfährt, wohingegen der Kummer Egerias (die Trauer über den Tod Numas) innerlich ist, weshalb Hippolytus als Tröster scheitern muß. Zum fast regelmäßigen Scheitern intradiegetischer Redeabsichten in den Metamorphosen vgl. oben Anm. 224.

${ }^{230}$ met. XV 545.

${ }^{231}$ Granobs 1997, 35 spricht von einer „,denkbar oberflächlichen Art der Anknüpfung“‘.

${ }^{232}$ met. X $64 \mathrm{ff}$. 
einer kleinen Geschichte ausgestaltet. Die Geschichte handelt von einem römischen Beamten namens Cipus nicht näher zu bestimmender Zeit, der aus Furcht vor der Prophezeiung, er werde als König über Rom herrschen, wenn er die Stadt betrete, die freiwillige Verbannung einer Rückkehr nach Rom vorzieht. Diese - als einer von drei Vergleichen ohne chronologische Rücksicht auf die im Rahmen der Königsliste gerade behandelte Epoche (Numa) angeschlossene - Erzählung antizipiert den kühnen Sprung von der frühesten Königszeit in die Republik ${ }^{233}$, welchen Ovid unternimmt, wenn er im folgenden zur Einholung des Heilgotts Aesculap übergeht. Insofern die Furcht vor dem Königtum als unausgesprochene Voraussetzung über der Geschichte schwebt, muß es sich um ein Ereignis aus republikanischer Zeit handeln, welches jedoch den unmittelbaren thematischen Bezug zur Königsepoche in sich trägt. Ähnlich hatte Ovid den Übergang von der griechischen zur römischen Epoche angekündigt, indem er Macareus im Zusammenhang der Fahrten des Aeneas die Geschichte von dem italischen König Picus und seiner Gattin Canens erzählen ließ. Sowohl die Hippolytus-Erzählung als auch die in Vergleichsform angeschlossene Cipus-Episode $^{234}$ dienen also der Überleitung vom ersten (römische Königszeit: Numa; Pythagoras und seine Philosophie) zum zweiten Großteil (römische Republik: Aesculap und Caesar) des fünfzehnten Buches.

In diesem zweiten Großteil werden Aesculap und Caesar vom Dichter explizit parallelisiert unter dem Gesichtspunkt der Göttlichkeit: Während Aesculap als ein „Neuankömmling“ in den römischen Kult kam, wird Caesar ,in seiner eigenen Stadt“ Gott $^{235}$ (die Funktion der Apotheose als ein Erzählblöcke abschließender Signalpunkt ist bereits im vierzehnten Buch vorbereitet worden). Die Darstellung trägt dezidiert epische Züge, zumal im Caesar-Abschnitt, wo Venus bei den Göttern über das Unglück ihrer Nachkömmlinge Klage führt und von Jupiter durch einen Blick in die (natürlich von Augustus geprägte) Zukunft beruhigt wird - ganz in Entsprechung zum ersten Aeneis-Buch ${ }^{236}$; das Vorbild der ganzen Szene wird von der Sprecherin Venus selbst offenbart durch einen Verweis auf ihren einstigen Schützling Aeneas ${ }^{237}$. Die vergilische Geschichtskonzeption, die in der Aeneis auf eine ferne mythische Vergangenheit angewandt wird (Augustus als lohnendes Ziel aller Anstrengungen mythischer Gründungsheroen), wird hier von Ovid übertragen auf die unmittelbar vor Augustus liegende Epoche ${ }^{238}$. Der schwerpunktmäßig philosophisch geprägte erste Großteil des fünfzehnten Buchs erhält ein deutliches Gegengewicht durch den episch bestimmten zweiten ${ }^{239}$.

\footnotetext{
${ }^{233} \mathrm{Zu}$ dieser „Lücke“ in der ovidischen Darstellung vgl. Granobs 1997, 131. Fragwürdig ist die Auffassung von Wheeler 2000, 129 f., der Cipus als Praefiguration von Caesar bzw. Augustus zu verstehen tendiert. Insofern Cipus die Monarchie im Sinne des republikanischen Wertesystems konsequent ablehnte, könnte eine solche Parallelisierung, wenn sie von Ovid intendiert wäre, nur zum Nachteil von Caesar bzw. Augustus wirken.

${ }^{234}$ Kritisch gegen eine Einordnung der Cipus-Geschichte in die Kategorie der „link episodes“ äußert sich Galinsky 1967, $182 \mathrm{f}$.

${ }^{235}$ met. XV $745 \mathrm{f}$.

236 Tissol 1993, 77 f. sieht hinter dieser Vergil-Imitation nur „comical exaggeration“. Zur entsprechenden grundsätzlichen Streitfrage um die ,ovidische Aeneis“"vgl. oben Anm. 193.

${ }^{237}$ met. XV $771 \mathrm{ff}$.

${ }^{238}$ Vgl. Smith 1994, 52: ,... distant prophecy in Aen. 1 has now become present reality in Met. 15“ (vgl. auch a.a.O. 50: ,... Ovid updates the epic situation ... He thus reshapes and modernizes the tradition that he inherits, most recently, from Virgil").

${ }^{239}$ Zum Fehlen erotischer Elemente in met. XV vgl. Holzberg 1998, 93.
} 


\section{Das Problem der Buchgrenzen}

Die Abgrenzungen zwischen den einzelnen Metamorphosenbüchern ${ }^{240}$ sind im Sinne der hier versuchten Abteilung in Großteile konträrer (meist entweder epischerhabener oder elegisch-erotischer Ausprägung) recht klargeschnitten und tendieren eher dazu, die Einzelabschnitte mit deutlicher Schärfe herauszustellen als sie durch fließende Übergänge zu verwischen ${ }^{241}$.

So wird am Ende des ersten Buchs, ehe die Handlung sich am Anfang von met. II zu kosmischer Erhabenheit erhebt, noch die in naiv-kindlicher Sphäre spielende Vorgeschichte abgehandelt, der Streit zwischen Epaphus, dem Sohn der Io, und Phaethon sowie die Tröstung des letztgenannten durch seine Mutter. Unmittelbar vor dem Schluß des ersten Buchs macht sich Phaethon auf den Weg zur überirdischen Sonnenburg, und daß der folgende Abschnitt der Geschichte auf übermenschlichem Niveau spielt, wird durch die programmatische Formulierung concipit aethera mente (I 777) verdeutlicht. Dieses Niveau ist gerade am Anfang von met. II erreicht, wo die Sonnenburg ausführlich beschrieben wird; deren eindrucksvolle materielle Ausstattung (II 1-4) wird auf dem Weg einer erneuten Steigerung (II 5 Materiam superabat opus) noch überboten durch eine Bildbeschreibung (II 5-18), welche wiederum programmatisch — den kosmischen Charakter der folgenden Ereignisse (Sturz des Sonnenwagens) praefiguriert, die wie die Bildbeschreibung alle Bereiche der Welt (Meer, Erde und Himmel) tangieren werden.

Ein ähnlich programmatischer Genrewechsel findet sich an der Grenze zwischen met. II und met. III: Bereits oben wurde angedeutet, daß das erotische Vorspiel (Jupiter und Europa) zu der ernsten epischen Episode der thebanischen Stadtgründung bewußt in den zu großen Teilen erotisch geprägten zweiten Großteil von met. II verlagert ist. In Jupiter vereinigen sich nicht ohne Widersprüche zwei konträre Rollen, die des besorgten Weltenlenkers und die des lasziven Liebhabers: Non bene conveniunt nec in una sede morantur/ Maiestas et amor (II $846 \mathrm{f}$. - eine für das Verständnis des offenbar intendiertermaßen in sich widersprüchlichen ovidischen Götterbilds höchst bedeutsame Aussage). Indem sich Jupiter in einen Stier verwandelt, legt er die Rolle des Weltenlenkers symbolisch ab (I 847-850 sceptri gravitate relicta/ Ille pater rectorque deum, cui dextra trisulcis/ Ignibus armata est, qui nutu concutit orbem,/ Induitur faciem tauri). Die neue erotische Rolle wird jedoch genau am Anfang des dritten Buchs ebenso nachdrücklich - verdeutlicht durch die sprachlich entsprechende Form eines Ablativus absolutus wieder abgelegt (II $1 \mathrm{f}$. Iamque deus posita fallacis imagine tauri/ Se confessus erat). Nach dieser „Rückverwandlung“ kann Jupiter wieder die Rolle spielen, die er in der thebanischen Gründungsgeschichte spielen muß: die des Theben begünstigenden Widerparts zu der gegen die neugegründete Stadt stets aus persönlichen Gründen intrigierenden Götterkönigin Juno.

Der Übergang vom drittem zum vierten Buch ist nicht durch einen Genrewechsel bestimmt, da - wie oben gezeigt — zu Beginn des vierten Buchs chiastisch bzw. spiegelsymmetrisch auf den Schluß des dritten zurückgegriffen wird. Die den

\footnotetext{
${ }^{240}$ Eine systematische Untersuchung sämtlicher Buchgrenzen bietet Holzberg 1998.

${ }^{241}$ Diese als communis opinio angesehene Auffassung über die Buchgrenzen in den Metamorphosen formuliert etwa Schetter 1960, 94 (mit einer Doxographie älterer, in die gleiche Richtung gehender Urteile in Anm. 31).
} 
Schluß von met. III und den Anfang von met. IV verbindende Komponente ist vor allem das bacchische Element: Pentheus und die Minyaden haben den vergeblichen und verderblichen Widerstand gegen den Kult der neuen Gottheit gemeinsam, und so setzt der Dichter am Buchübergang moralisierend die Minyaden den übrigen Ismenides entgegen, die aus dem Untergang des Pentheus ihre Lehre zogen (III 732 IV 2):

Talibus exemplis monitae nova sacra frequentant

Turaque dant sanctasque colunt Ismenides aras.

IV 1 At non Alcithoe Minyeias orgia censet

Accipienda dei ...

Damit wird das Verhalten der Minyaden summarisch als ein Fehlverhalten dargestellt und insbesondere das Fehlen einer adaequaten gedanklichen Reaktion bei den Figuren der folgenden Geschichte auf den Ausgang der vorausgegangenen Episode hervorgehoben. In analoger Weise bildet die (dort gleichwohl erfolgende) gedankliche Reaktion einer Person der Handlung auf die zuletzt erzählte Episode in met. V/ VI den Buchübergang: Minerva billigt das Vorgehen der Musen gegen die impertinent mit ihnen rivalisierenden Pieriden und entschließt sich infolgedessen $\mathrm{zu}$ einem ähnlich rigorosen (bei genauerer Betrachtung noch viel grausameren) Vorgehen gegen ihre eigene künstlerische Rivalin Arachne. In diesen beiden Fällen stehen die durch die Buchgrenze getrennten Handlungen einander derart nahe, daß die zweite als Resonanz bzw. Nicht-Resonanz auf die erste aufgefaßt werden kann. Dieser Typos des Buchübergangs ist natürlich in solchen Fällen, wo das neue Buch mit einem programmatischen Genrewechsel beginnt (wie am Anfang von met. II und met. III) von vorneherein ausgeschlossen.

Das fünfte Buch beginnt mit einem sich unmittelbar an die Erzählung des Perseus über seine früheren Taten anschließenden Schlachtgetümmel (1-4):

Dumque ea Cephenum medio Danaeius heros

Agmine commemorat, fremida regalia turba

Atria conplentur, nec coniugialia festa

Qui canat est clamor, sed qui fera nuntiet arma.

Diese unmittelbare Konfrontation von wörtlicher Rede und einem tätlichen Angriff gegen den Sprechenden (die sich am Anfang von met. XI beim Tod des Orpheus mit signifikanten Reminiszenzen wiederholt) verdeutlicht in diesem Fall die oben erläuterte konzentrierte Verdichtung zwischen odysseischem Tatenbericht und iliadischem Kampfgeschehen; verbunden werden die beiden durch die Buchgrenze getrennten Strukturteile durch die Identität des Schauplatzes (Hochzeitsgelage).

Der Auftakt des sechsten Buchs schließt wie derjenige des fünften unmittelbar an eine Oratio recta an, jedoch nicht im Sinne eines tätlichen Angriffs gegen den Sprechenden, sondern in Form einer gedanklichen Reaktion auf das berichtete Geschehen, welches sich dann im neuen Buch in einer (zumindest äußerlich) ähnlichen Handlungsstruktur widerspiegelt (vgl. oben zum Auftakt von met. IV).

Der Übergang met. VI/ VII hat bemerkenswerte Ähnlichkeiten mit met. I/ II. Am Schluß des sechsten Buchs werden die beiden Söhne des Windgotts Boreas und der Athenerin Orithyia mitsamt ihrer Kindheitsgeschichte abgehandelt, ähnlich wie am Ende von met. I die letzte Liebesgeschichte (Jupiter und Io) durch ein Kindheitserlebnis von deren Sohn Epaphus erweitert wird. Damit werden jeweils Kindheitserlebnisse von Helden des folgenden Buchs (Phaethon bzw. Calais und Zetes) noch in den Bereich erotisch-episodischer nugae verwiesen, während die erste nennenswerte Unternehmung der jeweiligen Helden (Phaethons Fahrt mit dem 
Sonnenwagen bzw. die Argonautenfahrt, vgl. VI 719 Ergo ubi concessit tempus puerile iuventae) an der Schnittstelle zum neuen Buch programmatisch einen epischen oder zumindest auf den ersten Blick episch wirkenden Großteil einleitet. Die Kindheitserlebnisse werden noch dem erotisch-elegischen Bereich des elterlichen Liebesverhältnisses beigegeben, während die erste Unternehmung des bzw. der jungen Helden einen neuartigen eposähnlichen Erzählblock einleitet. Der Erhabenheitsgrad der Handlung ist entscheidender für die Buchabgrenzung als die sonst öfters einigend wirkenden Faktoren „Einheit der Person“ bzw. „Einheit der Handlung“; Ovid will durch die Buchgrenzen primär Erhaben-Episches von Erotisch-Genrehaftem distanzieren und nicht etwa sachlich geschlossene oder um Personen zentrierte Ereigniskomplexe strukturell vereinigen.

Auch die Buchgrenze zwischen met. VII und met. VIII wird durch einen programmatischen Genrewechsel bestimmt: Am Ende vom siebenten Buch mutiert der zuvor als elegischer Erzähler profilierte Cephalus wieder zum epischen Helden (863-865 Flentibus haec lacrimans heros memorabat: et eccel Aeacus ingreditur duplici cum prole novoque/ Milite, quem Cephalus cum fortibus accipit armis $)^{242}$. Auf der so erreichten episch-militaerischen Ebene wird nach fünf Versen im neuen Buch einfach mit einem Interea die Seite gewechselt von der athenischen Partei (Cephalus) zur kretischen (Minos). Auch in der Aeneis wird zweimal mit einem interea an einer Buchgrenze die Perspektive gewechselt (Aen. IV/ V: von Dido zu Aeneas; Aen. IX/ $\mathrm{X}$ : von den Menschen zu den Göttern), aber dort findet sich der mit interea bezeichnete Wechsel bezeichnenderweise jeweils exakt in der Buchgrenze, während er hier — im Falle von met. VII/ VIII — um einige Verse hinter die Buchgrenze versetzt wird, die ihrerseits nicht durch einen Perspektivenwechsel, sondern durch einen Genrewechsel (epische Kampfschilderung statt elegischer Erzählung, sich manifestierend im „Rollenwechsel“ des Cephalus) bestimmt ist.

Der Beginn des neunten Metamorphosenbuchs zertrennt bei oberflächlicher Betrachtung die Wiedergabe des Achelous-Symposions, insofern die letzte Erzählung über den Ringkampf zwischen Achelous und Hercules in das folgende Buch verlagert wird. Richtet man seinen Blick jedoch genauer auf die thematische Ausprägung der einzelnen Binnenreden, so erkennt man, daß bis zum Ende des achten Buchs die metapoetisch-reflektive Metamorphosenthematik im Mittelpunkt bleibt: Achelous führt den Ringkampf als ein Exempel für die spezielle Metamorphosenausprägung „multiple Verwandlungsgabe“ ein (VIII 879 f. Quid moror externis? etiam mihi saepe novandi est/Corporis, o iuvenis, numero finita potestas). Dieser Einführung folgt eine Angabe des schmählichen Ergebnisses der Auseinandersetzung (des Verlusts eines Horns der Stiergestalt), woran sich dann zu Beginn des neuen Buchs die mitleidsvolle Frage des Theseus nach dem genauen Hintergrund dieser Mißhandlung anschließt, welche dann wiederum zu einer ausführlichen epischen Erzählung des Kampfes Anlaß gibt. Damit ist der Übergang vom thematischen Aspekt (Metamorphosenthematik im zweiten Großteil von met. VIII) zu epischer Kampfschilderung („Herculeis“ im ersten Großteil von met. IX) ${ }^{243}$ geschafft, und es muß nur noch nach der Erzählung des Achelous der formal-intradiegetische Charakter der Darstellung (gewissermaßen ein Relikt aus dem vorigen Buch) beiseitegeschoben werden, was durch die unmittelbare, kontrastive Anknüpfung des Fortgangs der Erzählung (Nessus, Deianira und Hercules, IX $101 \mathrm{ff}$.) an den Inhalt der Binnenrede (Achelous und Hercules) in zwar unkonventioneller, aber doch höchst ökonomischer Weise

\footnotetext{
${ }^{242}$ Vgl. Holzberg 1998, 84.

${ }^{243}$ Vgl. Holzberg 1998, $83 \mathrm{f}$.
} 
gelingt. Einer scheinbaren Vermeidung harter Übergänge durch die Hinüberziehung der letzten Rede des Symposions ins neue Buch steht also bei genauerer Betrachtung eine scharfe Separierung des neuen epischen Stoffs von der metapoetisch-reflexiven Thematik der Gelageerzählungen gegenüber.

$\mathrm{Zu}$ Beginn des zehnten Buchs ist der Metamorphosendichter wieder in der Lage, keinen Genrewechsel motivieren zu müssen, sondern innerhalb des erotischen Themenkreises verharren zu können. Es findet lediglich ein kontrastiver Übergang statt von zunächst aussichtslos erscheinender, dann aber unerwartetermaßen doch noch erfolgreich verlaufender Erotik (Iphis und Ianthe) zu einem von vorneherein unter einem Unstern stehenden und schließlich auch katastrophal endenden Liebesverhältnis (Orpheus und Eurydike) ${ }^{244}$. Dieser Wechsel wird formal bewerkstelligt durch eine am Anfang von met. X geschilderte Weiterbewegung des im vorletzten Vers von met. IX eingeführten Hochzeitsgotts Hymenaeus, der von Orpheus ,vergeblich herbeigerufen wird“ (X 3). Diese Übergangstechnik antizipiert symbolisch die Einführung einer sich aus der unglücklichen Beziehung des Orpheus zu Eurydike herausentwickelnden pervertierten Form von Sexualität (der Knabenliebe), die dem großen Binnengesang des zehnten Buchs zumindest einen formalen Rahmen gibt.

Der Auftakt des elften Metamorphosenbuchs schildert die Aggression der thrakischen Bacchantinnen gegen den Sänger Orpheus und schließt unmittelbar an den bis an das Ende von met. X geführten Binnengesang des Orpheus an. Diese charakteristische Form eines Buchauftakts (plötzliche Aggression gegen den Sprecher bzw. Sänger einer Binnenrede bzw. eines Binnengesangs) knüpft mit signifikanten Korrespondenzen an den Auftakt von met. V an, wie die folgende Gegenüberstellung verdeutlicht:

met. XI 1-8

Carmine dum tali silvas animosque ferarum

Threicius vates et saxa sequentia ducit,

Ecce nurus Ciconum tectae lymphata ferinis

Pectora velleribus tumuli de vertice cernunt

$5 \quad$ Orphea percussis sociantem carmina nervis.

E quibus una leves iactato crine per auras:

„En", ait „en hic est nostri contemptor!“ et hastam

Vatis Apollinei vocalia misit in ora.

met. V $1-10$

Dumque ea Cephenum medio Danaeius heros

Agmine commemorat, fremida regalia turba

Atria complentur, nec coniugialia festa

Qui canat est clamor, sed qui fera nuntiet arma,

$5 \quad$ Inque repentinos convivia versa tumultus

Adsimilare freto possis, quod saeva quietum

Ventorum rabies motis exasperat undis.

Primus in his Phineus, belli temerarius auctor,

Fraxineam quatiens aeratae cuspidis hastam, „En, “ ait „, en adsum praereptae coniugis ultor/..."

${ }^{244}$ Vgl. Holzberg 1998, 85. 
In beiden Fällen leitet eine emotionale Rede der angreifenden Instanz (der Bacchantinnen bzw. des Phineus) von rhetorischer bzw. musikalischer Erzählung zu brutalem Kampfgeschehen über. Im Falle von met. IV/ V führt dieses neu ausbrechende Kampfgeschehen die bereits im vorigen Buch — sowohl in direkter auktorialer Erzählung als auch in Form einer homodiegetischen Binnenerzählung des Perseus selbst - begonnene Schilderung der Taten des Perseus fort, bewirkt also, abgesehen von einem Übergang zu einem „odysseischen“ zu einem ,iliadischen“ Abschnitt, keinen wirklichen Wechsel des Darstellungsgenres. Anders steht es dagegen beim Übergang von met. X zu met. XI: Die erotischen Erzählungen des Orpheus nehmen ein jähes Ende, die wilden Bacchantinnen stören sich an der (vermeintlichen) homosexuellen Tendenz seines Gesanges und seiner neuen Lebensweise und richten sich gewalttätig gegen ihn. Hier prallen zwei konträre Darstellungsgenres scharf aufeinander: einerseits ein Liebesgesang, der sich an seinem Anfang programmatisch gegen epische Darstellung bekennt, und andererseits eine brutale Tötungsszene, die dann über das Verbindungsmotiv der göttlichen Bestrafung durch Bacchus bzw. Apollo zum kriegerischen Trojamythos hinführt.

Das zwölfte Metamorphosenbuch wird eingeleitet durch das Motiv der Unwissenheit des Priamus über die Verwandlung seines Sohns Aesacus. Die Unwissenheit eines Vaters über die Verwandlung seines Kindes begegnet abgesehen von der hier besprochenen Buchgrenze auch an anderen strukturellen Verknüpfungspunkten in den Metamorphosen (I 583 ff.: Inachus; IV 563 ff.: Cadmus). Charakteristisch für den hier praktizierten Buchübergang ist, wie der Dichter die Geschicke von $\mathrm{zw}$ e i Söhnen des Priamus über die Buchgrenze hinweg miteinander konfrontiert: Aesacus ist nach seiner Vorstellung zwar ein dem höfischen Geschehen in Troja abgewandter und dem Landleben zugetaner Typ, also ein typisch elegischer Held (XI 764 ff.), der aber im Falle eines längeren Lebens durchaus einen ebenso bedeutenden Namen wie der berühmte Kämpfer Hector hätte erlangen können (759 ff.); dagegen ist Paris als Verursacher des Trojanischen Kriegs zwar ein epischer Held in höchster Potenz, aber unter den übrigen Trojakämpfern steht er doch immer wieder im Rufe eines weichlichen Frauenhelden. Die ovidische Aesacus-Geschichte nimmt ihren Ausgangspunkt bei einem ehrenden Vergleich des Aesacus mit Hector (759 ff.) und verläuft dann völlig in erotisch-elegischen Bahnen, während Paris am Anfang des neuen Buchs (XII 5) kurz als neuer Ehemann der Helena eingeführt wird, bevor die dezidiert epische Handlung des zweiten Trojanischen Kriegs einsetzt. Mit den Typen Aesacus und Paris werden auch die konträren Typen der ovidischen Erzählung miteinander konfrontiert (erotische Erzählung mit epischem Ansatzpunkt bzw. epische Erzählung mit erotischem Ansatzpunkt), und die zu einer Totenfeier führende Unwissenheit des Priamus am Anfang des neuen Buchs bildet den Scharnierpunkt, durch den beide Erzählungen mit ihren charakteristisch konträren Tendenzen scharf voneinander abgesetzt werden.

Das zwölfte Buch endet mit der Exposition der Situation des Armorum iudicium, dessen Verlauf beginnend mit met. XIII 1 geschildert wird. Am Ende des zwölften Buchs wird diese Auseinandersetzung noch als eine (metaphorische) Fortführung des eigentlichen Kriegs dargestellt (620 f.):

Ipse etiam, ut, cuius fuerit, cognoscere posses,

Bella movet clipeus, deque armis arma feruntur.

Insofern erscheint der „Wettkampf um die Waffen“ zunächst nur als eine Fortführung des eigentlichen Kriegsgeschehens auf anderer Ebene, gewissermaßen eine Miniaturabbildung des Trojanischen Kriegs in einer Redeschlacht. In der Tat spiegeln sich in 
den Reden des Agons viele Details des Krieges, die in dessen eigentlicher Darstellung überhaupt nicht erwähnt wurden, so daß sich hier tatsächlich eine Art intradiegetischer Fortführung des eigentlichen Kriegsgeschehens ergibt. Die eigentliche (extradiegetische) Kampfschilderung ist aber mit dem Beginn des von Achills Waffen initiierten „Kampfes“ genaugenommen fast vollständig abgeschlossen: Denn nach der Wiedergabe der beiden Reden (fast 400 Verse) wird der Untergang Trojas in kaum zwei Hexametern (XIII 403 f.) abgetan. Die im folgenden breiter ausgeführten Episoden (Hecuba, Aurora, Anius) blicken wie die beiden Agonreden aus der Retrospektive (und insbesondere aus der Perspektive von durch den Krieg Betroffenen) auf die Kriegsereignisse zurück. Der Beginn des dreizehnten Buchs markiert den Übergang von der direkten auktorialen Schilderung des Kriegsgeschehens zu dieser Retrospektive aus der Sicht betroffener Figuren. Diese neue Darstellungsform reicht über die äußeren Endpunkte der Geschehenskomplexe hinaus: Sie beginnt vor dem eigentlichen Kriegsende und ragt bis in die erste Episode der Aeneadenfahrt (Anius) hinein.

Das vierzehnte Buch beginnt mit der geographischen Bewegung des Glaucus hin zu der Insel der Circe. Diese Bewegung findet ein intertextuelles Echo in der späteren Warnung vor einer solchen Bewegung in Richtung Circes, welche der Binnenerzähler Macareus an Aeneas richtet (XIV 247 fuge litora Circes). Die beiden derartig innerhalb des vierzehnten Buchs miteinander korrespondierenden CirceEpisoden umschließen nun ein Segment der Aeneadenfahrt (XIV 75-157), welches kaum zufällig genau der ersten Hälfte der vergilischen Aeneis entspricht: Es beginnt mit dem Seesturm, welcher die Aeneaden von der italischen Küste nach Afrika zurückwirft, und endet mit der Rückkehr des Aeneas aus der Unterwelt; met. XIV 157 Litora adit nondum nutricis habentia nomen mutet an wie eine beckmesserische Korrektur von Aen. VI 900 Tum se ad Caietae recto fert limite portum (denn insofern die Amme erst am Anfang von Aen. VII stirbt, kann der Hafen zu diesem Zeitpunkt strenggenommen noch nicht so heißen), und die Fortführung der Aeneashandlung nach dem langen Binnengespräch zwischen Achaemenides und Macareus, die Bestattung der Amme Caieta (XIV 441-444), korrespondiert mit der analogen Verstetrade Aen. VII 1-4. Folglich scheinen die beiden auf die Odyssee-Figur Circe bezüglichen Episoden am Anfang und in der Mitte von met. XIV einen kompositorischen Rahmen um die ovidische Gestaltung der odysseischen Aeneishälfte zu legen. Dieser Gesamtabschnitt umfaßt die Verse met. XIV 1-440, also ungefähr die Hälfte des vierzehnten Buchs (insgesamt ca. 850 Verse). Insofern die zweite Hälfte mit der signalhaften Bestattung der Amme Caieta beginnt und sich dann den Kämpfen des Aeneas in Latium zuwendet (programmatisch 450 Non sine Marte tamen), darf man vielleicht sogar - entgegen den oben gemachten Aussagen zum Fehlen einer dichotomischen Zweiteilung in met. XIV — auch hier eine rudimentäre Dichotomie annehmen, welche die Unterteilung der Aeneis in eine odysseische und eine iliadische Hälfte reflektiert: Bis Vers 440 wird die odysseische Hälfte reproduziert, umschlossen von zwei nicht-homerischen Episoden über die odysseische Figur Circe, und mit Vers 441 beginnt das ovidische Pendant zur iliadischen Aeneishälfte; allerdings füllt dieses Pendant nicht die zweite Buchhälfte, sondern endet bereits mit met. XIV 572 f., und im Rest des vierzehnten Buchs wird die italische Herrschergeschichte bis zum ersten römischen König Romulus wiedergegeben. Allerdings hindert nichts daran, die erste Hälfte von Buch XIV als die Darstellung der abenteuerlichen Anreise der Trojaner nach Italien und die zweite Hälfte als die Schilderung ihrer genealogisch zu verstehenden Festsetzung in Latium bis hin zum 
ersten römischen König auszudeuten; die Gesamtstruktur von met. XIV scheint ansatzweise von der Dichotomie der vergilischen Aeneis geprägt.

Der Anfang des fünfzehnten Buchs markiert insofern einen gewissen Wechsel des Erzählgenres, als der neue König Numa mit seinen im Vergleich zu dem kriegerischen Romulus weitläufigeren philosophischen Interessen (5 f. animo maiora capaci/ Concipit, vgl. den „Aufschwung“ zu kosmischer Erzähldimension in met. I 777 concipit aethera mente) auf die durch die Pythagorasrede geprägte erste, philosophisch ausgerichtete Buchhälfte von met. XV vorbereitet: Der Gegensatz zwischen dem Naturell beider an dieser Buchgrenze konfrontierter Könige reflektiert - vergleichbar der Funktion der Priamussöhne Aesacus und Paris an der Buchgrenze met. XI/ XII - den Genrekontrast zwischen der ersten Buchhälfte von met. XV und der zweiten von met. XIV, die — abgesehen von der Vertumnus-Pomona-Episode weitgehend militärisch bestimmt ist. Im ganzen vermag sich Ovid hier natürlich nicht mehr aus der annalistisch geprägten Struktur seiner historischen Vorlage (römische Königsliste) zu lösen, und so kann er nicht mehr — wie so oft in den früheren Büchern - einen elegisch-erotischen Abschnitt an der Buchgrenze programmatisch mit einem episch-militärischen konfrontieren. Diese Besonderheit der Quellenlage (Konfrontation zweier etwas verschieden nuancierter „annalistischer“ Blöcke) schlägt sich in der bereits oben berührten ${ }^{245}$ intertextuellen Aneignung der ersten Buchgrenze aus den ennianischen Annalen (ann. I/ II) nieder.

Privatdozent Dr. Thomas Gärtner

Universität zu Köln, Institut für Altertumskunde

E-Mail:th-gaertner@gmx.de

${ }^{245}$ Vgl. Anm. 226. 


\section{Literaturverzeichnis}

Adamik, T. (1999) ,In speciem unius corporis. Struktur und Botschaft von Ovids Metamorphosen.' - Ovid. Werk und Wirkung. Festgabe für Michael von Albrecht zum 65. Geburtstag, Teil I, ed. W. Schubert, Bern, Frankfurt a.M.: Lang (Studien zur klassischen Philologie; 100), 257-268.

Albrecht, M. von (2000) Das Buch der Verwandlungen. Düsseldorf, Zürich: Artemis \& Winkler.

Anderson, W. S. (1963) ,Multiple Change in the Metamorphoses.' - TAPhA 94, 127.

Anderson, W. S. (1982) ,The Orpheus of Virgil and Ovid: flebile nescio quid.' Orpheus. The Metamorphoses of a Myth, ed. J. Warden, Toronto: University of Toronto Press, 25-50.

Anderson, W. S. (1989a) ,The Artist's Limits in Ovid: Orpheus, Pygmalion, and Daedalus.' - Syllecta Classica 1, 1-11.

Anderson, W. S. (1989b) ,Lycaon: Ovid's Deceptive Paradigm in Metamorphoses 1.' - ICS 14, 91-101.

Anderson, W. S. (1990), The Example of Procris in the Ars Amatoria.' - Cabinet of the Muses. Essays on Classical and Comparative Literature in Honor of Thomas G. Rosenmeyer (edd. M. Griffith et D. J. Mastronarde), Atlanta: Scholars Press, 131-145.

Baier, Th. (1999) ,Die Wandlung des epischen Erzählers. Apologe bei Homer, Vergil und Ovid.' - Hermes 127, 437-454.

Barchiesi, Al. (2002) ,Narrative technique and narratology in the Metamorphoses.' The Cambridge Companion to Ovid, ed. Ph. Hardie, Cambridge: Cambridge University Press, 180-199.

Barnard, M. E. (1975/76) ,Ovid's Apollo and Daphne: A foolish god and a virgin tree.' - Anales de historia antigua, medival y moderna 18/19, 353-362.

Bartenbach, Al. (1990) Motiv- und Erzählstruktur in Ovids Metamorphosen. Das Verhältnis von Rahmen- und Binnenerzählungen im 5., 10. und 15. Buch von Ovids Metamorphosen. Frankfurt a.M.: Lang. (Studien zur klassischen Philologie; 52.)

Bernsdorff, H. (1997) ,Arachnes Efeusaum (Ov. Metamorphosen 6,127-8).' Hermes 125, 347-356.

Binroth-Bank, Chr. (1994) Medea in den Metamorphosen Ovids. Frankfurt: Lang. (Europäische Hochschulschriften, Reihe XV; 62.)

Bömer, Fr. (1969 ff.) P. Ovidius Naso. Metamorphosen. Kommentar. Heidelberg: Winter.

Brenk, F. E. (1999) ,Non inpune negare: Theme and Ideology in the Galatea and the Cyclops Story of Ovid's Metamorphoses.' - F. E. Brenk, Clothed in purple light. Studies in Vergil and in Latin literature, including aspects of philosophy, religion, magic, Judaism, and the New Testament background, Stuttgart: Steiner, 176-183.

Bretzigheimer, G. (1994) ,Diana in Ovids „Metamorphosen“.' - Gymnasium 101, 506-546.

Buchheit, V. (1966) ,Mythos und Geschichte in Ovids Metamorphosen I.' - Hermes 94, 80-108.

Buchheit, V. (1993) ,Numa - Pythagoras in der Deutung Ovids.' - Hermes 121, 77 99. 
Cahoon, L. (1996) ,Calliope's Song: Shifting Narrators in Ovid, Metamorphoses.' Helios 23, 43-66.

Classen, C. J. (1992) ,Ennius: ein Fremder in Rom.' - Gymnasium 99, 121-145.

Clauss, J. J. (1989), The episode of the Lycian farmers in Ovid's Metamorphoses.' HSPh 92, 297-314.

Coleman, K. M. (1990) ,Tiresias the judge: Ovid Metamorphoses 3.322-38.' - $C Q$ 84, 571-577.

Coleman, R. (1971) ,Structure and Intention in the Metamorphoses.' $-C Q 65,461-$ 477.

Crabbe, A. (1981) ,Structure and Content in Ovid's Metamorphoses.' - ANRW II.31.4, 2274-2327.

Davis, Gr. (1983) The Death of Procris. „Amor" and the Hunt in Ovid's Metamorphoses. Roma: Edizioni dell'Ateneo. (Instrumentum Litterarum; 2.)

Dippel, M. (1990) Die Darstellung des trojanischen Krieges in Ovids Metamorphosen (XII 1 -XIII 622). Frankfurt a.M.: Lang. (Europäische Hochschulschriften, Reihe $\mathrm{XV} ; 46$.

Doblhofer, E. (1960) ,Ovidius urbanus. Eine Studie zum Humor in Ovids Metamorphosen.' - Philologus 104, 63-91 und 223-235.

Doblhofer, E. (1975) ,Beobachtungen zur Callisto-Erzählung in Ovids Metamorphosen.' - Monumentum Chiloniense. Studien zur augusteischen Zeit. Kieler Festschrift für Erich Burck zum 70. Geburtstag, hrsg. von Eckard Lefèvre, Amsterdam: Hakkert, 496-513.

Döpp, S. (1991) ,Vergilrezeption in der ovidischen „Aeneis“.' - RhM 134, 327-346.

Döpp, S. (1992) Werke Ovids. Eine Einführung. München: dtv.

Ellsworth, J. D. (1980) ,Ovid's Iliad (Metamorphoses 12.1-13.622).' — Prudentia $12,23-29$.

Ellsworth, J. D. (1986) ,Ovid's „Aeneid“" reconsidered (met. 13.623-14.608).' Vergilius 32, 27-32.

Ellsworth, J. D. (1988) ,Ovid's „Odyssey“: Met. 13,623-14,608.' - Mnem. 41, 333340.

Erbse, H. (2003) ,Beobachtungen über die Funktion der Metamorphose bei Ovid.' Hermes 131, 323-349.

Faber, R. A. (1998) ,Daedalus, Icarus, and the Fall of Perdix. Continuity and Allusion in Metamorphoses 8.183-259.' - Hermes 126, 80-89.

Fantham, E. (1979) ,Ovid's Ceyx and Alcyone. The metamorphosis of a myth.' Phoenix 33, 330-345.

Fantham, E. (1993) ,Sunt quibus in plures ius est transire figuras. Ovid's selftransformers in the Metamorphoses.' - $C W$ 87, 21-36.

Feeney, D. C. (1991) The Gods in Epic. Poets and Critics of the Classical Tradition. Oxford: Clarendon Press.

Feldherr, A. (2002) ,Metamorphosis in the Metamorphoses.' - The Cambridge Companion to Ovid, ed. Ph. Hardie, Cambridge: Cambridge University Press, 163-179.

Fränkel, H. (1945) Ovid: A Poet Between Two Worlds. Berkeley/Los Angeles: University of California Press.

Fredericks, B. R. (1977) ,Divine wit vs. divine folly: Mercury and Apollo in Metamorphoses 1-2.' - CJ 72, 244-249.

Fuhrer, Th. (1999) ,Der Götterhymnus als Prahlrede.' - Hermes 127, 356-367.

Galinsky, K. (1967) ,The Cipus Episode in Ovid's Metamorphoses (15.565-621).' TAPhA 98, 181-191. 
Galinsky, K. (1998) ,The Speech of Pythagoras at Ovid Metamorphoses 15.75-478.' - PLLS 10, 313-336.

Galinsky, K. (1999) ,Ovid's Poetology in the Metamorphoses.' - Ovid. Werk und Wirkung. Festgabe für Michael von Albrecht zum 65. Geburtstag, Teil I, ed. W. Schubert, Bern, Frankfurt a.M.: Lang (Studien zur klassischen Philologie; 100), 305-314.

Gärtner, Th. (2004) ,Die Liebesaffaire mit Dido und der Unterweltsgang mit der Sibylle. Zwei berühmte Aeneisszenen in den ovidischen Metamorphosen.' Osnabrücker Online-Beiträge zu den Altertumswissenschaften 10.

Gauly, B. M. (1992) ,Ovid, Venus und Orpheus über Atalanta und Hippomenes. Zu Ov. met. 10,560-707.' - Gymnasium 99, 435-454.

Gildenhard, I; Zissos, A. (2000) ,Ovid's Narcissus (Met. 3.339-510).' - AJPh 121, $129-147$.

Glaser, H. A. (2001) Medea oder Frauenehre, Kindsmord und Emanzipation: Zur Geschichte eines Mythos. Frankfurt a.M.: Lang.

Glei, R. (1998) ,Der interepische poetologische Diskurs: Zum Verhältnis von Metamorphosen und Aeneis.' - New methods in the research of epic = Neue Methoden der Epenforschung, ed. H. L. C. Tristram, Tübingen: Narr (ScriptOralia; 107), 85104.

Gordesiani, R. (1985) ,Zu den Prinzipien der kompositionellen Organisation in Ovids Metamorphosen.' - Klio 67, 198-204.

Granobs, R. (1997) Studien zur Darstellung römischer Geschichte in Ovids Metamorphosen. Frankfurt a.M.: Lang. (Studien zur klassischen Philologie; 108.)

Griffin, A. H. F. (1983) ,Unrequited love: Polyphemus and Galatea in Ovid's Metamorphoses.' - G\&R 30, 190-197.

Griffin, A. H. F. (1991) ,Philemon and Baucis in Ovid's Metamorphoses.' Hermathena 151, 51-62.

Guthmüller, H.-B. (1964) Beobachtungen zum Aufbau der Metamorphosen Ovids. Diss. Marburg.

Hardie, Ph. (1990) ,Ovid's Theban history: The first „anti-Aeneid“?’ - $C Q$ 84, 224235.

Hardie, Ph. (1995) , The speech of Pythagoras in Ovid Metamorphoses 15: Empedoclean epos.' - CQ 89, 204-214.

Hardy, Cl. Sh. (1995) ,Ecphrasis and the male narrator in Ovid's Arachne.' - Helios $22,140-147$.

Harrauer, Chr. (2001) ,Zitat und Originalität in Ovids Metamorphosen-Prooemium.' - WS 114, 297-302.

Harries, B. (1990) ,The Spinner and the Poet. Arachne in Ovid's Metamorphoses.' $P C P h S$ 216, 64-82.

Haywood, M. S. (1988), Ceyx, Alcyone and Ovidian Wit (Metamorphoses 11,544567).' - Eranos 86, $172 \mathrm{f}$.

Heath, J. (1992) Actaeon, the Unmannerly Intruder. The Myth and its Meaning in Classical Literature. New York etc.: Lang. (Lang classical studies; 3.)

Heinze, R. ( $\left.{ }^{3} 1960\right)$,Ovids elegische Erzählung.' — R. Heinze, Vom Geist des Römertums. Ausgewählte Aufsätze, ed. Erich Burck, Darmstadt: Wissenschaftliche Buchgesellschaft, 308-403.

Herter, H. (1983) ,Daphne und Io in Ovids Metamorphosen.' - Hommages à Robert Schilling, ed. H. Zehnacker et G. Hentz, Paris: Les Belles Lettres, 315-335. 
Hinds, St. (1987) The Metamorphosis of Persephone. Ovid and the Self-conscious Muse. Cambridge: Cambridge University Press.

Hinds, St. (1998) Allusion and intertext. Cambridge, New York: Cambridge University Press.

Hoefmans, M. (1994) ,Myth into reality: The Metamorphosis of Daedalus and Icarus (Ovid, Metamorphoses, VIII, 183-235).' - Antiquité Classique 63, 137-160.

Hofmann, H. (1971) ,Ausgesprochene und unausgesprochene motivische Verwebung im sechsten Metamorphosenbuch Ovids.' - Acta Classica 14, 91-107.

Hofmann, H. (1986) ,Ovid's Metamorphoses. carmen perpetuum, carmen deductum.' - PLLS 5, 223-241.

Hollis, A. S. (1996) ,Ovid, Metamorphoses 1,445ff.: Apollo, Daphne, and the Pythian Crown.' - ZPE 112, 69-73.

Holzberg, N. (1997) Ovid. Dichter und Werk. München: Beck.

Holzberg, N. (1998), Ter quinque volumina as carmen perpetuum: The division into books in Ovid's Metamorphoses.' - MD 40, 77-98.

Holzberg, N. (1999) ,Apollos erste Liebe und die Folgen. Ovids Daphne-Erzählung als Programm für Werk und Wirkung.' - Gymnasium 106, 317-334.

Jacobsen, G. A. (1984), Apollo and Tereus: Parallel motifs in Ovid's Metamorphoses.' - CJ 80, 45-52.

Janka, M. (1999) ,Wenn Götterväter zürnen ... Von Zeus und Aigisth zu Jupiter, Augustus und Lykaon (Interpretationen zu Ov. met. 1,163-252).' - Hermes 127, 345-355.

Jenkins, Th. E. (2000) ,The writing in (and of) Ovid's Byblis episode.' - HSClPh 100, 439-451.

Johnson, P. J. (1996/97) ,Falsoque in honore gigantas ponit: Ovid's Typhoeus from Greece to Rome.' - New England Classical Newsletter 24, 7-15.

Johnson, W. R. (1997), Vertumnus in love.' - CPh 92, 367-375.

Kenney, E. J. (1976), Ovidius prooemians.' - PCPhS 202, 46-53.

Knox, P. E. (1986) Ovid's Metamorphoses and the traditions of Augustan poetry. Cambridge: Cambridge Philological Society. (Cambridge Philological Society Supplementary vol. 11.)

Konstan, D. (1991), The death of Argus, or what stories do: Audience response in ancient fiction and theory.' - Helios 18, 15-30.

Kovacs, D. (1987) ,Ovid, Metamorphoses 1.2.' - CQ 81, 458-465.

Latacz, J. (1979) ,Ovids "Metamorphosen" als Spiel mit der Tradition.' — WJA NF 5, $133-155$.

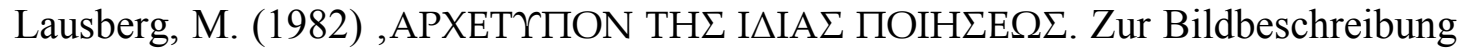
bei Ovid.' - Boreas 5, 112-123.

Lieberg, G. (1970) ,Apotheose und Unsterblichkeit in Ovids Metamorphosen.' Silvae. Festschrift für Ernst Zinn zum 60. Geburtstag, ed. M. von Albrecht et E. Heck, Tübingen: Niemeyer, 125-135.

Lieberg, G. (1998-9) ,De Ovidii deis non tristibus in Metamorphosesin.' — Orpheus 19-20, 74-94.

Little, D. A. (1970), The Speech of Pythagoras in Metamorphoses 15 and the Structure of the Metamorphoses.' - Hermes 98, 340-360.

Little, D. A. (1974) ,Non-Parody in Metamorphoses 15.' - Prudentia 6, 17-21.

Ludwig, W. (1965) Struktur und Einheit der Metamorphosen Ovids. Berlin: de Gruyter. 
Makowski, J. F. (1996) ,Bisexual Orpheus: Pederasty and Parody in Ovid.' - CJ 92, $25-38$.

Manuwald, B. (1975) ,Narcissus bei Konon und Ovid (Zu Ovid, met. 3, 339-510).' - Hermes 103, 349-372.

Merli, E. (2004) ,On the Number of Books in Ovid's Metamorphoses.' - CQ 98, 304-307.

Möller, M. (2003) ,Der staunende Achill: Eine poetologische Lektüre der CygnusEpisode (Ov. met. 12.64-167).' — GFA 6, 51-66.

Müller, D. (1987) ,Ovid, Iuppiter und Augustus. Gedanken zur Götterversammlung im ersten Buch der Metamorphosen.' - Philologus 131, 270-288.

Murgatroyd, P. (2001) , Ovid's Syrinx.' - CQ 95, 620-623.

Musgrove, M. W. (1998a) ,Nestor's centauromachy and the deceptive voice of poetic memory (Ovid Met. 12, 182-535).' - CPh 93, 223-231.

Musgrove, M. W. (1998b) ,Chronology and Anachrony in Ovid's Story of Scylla (Metamorphoses 13.730-14.74).' - Syllecta Classica 9, 95-102.

Myers, K. S. (1993-94), Ultimus ardor: Pomona and Vertumnus in Ovid's met. 14.623-771.' - CJ 89, 225-250.

Nagle, B. R. (1982) ,Byblis and Myrrha. Two Incest Narratives in the Metamorphoses.' - CJ 78, 301-315.

Nagle, B. R. (1988) ,Two Miniature carmina perpetua in the Metamorphoses: Calliope and Orpheus.' - GB 15, 99-125.

Nagle, B. R. (1989) ,Recent Structural Studies on Ovid.' — The Augustan Age 9, 2736.

Neumeister, Chr. (1986) ,Orpheus und Eurydike. Eine Vergil-Parodie Ovids (Ov. Met. X 1 - XI 66 und Verg. Georg. IV 457-527).' - WJA NF 12, 169-181.

Newlands, C. E. (1997), The metamorphosis of Ovid's Medea.' - Medea. Essays on Medea in Myth, Literature, Philosophy and Art, edd. J. J. Clauss et S. I. Johnston, Princeton: Princeton University Press, 178-208.

Nicoll, W. S. M. (1980) ,Cupid, Apollo, and Daphne (Ovid, met. 1.452 ff.).' $-C Q$ 74, 174-182.

Norwood, Fr. (1963) ,Unity in the Diversity of Ovid's Metamorphoses.' - CJ 59, $170-174$.

Otis, Br. $\left({ }^{2} 1971\right)$ Ovid as an epic poet. Cambridge: University Press.

Papaioannou, S. (2002) ,Poetische Erinnerung und epische Dichtung. Nestors Rede in Ovid, Metamorphosen Buch 12.' - Gymnasium 109, 213-234.

Pavlock, B. (1998) ,Daedalus in the Labyrinth of Ovid's Metamorphoses.' $-C W 92$, 141-157.

Pechillo, M. (1990-91) ,Ovid's framing technique: The Aeacus and Cephalus epyllion (met. 7.490-8.5).' - CJ 86, 35-44.

Porod, R. (2000) ,Typische narrative Verhältnisse zwischen Vorgeschichte und Verwandlungsakt in den Metamorphosen Ovids.' - GB 23, 111-141.

Pöschl, V. (1959) ,Kephalos und Prokris in Ovids Metamorphosen.' - Hermes 87, 328-343. (= Kunst und Wirklichkeitserfahrung in der Dichtung. Abhandlungen und Aufsätze zur Römischen Poesie. Kleine Schriften I, ed. W.-L. Liebermann, Heidelberg: Winter, 1979, 277-292.)

Pöschl, V. (1999) ,Arachne.' — Ovid. Werk und Wirkung. Festgabe für Michael von Albrecht zum 65. Geburtstag, Teil I, ed. W. Schubert, Bern, Frankfurt a.M.: Lang (Studien zur klassischen Philologie; 100), 423-429. 
Primmer, A. (1979) ,Das Lied des Orpheus in Ovids "Metamorphosen".' - Sprachkunst 10, 123-137.

Rieks, R. (1980) ,Zum Aufbau von Ovids Metamorphosen.' - WJA NF 6b, 85-103.

Robinson, M. (1999) ,Salmacis and Hermaphroditus: When Two Become One (Ovid, met. 4.285-388).' - CQ 93, 212-223.

Rosati, G. (2002) ,Narrative techniques and narrative structures in the Metamorphoses.' - Brill's Companion to Ovid, ed. by Barbara Weiden Boyd, Leiden: Brill, 271-304.

Rosner-Siegel, J. A. (1982), Amor, Metamorphosis and Magic: Ovid's Medea (met. 7.1-424).' - CJ 77, 231-243.

Schade, G. (2001) ,Ovids Aeneis.' - Hermes 129, 525-532.

Schetter, W. (1960) Untersuchungen zur epischen Kunst des Statius. Wiesbaden: Harrassowitz. (Klassisch-philologische Studien; 20.)

Schmidt, E. A. (1991) Ovids poetische Menschenwelt. Die Metamorphosen als Metapher und Symphonie. Heidelberg: Winter. (Sitzungsberichte der Heidelberger Akademie der Wissenschaften, Philosophisch-Historische Klasse; 2.)

Schmidt, E. A. (2001) ,Ovids Verwandlungserzählungen: Verfahren und Bedeutung.' - GGA 253, 166-196.

Schmitzer, U. (1990) Zeitgeschichte in Ovids Metamorphosen. Mythologische Dichtung unter politischem Anspruch. Stuttgart: Teubner. (Beiträge zur Altertumskunde; 4.)

Schmitzer, U. (2001) ,Strenge Jungfräulichkeit. Zur Figur der Göttin Diana in Ovids Metamorphosen.' - WS 114, 303-321.

Schönbeck, H.-P. (1999) ,Erfüllung und Fluch des Künstlertums: Pygmalion und Daedalus bei Ovid.' - Philologus 143, 300-316.

Schubert, W. (1989a) ,Medeas Flucht aus Iolcos (Ovid, Met. 7,350-393).' — WJA NF $15,175-181$.

Schubert, W. (1989b), Achaemenides und Macareus (Ovids Kunst des Erzählens in Met. 14,154-440).' - Journal of ancient civilizations 4, 115-125.

Schubert, W. (1992), Explizite und implizite Mythendeutung (Ovids Daedalus-IcarusErzählung met. 8, 183-235).' - Eirene 28, 25-31.

Segal, Ch. (1968) ,Circean Temptations: Homer, Vergil, Ovid.' - TAPhA 99, 419442.

Segal, Ch. (1978) ,Ovid's Cephalus and Procris: Myth and Tragedy.' - GB 7, 175205.

Segal, Ch. (1999) ,Ovid's Arcadia and the characterization of Jupiter in the Metamorphoses.' - Ovid. Werk und Wirkung. Festgabe für Michael von Albrecht zum 65. Geburtstag, Teil I, ed. W. Schubert, Bern, Frankfurt a.M.: Lang (Studien zur klassischen Philologie; 100), 401-412.

Segal, Ch. (2001/2002) ,Jupiter in Ovid's Metamorphoses.' — Arion 9, 78-99.

Smith, R. A. (1994) ,Epic Recall and the Finale of Ovid's Metamorphoses.' $-M H$ 51, 45-53.

Spahlinger, L. (1996) Ars latet arte sua. Untersuchungen zur Poetologie in den Metamorphosen Ovids. Stuttgart, Leipzig: Teubner. (Beiträge zur Altertumskunde; 83.)

Tarrant, R. J. (1982) ,Editing Ovid's Metamorphoses. Problems and possibilities.' CPh 77, 342-360.

Tissol, G. (1993) ,Ovid's Little Aeneid and the Thematic Integrity of the Metamorphoses.' - Helios 20, 69-79.

Tränkle, H. (1963) ,Elegisches in Ovids Metamorphosen.' — Hermes 91, 459-476. 
Tsitsiou-Chelidoni, Chr. (1999) ,Erzählerische Querverbindungen in Ovids Metamorphosen.' - Ovid. Werk und Wirkung. Festgabe für Michael von Albrecht zum 65. Geburtstag, Teil I, ed. W. Schubert, Bern, Frankfurt a.M.: Lang (Studien zur klassischen Philologie; 100), 269-303.

Verstraete, B. C. (1975), Ovid on Homosexuality.' - Classical News and Views 19, 79-83.

Wheeler, St. M. (1999) A Discourse of Wonders: Audience and Performance in Ovid's Metamorphoses. Philadelphia: University of Pennsylvania Press.

Wheeler, St. M. (2000) Narrative Dynamics in Ovid's Metamorphoses. Tübingen: Narr. (Classica Monacensia: Münchener Studien zur Klassischen Philologie; 20.)

Wilhelm, M. P. (1990-92) ,The Medeas of Euripides, Apollonius and Ovid.' - The Augustan Age 10, 43-57.

Zissos, A. (1999) , The Rape of Proserpina in Ovid Met. 5.341-661: Internal Audience and Narrative Distortion.' - Phoenix 53, 97-113. 